\title{
SUSIMEIRE BUGLIA
}

Comparação entre o teste ergométrico e a cintilografia miocárdica na avaliação do precondicionamento isquêmico precoce

Tese apresentada ao Instituto Dante Pazzanese de Cardiologia, entidade associada à Universidade de São Paulo para obtenção do título de Doutor em Ciências.

Área de concentração: Medicina, Tecnologia e Intervenção em Cardiologia.

Orientador: Prof. Dr. Michel Batlouni

São Paulo 


\section{SUSIMEIRE BUGLIA}

Comparação entre o teste ergométrico e a cintilografia miocárdica na avaliação do precondicionamento isquêmico precoce

(versão corrigida)

Tese apresentada ao Instituto Dante Pazzanese de Cardiologia, entidade associada à Universidade de São Paulo para obtenção do título de Doutor em Ciências.

Área de concentração: Medicina, Tecnologia e Intervenção em Cardiologia.

Orientador: Prof. Dr. Michel Batlouni

São Paulo 
Dados Internacionais de Catalogação na Publicação (CIP)

Preparada pela Biblioteca do Instituto Dante Pazzanese de Cardiologia

Oreprodução autorizada pelo autor

Buglia, Susimeire

Comparação entre o teste ergométrico e a cintilografia miocárdica na avaliação do precondicionamento isquêmico precoce/ Susimeire Buglia. São Paulo, 2012.

Tese (doutorado)--Instituto Dante Pazzanese de Cardiologia,

Universidade de São Paulo.

Área de Concentração: Medicina, Tecnologia e Intervenção em Cardiologia Orientador: Prof. Dr. Michel Batlouni

Descritores: 1. PRECONDICIONAMENTO ISQUÊMICO. 2. TESTE DE ESFORÇO 3. DIAGNÓSTICO POR IMAGEM. 4.CINTILOGRAFIA. 5. ELETROCARDIOGRAFIA.

USP/IPFPC/Biblioteca-015/12 
Dedicatória 
A minha amada irmã, Eliana (in memorian) A sua existência e seu exemplo de vida foram as inspirações para eu trilhar este caminho. Contigo aprendi o verdadeiro significado do verbo amar.

Aos meus pais, Victório e Dirce, que me trouxeram ao mundo e me ensinaram a lutar pela vida com coragem e dignidade. Sem vocês este trabalho não existiria.

Ao meu chefe e amigo Dr. Romeu Sérgio Meneghelo, pelos ensinamentos, pela paciência quase infinita, perseverança e amizade ao longo dos anos que foram fundamentais para o desenvolvimento desta pesquisa. 
Agradecimentos 
Ao meu orientador, Prof. Dr. Michel Batlouni, pela incansável dedicação, ensinamentos e críticas sempre pertinentes para a construção desta tese.

À Profa. Dra. Amanda Moraes Rego Souza, pela determinação e empenho no desenvolvimento científico do Instituto Dante Pazzanese de Cardiologia

À Dra. Paola Emmanuela Smanio e à Dra. Flávia Penhalves Alves pelo apoio, paciência e dedicação na elaboração dos exames cintilográficos.

Aos Drs. Marco Antonio Conde de Oliveira, Rafael Willian Lopes pela paciência, disponibilidade e contribuição na discussão e seleção dos casos.

A Dra. Andrea de Andrade Vilella e Dr. Mohamed Saleh. pelo apoio e companheirismo inestimável contribuição na realização dos exames ecocardiográficos.

Ao Dr. Jorge Assef pela possibilidade de realização dos ecocardiogramas na Seção Médica de Ecocardiografia do Instituto Dante Pazzanese de Cardiologia.

Ao meu chefe e amigo, Dr. Luiz Eduardo Mastrocola, pela sua incansável disposição e alegria em contribuir com seus conhecimentos e sugestões.

Às minhas colegas de seção, Dra. Rica Dodo Delmar Buchler e Angela Rúbia Cavalcanti Fuchs pela amizade e disponibilidade de seus conhecimentos e experiência na elaboração desta tese.

Aos meus colegas, Dr. Sandro Felicioni, Dr. Almir Ferraz, Dr. Carlos Hossri pelo apoio, conselhos, sugestões e participação na busca e seleção dos casos. 
Aos meus colegas do Serviço de Ergometria do Hospital do Coração pela compreensão e auxílio nos momentos de ausência, necessários a elaboração desta pesquisa.

Aos médicos residentes do Instituto Dante Pazzanese de Cardiologia pela atenção e auxílio na seleção dos casos.

Aos biomédicos, Leonardo Caetano, Andreia Tassinari, Cristiane Aparecida Costa, Mariana Foltran e José Henrique de Mendonça pela aquisição, processamento e gravação das imagens cintilográficas.

A Srta. Roberta de Souza pela valiosa contribuição da análise estatística.

Às secretárias da Seção de Medicina Nuclear Alexssandra Silva, Ana Paula Vitorino, Josely de Medeiros e Luana Santos pelo auxilio na marcação, organização e arquivamento dos exames, bem como contato telefônico e orientação dos pacientes.

Às secretárias da Seção de Reabilitação, Silvânia Oliveira, Loraine Blanco e Francilânia da Silva pelo auxílio na organização dos dados e contato telefônico com os pacientes.

Às secretárias da Seção de Ecocardiografia pelo auxílio no arquivamento dos laudos ecocardiográficos.

Aos auxiliares e técnicos de enfermagem Antonia dos Santos, Benedito Santos, Cecília Pimenta e Maria Lúcia da Silva pelo auxílio na execução dos testes ergométricos

Às auxiliares técnicas de monitorização eletrocardiográfica Cosma Maria Alexandre, Ana Priscila Pinto, Romilda de Souza, Maria Isabel Dias, Rosana Fontich, pelo auxílio no preparo dos pacientes. 
Às funcionárias da Biblioteca do Instituto Dante Pazzanese de Cardiologia, Anna Simene e Claudiana Gois pelo auxílio na pesquisa, análise bibliográfica e estruturação da tese.

Às Secretárias da Pós-Graduação, Janeide A. Santos e Valquíria Cristina S. Dias pelas orientações do caminho a seguir na execução desta tese.

Ao Sr. Reginaldo Barreto de Jesus pela sua amizade, companheirismo, abnegação na elaboração do banco de dados desde a fase embrionária desta pesquisa.

À Adriana Quadros pela formatação do tex to desta tese.

\section{Agradecimentos Especiais:}

Ao meu querido e amado amigo Ricardo Garbe Habib, que esteve ao meu lado em todos os momentos, enxugando minhas lágrimas, acalmando meu coração e ofertando carinhosamente suas opiniões e críticas que muito contribuíram para a elaboração do texto desta tese.

A todos os meus professores, desde a infância, que me ensinarão o amor pelo conhecimento e, principalmente àqueles que fomentaram meu amor pela medicina.

A todos os pacientes que gentilmente se disponibilizaram a participar desta pesquisa, sem os quais nenhuma pesquisa seria possivel e a quem devemos manter o mais profundo respeito $e$ devotar o nosso melhor conhecimento acima de qualquer outro interesse.

Ao Meu Grande Pai, Deus, que me permitiu estar neste mundo, realizar esta missão e que me ensina e auxilia diariamente a me tornar uma pessoa melhor. 
"O que a lagarta chama de fim do mundo, o mestre chama de borboleta"

autor desconhecido 
Sumário 


\section{LISTA DE ABREVIATURAS E SIGLAS}

LISTA DE SÍMBOLOS

LISTA DE FIGURAS

LISTA DE TABELAS

\section{RESUMO}

SUMMARY

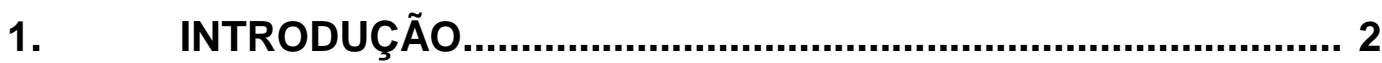

1.1 Precondicionamento isquêmico................................................ 3

1.2 Mecanismos do precondicionamento isquêmico......................... 6

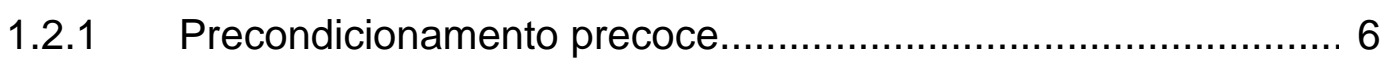

1.2.2 Precondicionamento tardio................................................... 8

$1.3 \quad$ Alterações eletrocardiográficas.................................................. 11

1.4 Cintilografia de perfusão miocárdica........................................ 12

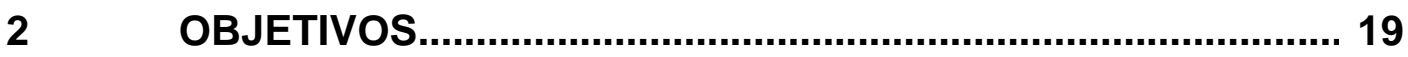

$2.1 \quad$ Objetivo primário................................................................. 19

$3 \quad$ MÉTODOS

3.1 Casuística...................................................................... 21

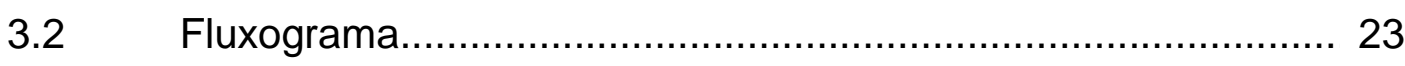

3.3 Teste ergométrico............................................................. 24

3.3.1 Critérios para execução........................................................... 24

3.3.2 Critérios diagnósticos da prova ergométrica.............................. 30

3.3.3 Variáveis analisadas nos testes da primeira e segunda etapa.

3.4 Cintilografia de Perfusão Miocárdica.......................................... 34

3.4.1 Aquisição das Imagens......................................................... 35 
3.4.2 Interpretação das imagens................................................... 39

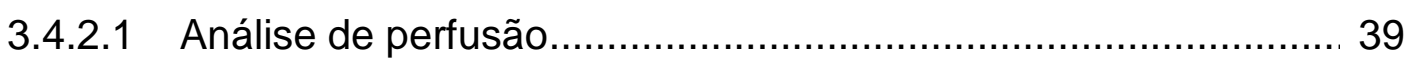

3.4.2.2 Analise qualitativa................................................................... 39

3.4.2.3 Análise semi-quantitativa........................................................ 40

3.4.2.4 Análise quantitativa.................................................................. 44

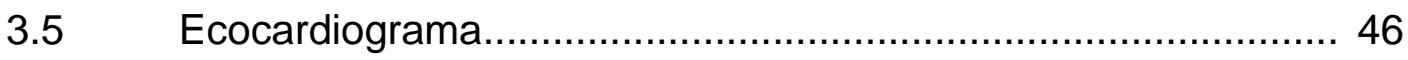

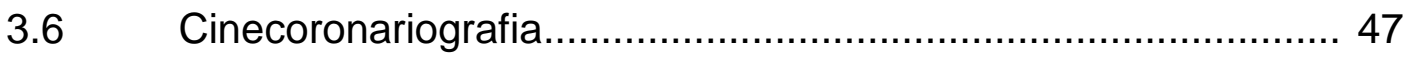

3.7 Análise Estatística................................................................ 47

3.7.1 Estimativa do tamanho da amostra.......................................... 47

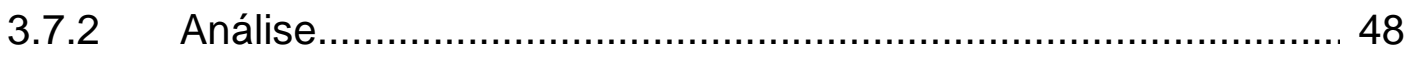

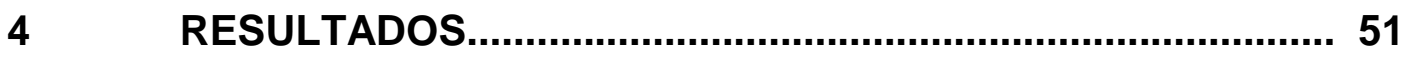

4.1 Resultados clínicos............................................................. 51

4.1.1 Características da população estudada.................................... 51

4.1.2 Métodos de avaliação anatômica............................................. 52

4.1.2.1 Ecocardiograma e Angiografia coronária................................. 52

4.1.3 Métodos de avaliação funcional................................................ 54

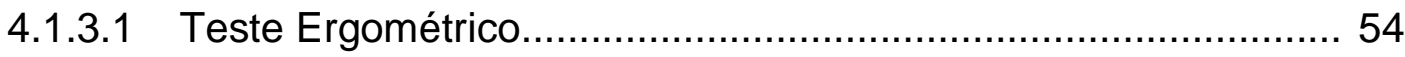

4.1.3.2 Cintilografia de Perfusão Miocárdica........................................ 57

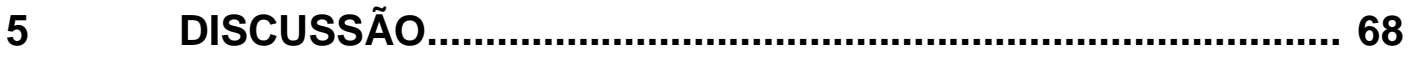

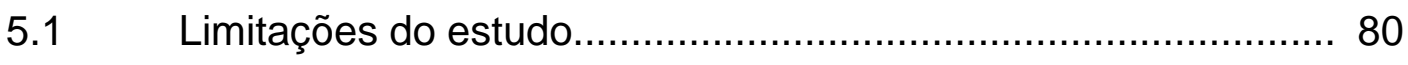

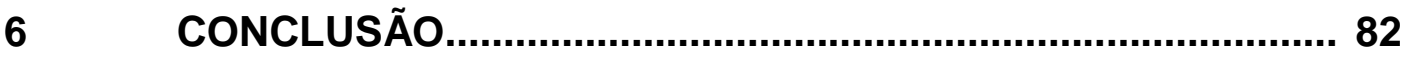

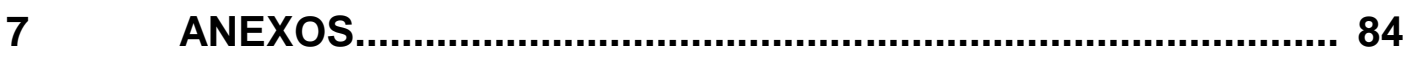

8 REFERÊNCIAS BIBLIOGRÁFICAS........................................ 93 


\section{LISTA DE SIGLAS E ABREVIATURAS}

ACC/AHA American College of Cardiology / American Heart Association ACD Artéria Coronária Direita

ACX Artéria Coronária Circunflexa

ADA Artéria Coronária Descendente Anterior

ATP Trifosfato de Adenosina

CPM Cintilografia de Perfusão Miocárdica

cm centímetros

DAC Doença Arterial Coronária

DP Duplo produto

dp desvio padrão

ECG Eletrocardiograma

FE Fração de Ejeção

FEVE Fração de Ejeção do Ventrículo Esquerdo

FC Frequência Cardíaca

GE General Eletrics

$\mathbf{H}^{+} \quad$ íon Hidrogênio

K ATP $\quad$ Canais de potássio dependentes de ATP

$\mathrm{KeV} \quad$ quilo elétron-volt

Km/h Quilômetros por hora

IAM Infarto Agudo do Miocárdio

MBq megaBequeréiis

mCi miliCuries

MIBI 2-metoxi-isobutil-isonitrila

Tc-99m Tecnécio metaestável 
MIBI-TC-99m 2-metoxi-isobutil-isonitrila marcada com Tecnécio metaestável mm milímetros

min. minutos

PA Pressão Arterial

PAS Pressão Arterial Sistólica

PCl Precondicionamento Isquêmico

seg. segundos

SPECT Single Photon Emission Computed Tomography

SDS Summed Difference Score

SRS Summed Rest Score

SSS Summed Stress Score

TE Teste Ergométrico

TID Transient Ischemic Dilation

VE Ventrículo Esquerdo

VDF Volume Diastólico Final

VSF Volume Sistólico Final 


\section{LISTA DE SÍMBOLOS}

$\begin{array}{ll}\% & \text { porcentual } \\ > & \text { maior } \\ < & \text { menor } \\ = & \text { igual } \\ \Delta & \text { delta ou variação }\end{array}$




\section{LISTA DE FIGURAS}

Figura 1 Representação esquemática demonstrando a natureza temporal das duas janelas do precondicionamento (adaptado de Yellon e Downey, 2003)

Figura 2 Cascata de Reações do Precondicionamento Isquêmico (PCl).

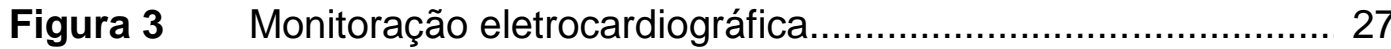

Figura 4 Apresentação do padrão de imagens tomográficas pela Tomografia por emissão de fóton único......................... 36

Figura $5 \quad$ Gated-SPECT. Exemplo \#19......................................... 37

Figura $6 \quad$ Fração de Ejeção. Exemplo \#19.......................................... 38

Figura 7 Representação dos 17 segmentos do VE. Esquematização para análise comparativa entre as fases de estresse e repouso.

Figura 8 Escore de perfusão entre estresse e repouso pelo mapa polar (Bull's eye). Exemplo \#19.

Figura 9 Correlação de Pearson para a diferença do SSS e a diferença do desnível de ST no pico do exercício: (A) entre as etapas 0 e 1 ; (B) entre as etapas 1 e 2 .

Figura 10 Anexo A. Evolução eletrocardiográfica durante as três etapas do protoloco (seleção, etapa 1, etapa 2) em momentos distintos do teste (repouso, pico do esforço, imediatamente após esforço e recuperação). Exemplo \#3....

Figura 11 Anexo A. Cortes tomográficos em eixo longo vertical mostrando isquemia em área inferior (CPM0 e CPM2) e o efeito do precondicionamento (CPM1), em comparação com a imagem de repouso. Exemplo \# 3

Figura 12 Anexo A. Mapa polar com análise por segmentos nos momentos de CPM0, CPM1 e COM2. Exemplo \#3. 


\section{LISTA DE TABELAS}

Tabela 1 Protocolo de Bruce para esteira rolante................................... 25

Tabela 2 Protocolo de Bruce Modificado para esteira rolante.................. 26

Tabela 3 Escore de perfusão à cintilografia de perfusão miocárdica 41 (Berman et al, 2004)

Tabela 4 Analise semiquantitativa (Hendel et al, 2009)......................... 41

Tabela 5 Medida de concordância (Landis; Koch 1977)......................... 49

Tabela 6 Características demográficas e clínicas................................... 52

Tabela 7 Avaliação anatômica........................................................... 54

Tabela 8 Resultado das variáveis do Teste Ergométrico - I..................... 58

Tabela 9 Resultado das variáveis do Teste Ergométrico - II................... 59

Tabela 10 Variáveis Cintilográficas Qualitativas.................................... 61

Tabela 11 Variáveis Cintilográficas Quantitativas................................... 62

Tabela 12 Associação das medidas categorizadas entre o infradesnível 64 do segmento ST e o escore SSS.

Tabela 13 Correlação entre infradesnível de ST e as diferenças do escore de perfusão 
BUGLIA, S. Comparação entre o teste ergométrico e a cintilografia miocárdica na avaliação do precondicionamento isquêmico precoce. [Tese] São Paulo - Instituto Dante Pazzanese de Cardiologia, Entidade Associada da Universidade de São Paulo, 2012. 105 p.

O fenômeno do precondicionamento isquêmico é definido como o aumento da tolerância à isquemia e à lesão de reperfusão, induzida por curtos e sucessivos episódios de isquemia prévios a período de isquemia prolongada. A angina do aquecimento e a de pré-infarto são duas condições clínicas relacionadas ao precondicionamento. Este fenômeno apresenta duas fases distintas, clássica ou precoce e tardia. A atenuação do infradesnível do segmento ST provocada pelo precondicionamento precoce está bem documentada, porém sua expressão cintilográfica permanece controversa. O objetivo desta pesquisa foi avaliar se as atenuações eletrocardiográficas do precondicionamento durante testes sequenciais estão associadas a modificações simultâneas das imagens de cintilografia de perfusão miocárdica em indivíduos com doença coronariana. Vinte e três pacientes foram selecionados entre março de 2009 e julho de 2011. A média de idade foi 64,5 anos $(\mathrm{dp}=7,0), 19(82,6 \%)$ do sexo masculino e todos tinham lesão coronária em pelo menos um vaso superior a $60 \%$. A medicação antiisquêmica foi suspensa por três a cinco dias. Os pacientes foram submetidos a três testes ergométricos a partir do exame de seleção, sendo dois deles sequenciais e o terceiro realizado após sete dias. A injeção do radiofármaco sestamibi-Tc-99m no teste de precondicionamento e contraprova foi administrado no tempo de aparecimento do infradesnível de ST de $-2,0 \mathrm{~mm}$ na derivação MC5 e/ou dor precordial anotados no teste inicial ou de seleção. A imagem cintilográfica foi adquirida entre 60 a 90 minutos após o esforço. Os resultados do segundo teste (precondicionamento) mostraram aumento significativo do tempo para o aparecimento da depressão do segmento ST de

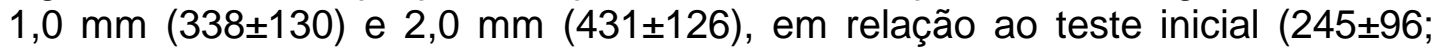
$366 \pm 103) p<0,001$. A diferença na redução do valor máximo de infradesnível de ST entre os três testes foi significativa $(3,8 \pm 0,8 ; 2,3 \pm 0,6 ; 3,1 \pm 1,0) p<0,001$. Houve redução significativa nos escores de perfusão de estresse $(p=0,045)$ entre o primeiro e o segundo testes, bem como para o escore da diferença entre o estresse e repouso $(p=0,03)$, sem diferença na extensão da área de isquemia entre as três etapas detectadas pela cintilografia $(p=0,691)$. Em conclusão, houve redução significativa das alterações eletrocardiográficas induzidas pelo precondicionamento isquêmico precoce em maior proporção do que as observadas nas respectivas imagens de cintilografia de perfusão miocárdica; não se observou associação entre a redução da depressão do ST e a redução do escore de perfusão na fase de precondicionamento, nem correlação entre a magnitude do infradesnível máximo de ST e a redução do escore de perfusão $(r=0,07$ e $p=0,75)$.

Descritores: 1. Precondicionamento isquêmico. 2. Teste de esforço 3. Diagnóstico por imagem. 4. Cintilografia. 5. Eletrocardiografia. 
BUGLIA, S. The comparison between the exercise testing and myocardial scintigraphy in the assessment of early ischemic preconditiong. [Thesis]São Paulo - Instituto Dante Pazzanese de Cardiologia affiliated to Universidade de São Paulo, 2012. 105 p.

The phenomenon of ischemic preconditioning is defined as the increase of tolerance to ischemia and injury of reperfusion induced by short and consecutive episodes of isquemia prior to prolonged arterial occlusion. Warm-up and preinfarction angina are two clinical conditions regarding this phenomenon. The ischemic preconditioning has two distinct windows designed as classical and late. The improvement of ST depression induced by classical preconditioning is well documented, however its scintigraphy expression is still controversial. The aim of this research was to assess whether the reduction of ST depression induced by preconditioning during these sequencial exercise testing are associated to simultaneous alterations of the scintigraphy images of myocardial perfusion in individuals with coronary artery disease. From March 2009 to July 2011, 23 patients were selected, mean age $64,5(\mathrm{sd}=7,0), 19(82,6 \%)$ male. All patients had coronary artery stenosis at least $60 \%$ in one vessel. The anti ischemic therapy was discontinued for three days. Patients underwent three exercises testing after screening process; two of these tests were in a sequence and the other one performed after seven days. Tc-99m-sestamibi radiotracer injection was applied in the preconditioning test as well as for the third test at the time of development of ST depression 2,0 mm in the CM5 lead and/or chest pain estabilished in the screening process or first test. The scintigraphy image was obtained from 60 to 90 minutes after exertion. The results of the preconditioning test showed a significant increase of time for manifestation of the ST depression $1,0 \mathrm{~mm}(338 \pm 130)$ and $2,0 \mathrm{~mm}(431 \pm 126)$ regarding the first test $(245 \pm 96$; $366 \pm 103), p<0,001$. There was a significant difference in the decrease of maximum value of ST depression among the three tests $(3,8 \pm 0,8 ; 2,3 \pm 0,6$; $3,1 \pm 1,0), p<0,001$. A significant reduction in stress perfusion score $(p=0,045)$ occurred between the first and second test as well as for the difference score between stress and rest $(p=0,03)$. However, there was not a significant difference in the total defect size among the three stages detected by myocardial scintigraphy $(p=0,691)$. In conclusion, there was a significant decrease of electrocardiographic alterations resulting from early preconditioning in greater proportion than the observed in scintigraphy images. It was not observed an association between the decrease of ST depression with the stress perfusion score during the preconditioning period nor the correlation between the magnitude of the maximum value of ST depression and the decrease of perfusion score $(r=0,07$ and $p=0,75)$.

Descriptors: 1. Ischemic preconditioning. 2. Exercise Testing. 3. Diagnostic imaging. 4. Scintigraphy. 5. Electrocardiography. 
1 Introdução 
A isquemia miocárdica é decorrente da desproporção entre oferta e consumo de oxigênio miocárdico, que pode ser causada principalmente por redução do fluxo coronário secundário a obstrução arterial por placa aterosclerótica ou trombo (Kern, 2005).

O miocárdio não possui reservas de oxigênio e depende quase inteiramente do metabolismo aeróbico para manter sua alta taxa de gasto energético. Durante o processo de isquemia, desencadeia-se uma cascata típica de eventos que se inicia com alterações metabólicas e bioquímicas que levam a déficit de relaxamento ventricular, disfunção diastólica, déficit contrátil, aumentos na pressão diastólica final do ventrículo esquerdo, anormalidades eletrocardiográficas com alterações do segmento ST, e finalmente, sintomas de angina pectoris. A sequência de eventos hemodinâmicos e eletrocardiográficos pode ser reproduzida por oclusão transitória durante procedimentos de angioplastia ou vasoespasmo espontâneo em artéria coronária.

Nas situações em que há redução do fluxo coronariano de forma transitória, por curtos períodos de tempo, o músculo cardíaco desenvolve respostas fisiológicas que conferem maior resistência à isquemia, desencadeando processos de proteção contra a morte celular, em maior ou menor grau. (Kloner, 1998). 


\subsection{Precondicionamento isquêmico}

O fenômeno do precondicionamento isquêmico tem sido reconhecido nos últimos 26 anos, e foi descrito pela primeira vez em 1986 por Murry et al em experimentos animais, nos quais períodos curtos de isquemia e reperfusão aplicados antes de oclusão coronária reduziu o tamanho do infarto. Nesse estudo, sete cães foram submetidos a quatro ciclos de cinco minutos de oclusão da artéria coronária circunflexa, separados por cinco minutos de reperfusão. Após o quarto ciclo procedeu-se à oclusão coronária sustentada por 40 minutos. Esse grupo de animais foi denominado grupo de precondicionamento isquêmico. $\mathrm{O}$ grupo controle foi submetido apenas à oclusão sustentada de 40 minutos. Ambos foram acompanhados por quatro dias. No grupo precondicionado houve menor área de infarto do miocárdio, com redução de $75 \%$ em relação ao grupo controle, indicando que os curtos períodos de oclusão de cinco minutos protegeram uma grande área do miocárdio.

Desta forma, o fenômeno do precondicionamento isquêmico é definido como o mecanismo de proteção que confere ao miocárdio aumento da tolerância à isquemia e á lesão de isquemia/reperfusão provocada por curtos e sucessivos episódios prévios de isquemia.

Este fenômeno pode estar relacionado à angina do primeiro esforço, também chamada de angina do aquecimento, reconhecida desde 1897, quando Osler a conceituou como a dor anginosa que aparece no início de uma atividade física e desaparece com a continuidade do exercício ou após 
um breve período de repouso. Pacientes com história de angina precedente ao infarto do miocárdio têm evolução mais favorável do que aqueles sem angina prévia, com menor tamanho da área de infarto (Ottani et al, 1995), menor incidência de insuficiência cardíaca (Anzai et al 1995), de arritmias ventriculares (Tamura et al, 1997; Gheeraert et al, 2001), e de menor mortalidade intra-hospitalar e anual (Kloner et al, 1995). Este efeito benéfico da angina ocorre 24 a 48 horas antes do evento agudo e pode não ser observado em diabéticos (Ishihara et al, 2001; Ferdinandy et al,2007). e idosos (Abete et al,1996; Abete et al, 1997)

O conceito do precondicionamento postula que, um ou dois curtos episódios de isquemia de pelo menos cinco minutos podem induzir proteção de alguns minutos a até três ou quatro horas. Este período é denominado de precondicionamento precoce. Uma nova fase de proteção, ou precondicionamento tardio, surge após 24 horas e permanece até 72 a 96 horas (Figura 1); e se isto ocorrer antes de uma oclusão prolongada seguida de reperfusão, pode-se ter redução na velocidade do aparecimento da lesão e limitação da área afetada (Yellon, 1993). Assim, o precondicionamento mostra-se como poderoso meio de proteção miocárdica endógena, sendo superado apenas pela reperfusão precoce. 


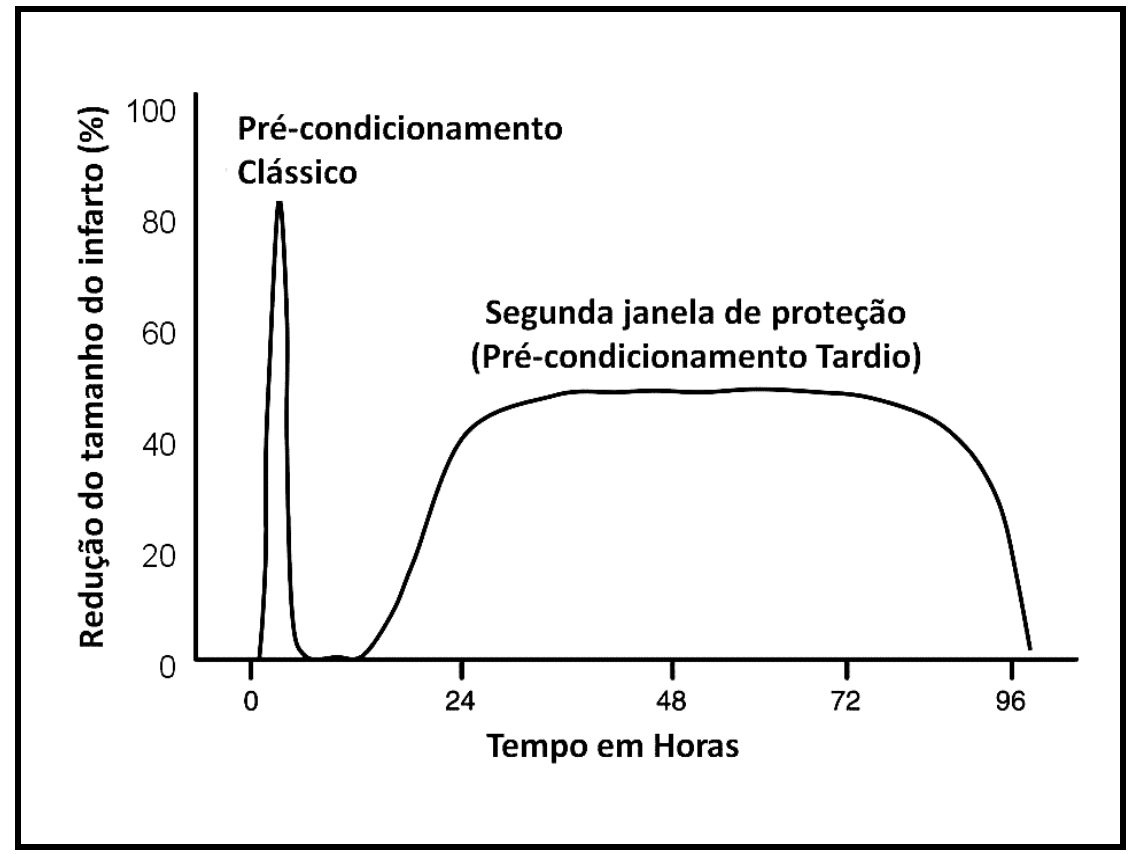

Figura 1. Representação esquemática demonstrando a natureza temporal das duas janelas do precondicionamento (adaptado de Yellon e Downey, 2003).

Em 2003, Lambiase et al demonstraram o comportamento bifásico do precondicionamento utilizando o teste ergométrico e oclusões seriadas durante procedimento percutâneo de revascularização. Nesse estudo, 30 pacientes com angina estável e estenose de artéria descendente anterior foram randomizados para dois protocolos de exercício. O grupo chamado precoce foi submetido a três testes ergométricos no mesmo dia, com intervalo de 15 minutos entre o primeiro e o segundo teste; o terceiro realizou-se após noventa minutos do segundo teste. Após 14 dias, os pacientes foram submetidos à intervenção coronária percutânea (ICP).O grupo tardio foi submetido também a três testes ergométricos consecutivos, de modo semelhante ao grupo precoce. Entretanto, 24 horas após a realização do primeiro teste, os pacientes realizaram mais dois testes com intervalos de 15 minutos e, quatro horas após, foram submetidos à ICP. A 
avaliação dos resultados deste estudo mostrou que o precondicionamento precoce ocorreu em ambos os grupos. No grupo precoce, houve aumento do tempo para o aparecimento de angina e maior produto da frequência cardíaca pela pressão arterial, também conhecido como duplo produto (DP), para o limiar de isquemia no segundo teste em comparação com o primeiro; esses efeitos foram atenuados no terceiro teste. No grupo tardio, o incremento da duração do exercício e do produto da frequência cardíaca pela pressão arterial recorreu no quarto teste, demonstrando a presença do precondicionamento tardio 24 horas após o estímulo inicial; não houve incremento adicional no quinto teste.

Durante a primeira insuflação do balão na angioplastia, o pico de elevação do segmento ST foi significantemente reduzido no grupo tardio em comparação ao grupo precoce. Assim, ficou demonstrado nesta pesquisa que a isquemia induzida por obstrução coronária foi atenuada em humanos pelo efeito do precondicionamento tardio provocado pelo exercício.

\subsection{Mecanismos do precondicionamento isquêmico}

\subsubsection{Precondicionamento precoce}

Diversos mecanismos têm sido propostos para explicar o fenômeno do precondicionamento, porém não estão plenamente esclarecidos. 
Este efeito protetor endógeno é de natureza complexa, e foi convencionalmente dividido em mecanismos deflagradores, mediadores e efetores (Yellon; Downey, 2003).

A falta de oxigênio provocada pela redução do fluxo sanguíneo coronariano promove desequilíbrio no suporte energético para o metabolismo celular. Há, então, o desencadeamento de sinalizadores bioquímicos e mecanismos efetores para evitar a morte celular. A ativação de receptores do sarcolema parece ser o primeiro passo para a manifestação do precondicionamento isquêmico.

O estímulo isquêmico causa a liberação de mediadores do estresse a partir do coração, incluindo adenosina, bradicinina, catecolaminas, opióides e espécies reativas de oxigênio (Okubo et al 1999; Rubino et al 2000). Estes mediadores se ligam a receptores específicos da membrana celular (proteína G), que amplifica o estímulo inicial para a fosfolipase C (PLC). A ativação da fosfolipase $\mathrm{C}$ leva à formação do trifosfato de inositol (IP3), que promove a liberação de $\mathrm{Ca}^{++}$do retículo sarcoplasmático e produção do diacilglicerol (DAG). O DAG ativa diferentes isoformas da proteína $\mathrm{C}$ quinase $(\mathrm{PKC})$. Além do diacilglicerol, a PKC pode ser ativada pela proteína $\mathrm{G}_{\mathrm{i}}$, concentração de $\mathrm{Ca}^{++}$intracelular aumentado, óxido nítrico (NO) e espécies reativas de oxigênio (ROS). Finalmente, a proteína C quinase induz a fosforilação e ativação dos canais de potássio dependentes de trifostato de adenosina (ATP) do sarcolema e da mitocôndria, os quais são os prováveis efetores do precondicionamento isquêmico em função do controle da concentração de $\mathrm{Ca}^{++}$intracelular (Zaugg; Schaub, 2003). Ou 
seja, a atividade aumentada com abertura maior de canais de potássio sensíveis ao ATP (canais $\mathrm{K}_{\mathrm{ATP}}$ ) na superfície da membrana mitocondrial promove acúmulo de cálcio no interior da célula (Ylitalo; Peuhkurinen, 2001), e proporciona a troca do potássio pelo íon hidrogênio e consequente conservação de ATP dentro da célula, garantindo a reserva de energia necessária para manutenção das funções celulares (Figura 2).

É importante salientar que o precondicionamento é um processo anterior ao evento isquêmico prolongado, enquanto a lesão de isquemiareperfusão ocorre durante e após a isquemia. Cabe também lembrar que o precondicionamento, por si só, não previne a morte de miócitos, mas retarda sua ocorrência durante as primeiras duas a três horas de isquemia sustentada, por até 90 minutos (precondicionamento precoce). Após esse período, a proteção conferida pelo estímulo isquêmico inicial desaparece retornando 24 horas depois podendo durar até 72-96 horas, o que é denominado precondicionamento tardio ou segunda janela de proteção (Figura 2).

\subsubsection{Precondicionamento tardio}

Se o episódio isquêmico não for persistente, o estado de proteção inicial é transitório e permanece por até três ou quatro horas. Contudo, este processo sinaliza para a síntese de proteínas, que proporcionam a preservação de energia intracelular, e que são responsáveis por um novo 
período de proteção, o precondicionamento tardio (Bolli, 2000). Menos intensa, embora mais prolongada, a segunda janela inicia-se 24 horas após o período de isquemia.

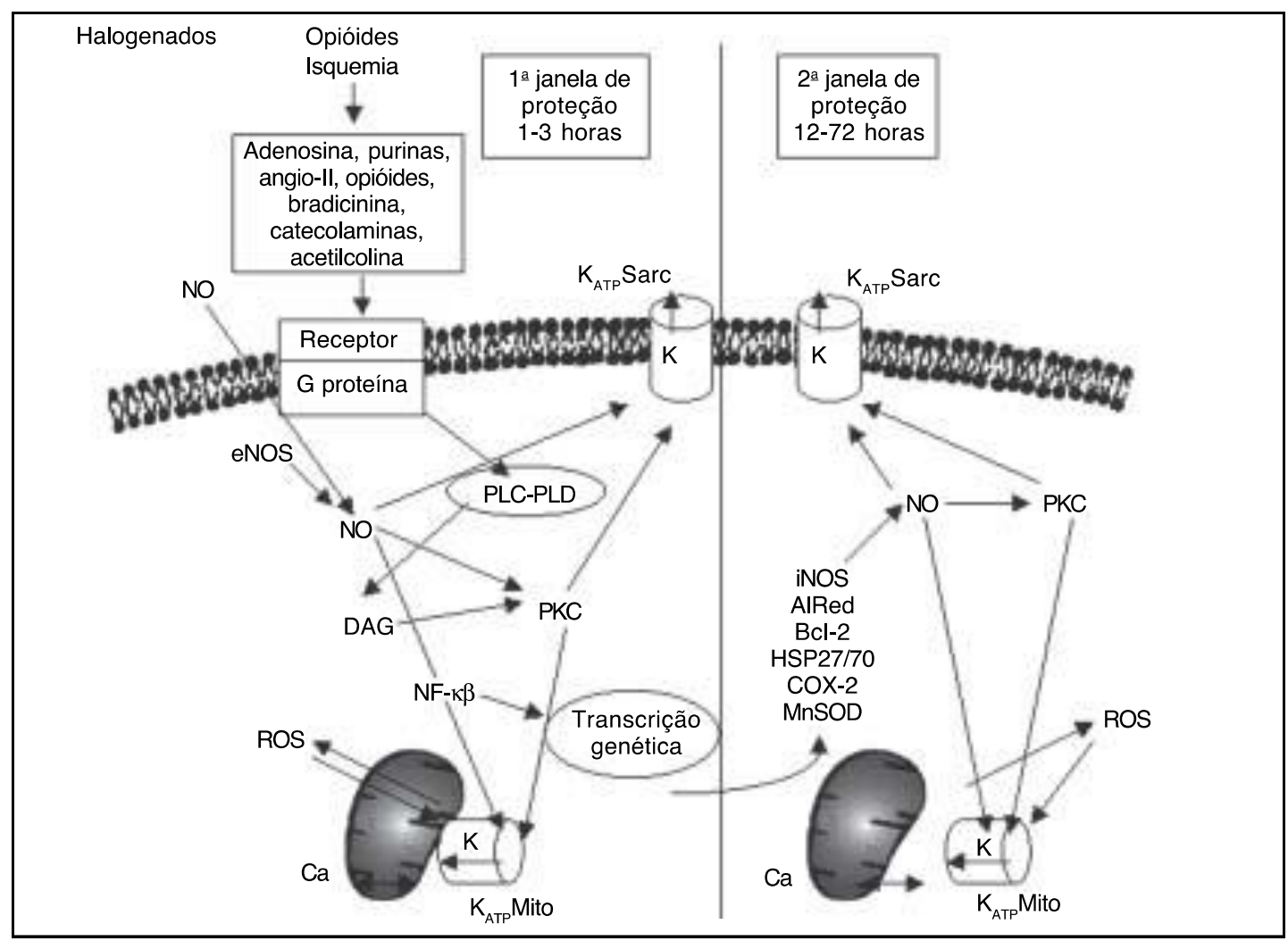

Figura 2. Cascata de reações do precondicionamento isquêmico (PCI). À esquerda está esquematizada a primeira janela de proteção e à direita a segunda janela de proteção. AlRed = aldose redutase; $\mathrm{Bcl}-2=$ proteína anti-apoptótica; $\mathrm{DAG}=$ diacilglicerol; COX-2 = cicloxigenase tipo 2; eNOS = óxido nítrico sintetase endotelial; G-proteína = proteína que contém receptores na membrana celular; HSP27 e HSP70 = heat shock proteins (proteínas "pró-sobrevivência"); iNOS = óxido nítrico sintetase induzida; KATP Mito e KATP SARC = canais de potássio ATP dependentes da mitocôndria e do sarcolema respectivamente; MnSOD = manganês superóxido desmutase; $\mathrm{NF} \kappa \beta=$ fator nuclear $\mathrm{k} \beta ; \mathrm{NO}=$ óxido nítrico; $\mathrm{PKC}=$ proteína quinase $\mathrm{C} ; \mathrm{PLC} / \mathrm{PLD}=$ fosfolipases $\mathrm{C}$ e $\mathrm{D} ; \mathrm{ROS}=$ espécies reativas de oxigênio. Adaptado de Pasqualin; Auler, 2008.

O precondicionamento precoce e tardio compartilham algumas similaridades (Marber, 1993). Em ambos os casos, o precondicionamento isquêmico provoca liberação de diversas substâncias gatilho que interagem com receptores na superfície celular e iniciam sinalizações para uma 
cascata de eventos. Estes gatilhos parecem ser os mesmos em ambas as fases de precondicionamento. $O$ intervalo de tempo entre a primeira e a segunda janela permite 0 processo de novas sínteses proteicas e modificações das proteínas existentes. O mecanismo envolve pelo menos duas vias de síntese de proteínas nucleares: a isoforma épsilon das proteínas quinase $\mathrm{C}$ e $\mathrm{Bcl}-2$, que pertencem a um grupo de proteínas que regulam a permeabilidade da membrana externa da mitocôndria (Rajesh et al, 2003).

Portanto, o distúrbio moderado na homeostase mitocondrial causado pela abertura dos canais $\mathrm{K}_{\text {ATP }}$ mitocondriais pode proporcionar maior tolerância à lesão isquêmica pela redução da sobrecarga de $\mathrm{Ca}^{++}$, prevenção de reações que resultam em necrose e apoptose, e a atenuação do estresse oxidativo. A preservação dos substratos de ATP e da estrutura mitocondrial pode facilitar uma transferência de energia mais eficiente entre a mitocôndria e o citosol logo após a isquemia.

Alguns fármacos podem inibir estes mecanismos de proteção pelo bloqueio dos canais $\mathrm{K}_{\mathrm{ATP}}$, como a glibenclamida (Tomai et al, 1994; Klepzig et al, 1999; Ferreira et al, 2005) e repaglinida (Hueb et al, 2007; Uchida et al, 2010). Inibidores da enzima de conversão e nitratos que diminuem a degradação da bradicinina, e outros fármacos que promovem a abertura dos canais $\mathrm{K}_{\text {ATP }}$ (por exemplo, diazóxido, nicorandil, alguns opióides e anestésicos)(Pasqualin et al, 2008), mantêm a homeostase do $\mathrm{Ca}^{++}$ mitocondrial e inibem a sobrecarga desse ín para o interior da organela (Holmuhamedov et al, 1998; Holmuhamedov et al, 1999; Ylitalo; 
Peuhkurinen, 2001). A alteração do equilíbrio mitocondrial nas reações de oxirredução provocadas pela abertura dos canais $\mathrm{K}_{\mathrm{ATP}}$ mitocondriais pode também agir como promotora de proteção celular (Minners et al, 2001). 


\subsection{Alterações eletrocardiográficas}

Pesquisas em animais (Murry et al., 1986; Cohen et al., 1991) e em humanos, mostraram diminuição das alterações eletrocardiográficas e intensidade da dor após sucessivas insuflações de balão durante procedimento de angioplastia; estas alterações estavam diretamente relacionadas com o tempo de insuflação (Deutsch et al.,1990). Os autores admitiram inicialmente que este fato se associava à presença de circulação colateral, porém Inoue et al. (1996) demonstraram redução da elevação do segmento ST sem aumento do fluxo coronário, a despeito do aumento da saturação de oxigênio no fluxo venoso e elevados níveis de adenosina sérica. Este achado sugere o não envolvimento do recrutamento da circulação colateral, mas de mecanismos celulares locais responsáveis pela redução da isquemia.

Estudos que incluíram a realização de três testes ergométricos sequenciais, com período de descanso entre o primeiro e segundo testes de 15 a 30 minutos, e mais tardiamente, entre o segundo e o terceiro de duas e quatro horas, mostraram atenuação da resposta isquêmica no segundo teste (Lambiase et al., 2003). Houve também aumento do tempo para o aparecimento do infradesnivelamento do segmento ST e/ou angina, caracterizando o precondicionamento precoce. A repetição da prova ergométrica após 24 horas mostrou reduções semelhantes que foram atribuídas ao precondicionamento tardio ou "segunda janela" (Tzivoni e 
Maybaum, 1997; Kay et al., 2000; Lambiase et al., 2003; Paraskevaidis et al., 2005).

Edwards et al. (2005) avaliaram a influência de três medicamentos: nicorandil, enalapril e losartana em comparação com placebo em pacientes com doença coronária conhecida, submetidos a testes ergométricos seqüenciais (0, 15 e 90 minutos). Observaram um efeito protetor mais significativo com o enalapril no segundo teste, traduzido por maior atenuação da alteração eletrocardiográfica. Contudo, até o presente momento não havia ainda sido descrito na literatura se esta atenuação refletiria real melhora do fluxo coronariano ou se afetaria apenas o potencial elétrico da célula miocárdica, traduzindo-se em redução da manifestação eletrocardiográfica de isquemia.

\subsection{Cintilografia de perfusão miocárdica}

O estresse físico promove modificações no fluxo coronariano, aumentando-o na ordem de três a quatro vezes em relação ao repouso. Nas regiões onde há menor reserva de fluxo miocárdico disponível, por doença arterial coronária obstrutiva (DAC), a cintilografia de perfusão miocárdica durante o esforço pode evidenciar alterações do fluxo coronariano em comparação com a condição de repouso. Os marcadores radioisotópicos habitualmente empregados para avaliação de perfusão miocárdica são: Tálio-201, sestamibi-Tc-99m e o tetrofosmin-Tc-99m. O sestamibi é uma 
isonitrila lipofílica, agente marcado com Tecnécio-99m mais utilizado na atualidade, com meia-vida de seis horas. O radiofármaco entra na célula por mecanismo passivo através do sarcolema e se liga às mitocôndrias. Desta forma, é também um marcador de integridade celular. O radiotraçador emite raios gama que são captados por câmaras de cintilação, registrados e transformados em imagens por programas de computação específicos. (Udelson et al. 2005)

Os diferentes padrões de captação e retenção do radiofármaco permitem a diferenciação de tecidos normais, isquêmicos e fibróticos, em condições de repouso e esforço.

Bogaty et al. em 2001, estudaram 12 pacientes com isquemia miocárdica que realizaram testes ergométricos sequenciais e cintilografia de perfusão miocárdica com Talio-201 em três sessões distintas. A primeira sessão incluiu um teste sinal-sintoma limitante e o radiofármaco foi administrado no pico do exercício. Na segunda sessão, um teste foi realizado com a injeção do Tálio-201, administrado no nível de mesmo duplo-produto do teste da primeira sessão. Na terceira sessão, houve a realização de dois testes sucessivos com intervalo de descanso de dez minutos entre eles, sendo injetado o radiofármaco no segundo teste, no mesmo nível de produto da frequência cardíaca pela pressão arterial do teste da primeira sessão. Embora tenha havido atenuação das alterações eletrocardiográficas entre o primeiro e terceiro teste, não houve alteração na extensão nem intensidade do defeito perfusional. 
A demonstração cintilográfica do precondicionamento isquêmico tardio, ou "segunda janela", foi realizada pela primeira vez por lliodromitis et al. (2008) com a utilização da técnica de duplo isótopo, envolvendo Tálio-201 e tetrofosmin marcado com Tecnécio-99m. O estudo incluiu 19 pacientes masculinos, submetidos a dois testes ergométricos sequenciais, com intervalo de trinta horas, associados à cintilografia miocárdica. A classificação por números do grau de isquemia encontrada em cada segmento do miocárdio permite a obtenção de um escore final representativo do montante da isquemia para cada situação. Os autores observaram uma redução do escore de perfusão de $21,0(\mathrm{dp}=7,4)$ para 14,2 $(d p=5,7)$ no segundo teste e no tamanho total do defeito de perfusão de $24 \%(d p=16)$ para $12 \%(d p=14)$. Em 2010, Koutelou et al., do mesmo grupo de pesquisadores, documentaram a "primeira janela" ou precondicionamento precoce em 21 pacientes, utilizando metodologia similar de duplo isótopo. Observaram redução do escore de perfusão de $19,2(\mathrm{dp}=11,5)$ para 10,0 $(d p=10,4)$ e tamanho total do defeito de $28,3 \%(d p=16,9)$ para $13,8 \%$ $(d p=15,8)$ no segundo teste em comparação com o primeiro.

A técnica de realização da cintilografia de perfusão miocárdica com duplo isótopo diminui o tempo total do exame, porém o Tálio-201 apresenta maior radioatividade, maior custo e menor disponibilidade no Brasil. Especialmente devido à maior exposição à radioatividade, a técnica de duplo isótopo está em desuso na prática cardiológica.

Não há dúvida que os trabalhos de lliodromitis et al. (2008) e de Koutelou et al. (2010) estão em concordância com os achados 
eletrocardiográficos do precondicionamento, utilizando a técnica de duplo isótopo, mas se contrapõem ao dados de Bogaty et al. (2001), que utilizaram apenas o Tálio-201 e não encontraram redução da hipoperfusão miocárdica pelo precondicionamento. Apesar da técnica de duplo isótopo ser considerada equivalente à de um único marcador, não há dados que permitem supor que, para estudos de precondicionamento, a técnica de duplo isótopo seria mais adequada, podendo ser esta uma das possibilidades para justificar a divergência dos resultados neste número pequeno de trabalhos publicados.

Até o momento do início da presente pesquisa, em 2007, o artigo de Bogaty et al. era o único artigo publicado sobre avaliação cintilográfica do precondicionamento isquêmico, com isótopo Tálio-201 e resultado frustrante. Os estudos com duplo isótopo são mais recentes e resultados mais promissores.

No nosso meio, os marcadores de perfusão utilizando Tecnécio-99m são os usados em larga escala e parece não existir ainda estudo, demonstrando o precondicionamento pela cintilografia apenas com esses marcadores.

Essa demonstração pode ter relevância clínica. Identificar pacientes com precondicionamento pode ser, no futuro, importante pela possibilidade de se utilizar esse fenômeno para ser aplicado em programas de reabilitação. Hoje, principalmente por motivos éticos, ele não é empregado de forma generalizada. Conhecê-lo de forma ampla poderá determinar mudanças na prescrição de exercícios em coronariopatas. Assim, uma das 
questões que parece fundamental é se as manifestações eletrocardiográficas guardam estreita relação com as alterações perfusionais nos métodos de imagem com os marcadores habitualmente empregados na prática cardiológica brasileira. Essa foi a motivação básica para a realização do presente estudo. 
2 Objetivos 


\subsection{Objetivo primário}

Avaliar se a atenuação eletrocardiográfica associada ao fenômeno do precondicionamento precoce, durante e após a realização de testes ergométricos seqüenciais, corresponde a modificações simultâneas das imagens de cintilografia de perfusão miocárdica com sestamibi-Tc-99m, em indivíduos com doença arterial coronariana documentada.

\section{$2.2 \quad$ Objetivo secundário}

Avaliar a correlação entre a magnitude do infradesnivelamento de ST com o escore de perfusão pela cintilografia miocárdica. 
3 Métodos 


\subsection{Casuística}

A partir de março de 2009 até julho de 2011 foram selecionados, 23 pacientes da Seção Médica de Medicina Nuclear e da Seção Médica de Provas Funcionais do Serviço de Reabilitação Cardiovascular do Instituto Dante Pazzanese de Cardiologia, de ambos os sexos, com idade entre 18 e 75 anos, que apresentaram testes ergométricos compatíveis com resposta isquêmica do miocárdio devido à presença de infradesnivelamento do segmento ST.

Os seguintes critérios de inclusão foram utilizados:

1. Teste ergométrico com presença de infradesnivelamento do segmento ST maior que $2,0 \mathrm{~mm}$ e concomitante alteração da perfusão miocárdica compatível com hipocaptacão transitória detectada na cintilografia;

2. História de doença arterial coronária (DAC), clinicamente estável e documentada pela cinecoronarianografia;

3. Eletrocardiograma em repouso normal ou com alterações discretas, que não interferissem na análise do segmento ST no teste ergométrico, como alterações de repolarização ventricular, sem infradesnivelamento de segmento ST superior a 0,5 mm, complexo QRS com duração inferior a 120 ms;

4. Termo de consentimento livre e esclarecido aprovado pelo Comitê de Ética da Instituição devidamente assinado pelo paciente. 
Os critérios de exclusão foram:

1. Lesão em tronco de coronária esquerda, ou equivalente;

2. Doença valvar;

3. Hipertrofia ventricular esquerda;

4. Miocardiopatia hipertrófica conhecida ou diagnosticada pelo ecocardiograma;

5. Insuficiência cardíaca congestiva descompensada, e/ou fração de ejeção ventricular < 40\% ao ecocardiograma;

6. Miocardiopatia chagásica diagnosticada;

7. Distúrbio de condução intraventricular, com duração do complexo QRS igual ou superior a $120 \mathrm{~ms}$;

8. Presença de pré-excitação ventricular;

9. Presença de dispositivo de marcapasso;

10. Instabilidade do quadro anginoso em qualquer momento do estudo;

11. Dificuldade de deambular adequadamente na esteira ergométrica;

12. Infarto prévio, caracterizado por presença de ondas $Q$ patológicas em mais de três derivações consecutivas. 


\section{$3.2 \quad$ Fluxograma}

\section{3 pacientes}

Teste ergométrico com alteração eletrocardiográfica e cintilografia de perfusão miocárdica compatíveis com isquemia miocárdica. (Teste de Seleção)

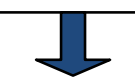

Primeira Etapa (10 a 30 dias após teste de seleção)

\section{$\underline{10 \text { teste }}$}

Limitado por sinal e/ou sintoma: anotado o tempo de aparecimento do infradesnivelamento do segmento ST de $2,0 \mathrm{~mm}$,

seguido de repouso por 15 a 20 minutos

$\underline{20}$ teste (precondicionamento precoce)

Injeção de sestamibi-Tc-99m no tempo de aparecimento do infradesnivelamento de ST de $-2,0 \mathrm{~mm}$ determinado no $1^{\circ}$ teste

Captação da imagem de cintilografia

(60 a 90 minutos após esforço)

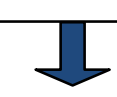

Segunda etapa (7 a 10 dias após a primeira)

$\underline{3^{\circ} \text { teste }}$ (contraprova)

Injeção de sestamibi-Tc-99m no tempo de aparecimento do infradesnivelamento de ST de $-2,0 \mathrm{~mm}$ no $1^{\circ}$ teste

Captação da imagem de cintilografia

(60 a 90 minutos após o esforço)

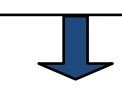

Ecocardiograma

(durante o período do estudo) 


\subsection{Teste Ergométrico}

\subsubsection{Critérios para execução}

\section{Preparo dos pacientes}

A terapêutica antiisquêmica (nitrato, betabloqueador, antagonista dos canais de cálcio, trimetazidina) foi interrompida por cinco dias para a realização do teste ergométrico, bem como outros medicamentos que pudessem influenciar a ativação do mecanismo de precondicionamento, como a glibenclamida, enalapril e sinvastatina. Foi também solicitado aos pacientes a abstinência de cafeína, alimentos com xantinas e tabaco por 24 horas. Eles receberam ainda a orientação para não se exercitarem ou realizarem grandes esforços durante todo o período do estudo.

Os pacientes selecionados realizaram três testes ergométricos, dois deles no mesmo dia, em sequência, com intervalo de quinze minutos de descanso, e o terceiro após intervalo de sete a dez dias.

Teste ergométrico de seleção

Os pacientes foram selecionados a partir de exames realizados na Seção Médica de Medicina Nuclear do Instituto Dante Pazzanese de Cardiologia, para avaliação de indivíduos com diagnóstico ou suspeita de DAC. A execução dos testes seguiu os critérios descritos nas II Diretrizes do 
Departamento de Ergometria e Reabilitação da Sociedade Brasileira Cardiologia (Andrade, 2002). O protocolo utilizado neste teste de seleção foi escolhido de acordo com o critério clínico, baseado na anamnese e exame físico e estimativa da capacidade funcional, para que o tempo de exercício se situasse entre oito e doze minutos. Este protocolo foi repetido nos testes subseqüentes.

Teste ergométrico da Primeira Etapa

Os testes ergométricos (TE) foram realizados em esteira rolante, limitados por sinais e/ou sintomas, com aplicação do protocolo de Bruce ou Bruce Modificado (Bruce, 1963), de acordo com o protocolo utilizado no teste de seleção (tabelas 1 e 2).

Tabela 1. Protocolo de Bruce para esteira rolante.

\begin{tabular}{lcc}
\hline \multicolumn{3}{c}{ PROTOCOLO DE BRUCE } \\
\hline Tempo (minutos) & Carga & Consumo $\mathrm{O}_{2}$ estimado \\
3 & $1.7 \mathrm{mph}-10 \%$ & $5 \mathrm{MET}$ \\
3 & $2.5 \mathrm{mph}-12 \%$ & $7 \mathrm{MET}$ \\
3 & $3.4 \mathrm{mph}-14 \%$ & $10 \mathrm{MET}$ \\
3 & $4.2 \mathrm{mph}-16 \%$ & $13 \mathrm{MET}$ \\
3 & $5.0 \mathrm{mph}-18 \%$ & $16 \mathrm{MET}$ \\
3 & $5.5 \mathrm{mph}-20 \%$ & $19 \mathrm{MET}$ \\
3 & $6.0 \mathrm{mph}-22 \%$ & $22 \mathrm{MET}$ \\
\hline $1 \mathrm{MET}=3,5 \mathrm{mlO}_{2} \cdot \mathrm{Kg}^{-\mathrm{min}^{-1} ; \mathrm{min}=}$ minutos; $\mathrm{mph}=\mathrm{milhas}$ por hora &
\end{tabular}

$1 \mathrm{MET}=3,5 \mathrm{mlO}_{2} \cdot \mathrm{Kg} \cdot \mathrm{min}^{-1} ; \mathrm{min}=$ minutos; $\mathrm{mph}=$ milhas por hora 
Tabela 2. Protocolo de Bruce Modificado para esteira rolante

\begin{tabular}{|c|c|c|}
\hline \multicolumn{3}{|c|}{ PROTOCOLO DE BRUCE MODIFICADO } \\
\hline Tempo (minutos) & Carga & Consumo $\mathrm{O}_{2}$ estimado \\
\hline & Velocidade- Inclinaçã & \\
\hline 3 & $1.7 \mathrm{mph}-0 \%$ & 3,5 MET \\
\hline 3 & $1.7 \mathrm{mph}-10 \%$ & $5 \mathrm{MET}$ \\
\hline 3 & $2.5 \mathrm{mph}-12 \%$ & $7 \mathrm{MET}$ \\
\hline 3 & $3.4 \mathrm{mph}-14 \%$ & $10 \mathrm{MET}$ \\
\hline 3 & $4.2 \mathrm{mph}-16 \%$ & 13 MET \\
\hline 3 & $5.0 \mathrm{mph}-18 \%$ & $16 \mathrm{MET}$ \\
\hline 3 & $5.5 \mathrm{mph}-20 \%$ & 19 MET \\
\hline 3 & $6.0 \mathrm{mph}-22 \%$ & $22 \mathrm{MET}$ \\
\hline
\end{tabular}

Após anamnese e exame físico sumário, os pacientes foram monitorados continuamente na derivação MC5 e nas 12 derivações clássicas modificadas por Mason e Likar (Mason RE e Likar I, 1966)(Figura 3), preparando-se a pele para redução da impedância com gaze embebida em álcool, seguindo-se ligeira escarificação com lixa d’água e aplicação de eletrodos de prata-cloreto de prata. Foi utilizado equipamento computadorizado APEX 2000® (TEB - Tecnologia Eletrônica Brasileira, São Paulo, Brasil) que também comandava automaticamente a esteira APEX 200. O sistema APEX2000 oferece a opção de captar a derivação MC5 de maneira alternativa que dispensa o uso de eletrodo no manúbrio. Através dos mesmos eletrodos colocados para a monitorização convencional, essa derivação é obtida por processo matemático. Este cálculo é possível devido ao fato de que o potencial do manúbrio ser, com boa aproximação, a média dos potenciais dos braços esquerdo e direito, obtidos pelos eletrodos RA e 
LA, quando posicionados nas extremidades superiores do tórax. A diferença entre esta média e o potencial colhido pelo eletrodo C5 é derivação MC5.
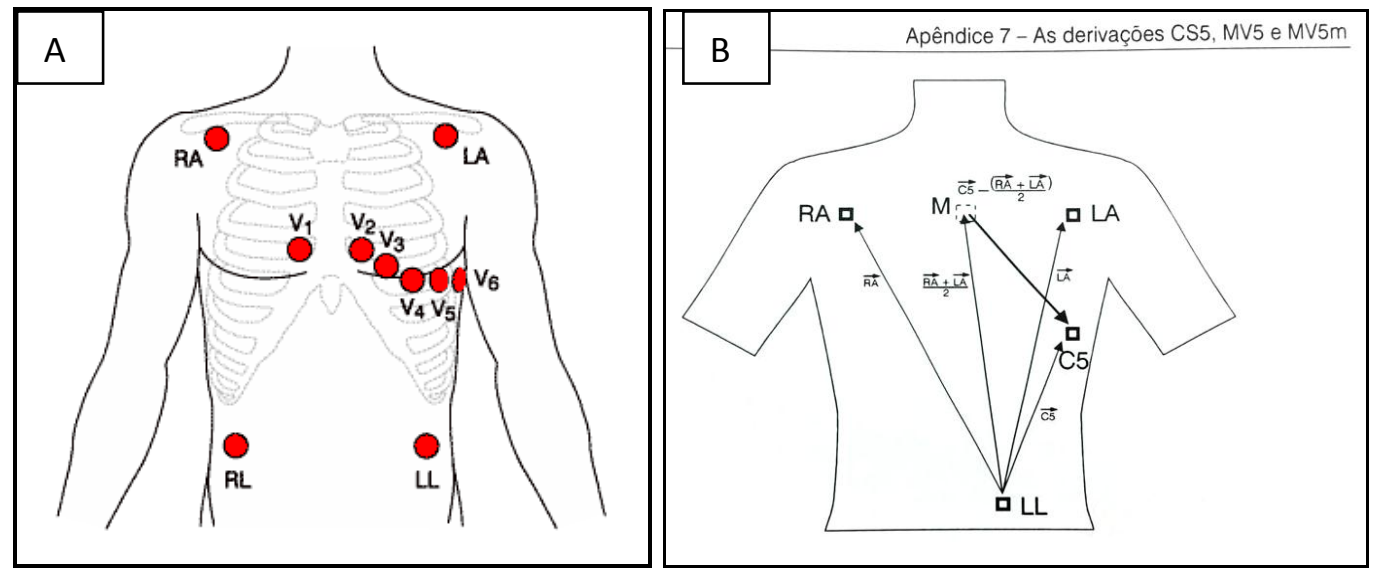

Figura 3. A) Monitoração eletrocardiográfica: $R A=$ eletrodo correspondente ao braço direito; $\mathrm{LA}=$ eletrodo correspondente ao braço esquerdo; $\mathrm{RL}=$ eletrodo correspondente à perna direita; $L L$ = eletrodo correspondente à perna esquerda; $V 1$ a $\mathrm{V} 6$ = eletrodos correspondentes ao plano horizontal.

B) Demonstração gráfica da derivação matemática MC5. Fonte: Manual do Usuário TEB APEX2000 - fundamentos e instalação - pag 70 e 71

Os registros eletrocardiográficos foram realizados: em repouso, com o paciente em decúbito dorsal e em posição ortostática; durante o exercício, em intervalos de um minuto, ao final de cada etapa e no momento do aparecimento de infradesnivelamento do segmento ST de 1,0 mm e 2,0 mm; durante a fase de recuperação, no primeiro, segundo, quarto e sexto minutos, pelo menos.

A observação da frequência cardíaca (FC) foi contínua no monitor, ou medida no traçado eletrocardiográfico a cada minuto e ao final de cada estágio do exercício. A pressão arterial (PA) foi aferida por esfigmomanômetro aneróide (marca Missouri e Welch-Allyn - modelo Tycos 767, ambos de coluna móvel), em repouso, decúbito dorsal e em posição 
ortostática, ao final de cada minuto de exercício, no pico de esforço, no final do primeiro minuto de recuperação e, posteriormente, a cada dois minutos até o final desta fase. No primeiro teste da primeira etapa não foi administrado o radiofármaco.

Seguiu-se, então, o período de repouso, que variou entre quinze e vinte minutos, depois do sexto minuto da fase de recuperação. Neste período, realizou-se a venóclise para a administração do radiofármaco e reiniciaram-se os mesmos procedimentos para a execução do segundo teste de esforço. No mesmo momento em que apareceu infradesnivelamento do segmento ST de 2,0 $\mathrm{mm}$ no primeiro teste, foi injetada a dose do radiofármaco. Após a administração endovenosa do rádiofármaco, os pacientes foram estimulados a caminhar na esteira por, pelo menos, um minuto antes da interrupção do esforço e início da fase de recuperação, em decúbito dorsal.

O primeiro teste teve como objetivo induzir isquemia e acionar o mecanismo de precondicionamento isquêmico, bem como servir de parâmetro para a determinação do tempo de aparecimento do sintoma e/ou alteração eletrocardiográfica.

Os critérios para interrupção do esforço, no teste de seleção e no primeiro teste da $1^{\underline{a}}$ etapa foram os descritos na II Diretrizes da Sociedade Brasileira de Cardiologia para Teste Ergométrico (Andrade et al., 2002) e as do American College of Cardiology/America Heart Association (Gibbons et al.., 2002) que são: 
- Obtenção da FC máxima preconizada para a idade do paciente (220 - idade em anos);

- Exaustão;

- $\quad$ Exaustão de membros inferiores;

- Angina progressiva com o incremento dos níveis de esforço;

- $\quad$ Dispnéia, fadiga, tontura, palidez, pré-sincope, dificuldade de deambulação;

- Taquiarritmias supraventriculares sustentadas;

- Arritmias ventriculares complexas (extra-sístoles ventriculares polimórficas, bigeminismo sustentado, taquicardia ventricular);

- Bloqueio completo do ramo esquerdo podendo ser confundido com taquicardia ventricular;

- Bloqueios átrio-ventriculares do $2^{\circ}$ e $3^{\circ}$ graus;

- Infradesnivelamento do segmento $\mathrm{ST} \geq 3,0 \mathrm{~mm}$, quando comparado ao traçado realizado em repouso;

- Supradesnivelamento do segmento ST (não valorizado em aVR ou V1) maior ou igual a 1,0 mm em derivação sem presença de onda Q patológica;

- Queda da PA sistólica igual ou maior que $20 \mathrm{mmHg}$ em relação à aferição em posição ortostática, em duas medidas consecutivas, independentemente do incremento da velocidade, acompanhado ou não de evidência de isquemia;

- $\quad$ PA sistólica igual ou superior a $250 \mathrm{mmHg}$, PA diastólica igual ou superior a $120 \mathrm{mmHg}$; 
- Dificuldade em manter a monitoração eletrocardiográfica adequada;

- $\quad$ Desejo do paciente de interromper o esforço.

Teste ergométrico da Segunda Etapa

A segunda etapa foi realizada no período de sete a dez dias após a primeira, seguindo as mesmas orientações quanto à execução de atividade física extenuante, dieta e uso dos medicamentos. $O$ protocolo e procedimento de execução dos testes foram os mesmos da primeira etapa. A administração do radiotraçador ocorreu no mesmo tempo de esforço do segundo teste da primeira etapa. Assim, os critérios de interrupção dos segundo e terceiro testes estiveram vinculados ao tempo de aparecimento do infradesnivelamento do segmento ST de 2,0 mm, ou desenvolvimento de angina, anotados do primeiro teste da primeira etapa.

\subsubsection{Critérios diagnósticos da prova ergométrica}

Os critérios eletrocardiográficos adotados para resposta isquêmica, por análise visual do segmento ST foram:

- Infradesnivelamento do ponto J, com segmento ST ascendente com valor igual ou maior que 2,0 $\mathrm{mm}$ para homens e mulheres, medidos no ponto $\mathrm{Y}$, ou seja, 80 milisegundos após o ponto J, na derivação MC5 e nas 12 derivações clássicas. 
- Em presença de segmento ST com morfologia horizontal ou descendente, infradesnivelamento foi medido em nível do ponto J.

Foi registrado e considerado para análise o maior valor da depressão do segmento ST na derivação MC5.

O critério clínico adotado para resposta isquêmica do miocárdio foi a presença de dor precordial sugestiva de insuficiência coronária, de caráter opressivo, reprodutível, progressiva ao esforço, limitante ou não.

\subsubsection{Variáveis analisadas nos testes da primeira e segunda etapa:}

1. Tempos:

a. Total de exercício realizado, em segundos;

b. Aparecimento de angina, em segundos;

C. Aparecimento de infradesnivelamento do segmento ST de 1,0 $\mathrm{mm}$ e 2,0 $\mathrm{mm}$ (em segundos);

d. Momento da administração do radiofármaco;

e. Recuperação do infradesnivelamento do ST (em segundos).

2. Carga de trabalho ou Medida da Capacidade Funcional:

a. em MET (ou unidades metabólicas); 
O cálculo da capacidade funcional foi realizado de acordo com as fórmulas descritas por Bruce (Bruce et al.., 1973).

- Para o sexo masculino considerou-se a equação:

VO2 máximo $=(2,9 \times$ tempo em minutos $)+8,33$

- Para o sexo feminino foi adotada a equação:

VO2 máximo $=(2,74 \times$ tempo em minutos $)+8,03$

Sendo que:

$-1 \mathrm{MET}=3,5 \mathrm{ml} \mathrm{O}_{2} \cdot \mathrm{kg} \cdot$ minuto $^{-1}$

- Número de $\mathrm{MET}=\mathrm{VO} 2$ máximo obtido/ $3,5 \mathrm{ml} \mathrm{O}_{2} \cdot \mathrm{kg} \cdot$ minuto $^{-1}$

3. O Produto da frequência cardíaca pela pressão arterial sistólica, ou duplo produto (DP), foi calculado pela fórmula:

DP = Frequência cardíaca $\times$ Pressão arterial sistólica

Foi anotado e avaliado nos seguintes momentos:

a. Aparecimento da manifestação eletrocardiográfica de isquemia, com infradesnível de 1,0 e 2,0 mm;

b. Aparecimento de angina, quando presente;

c. Injeção do radiofármaco;

d. No pico do exercício.

4. Magnitude do infradesnivelamento do segmento ST (em $\mathrm{mm}$ ): 

a. No pico do exercício;
b. No momento de injeção do radiofármaco;
c. No sexto minuto da fase de recuperação.

5. Pressão Arterial Sistólica (PAS) em milímetros de mercúrio $(\mathrm{mmHg})$
a. No repouso;
b. No pico do esforço;
c. Na fase de recuperação $\left(1^{\circ}, 2^{\circ}, 3^{\circ}\right.$ minutos $)$.

6. Frequência cardíaca (FC), em batimentos por minuto:
a. No pico do esforço e no $1^{\circ}, 2^{\circ}$ e $3^{\circ}$ minutos da fase de recuperação;
b. Análise do índice cronotrópico.

\section{Arritmias}
a. No esforço.

8. Sintoma:
a. Presença de angina ao esforço;
b. Tempo de aparecimento em segundos;
c. Tempo de desaparecimento em segundos. 
Todas estas variáveis foram analisadas nos três testes realizados: inicial ou de seleção, após indução de isquemia (segundo teste da primeira etapa ou precondicionamento) e o de contraprova (segunda etapa).

A execução de todos os testes ergométricos e a análise eletrocardiográfica foi realizada pelo pesquisador. A magnitude do infradesnível do segmento ST foi considerada, após 80 milissegundos do ponto J, ao nível do ponto Y para a morfologia ascendente lenta, e no ponto $\mathrm{J}$ para as morfologias horizontal e descendente. Os valores do ponto $\mathrm{J}$ e do ponto $Y$ foram determinados por análise computadorizada. $\mathrm{O}$ posicionamento dos pontos para a medida destes valores foi realizada pelo pesquisador.

\subsection{Cintilografia de Perfusão Miocárdica}

Os pacientes foram orientados a ingerir lanche com alto teor de gordura, após a conclusão dos respectivos testes, geralmente pão com manteiga, queijo, água gaseificada, e a caminhar por cerca de 20 minutos antes da aquisição das imagens. A aquisição das imagens cintilográficas de perfusão ocorreu entre 60 e 90 minutos após a injeção endovenosa do rádiofármaco. 


\subsubsection{Aquisição das Imagens}

O equipamento utilizado foi a Câmara Millenium VG (General Electrics Medical Sistems, Milwaukee, EUA) dotada de dois detectores de cintilação angular a 90 graus, com colimadores de furos paralelos de alta resolução e baixa energia. Definiu-se a janela de $10 \%$ para o fotopico de energia de $140 \mathrm{KeV}$ característico de Tecnécio-99-metaestável. Foram obtidas múltiplas imagens cardíacas, sequenciais a cada seis graus, com varredura desde a projeção oblíqua anterior direita com angulação de 45 graus, em sentido horário até a projeção oblíqua posterior esquerda na mesma angulação, representando, no total, 180 graus percorridos pelos detectores da gama câmara (90 graus cada) sobre o tórax do paciente. As imagens foram adquiridas a cada 30 segundos, num total de 30 projeções nos diversos ângulos, sendo 15 para cada cabeça de detecção, de forma intermitente ("Step and Shoot"). As imagens foram captadas pela técnica de tomografia por emissão de fóton único sincronizada com eletrocardiograma, também chamada "gated-SPECT". Esta técnica inclui imagens tomográficas dinâmicas de perfusão miocárdica geradas durante todo o intervalo $R R$, representativo de um ciclo cardíaco, possibilitando, dessa maneira, a avaliação da função ventricular (Figuras 4 e 5). 


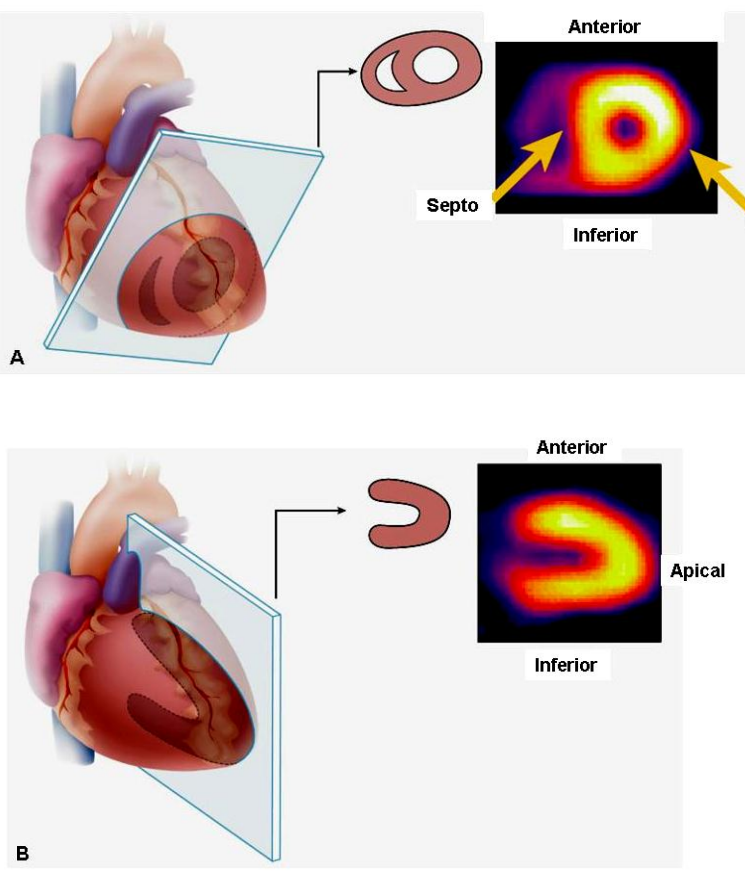

\section{Eixo Curto}

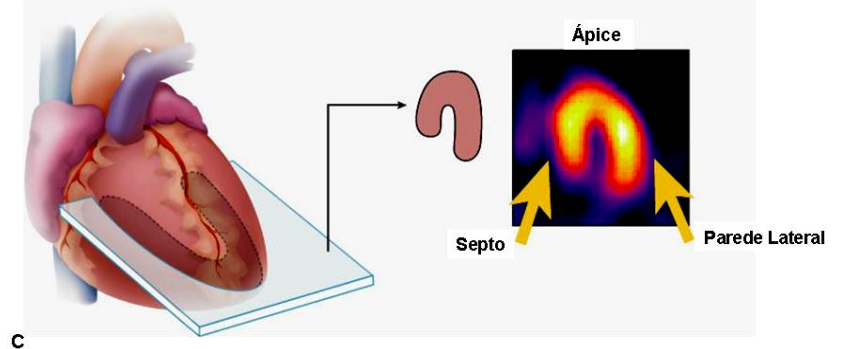

Eixo Longo

Horizontal

Figura 4. Apresentação do padrão de imagens tomográficas pela Tomografia por emissão de fóton único. A: Cada uma das imagens do eixo curto representa uma porção das paredes anterior, lateral, inferior e septal. B: Imagem do eixo longo vertical desenvolvido da esquerda para direita do bordo septal para a parede lateral e representa a parede anterior, apical e inferior. C: Imagem do eixo longo horizontal desenvolvido da esquerda para a direita da porção inferior para superior, representando o septo, ápice e parede lateral. Adaptado de Udelson (2005). 


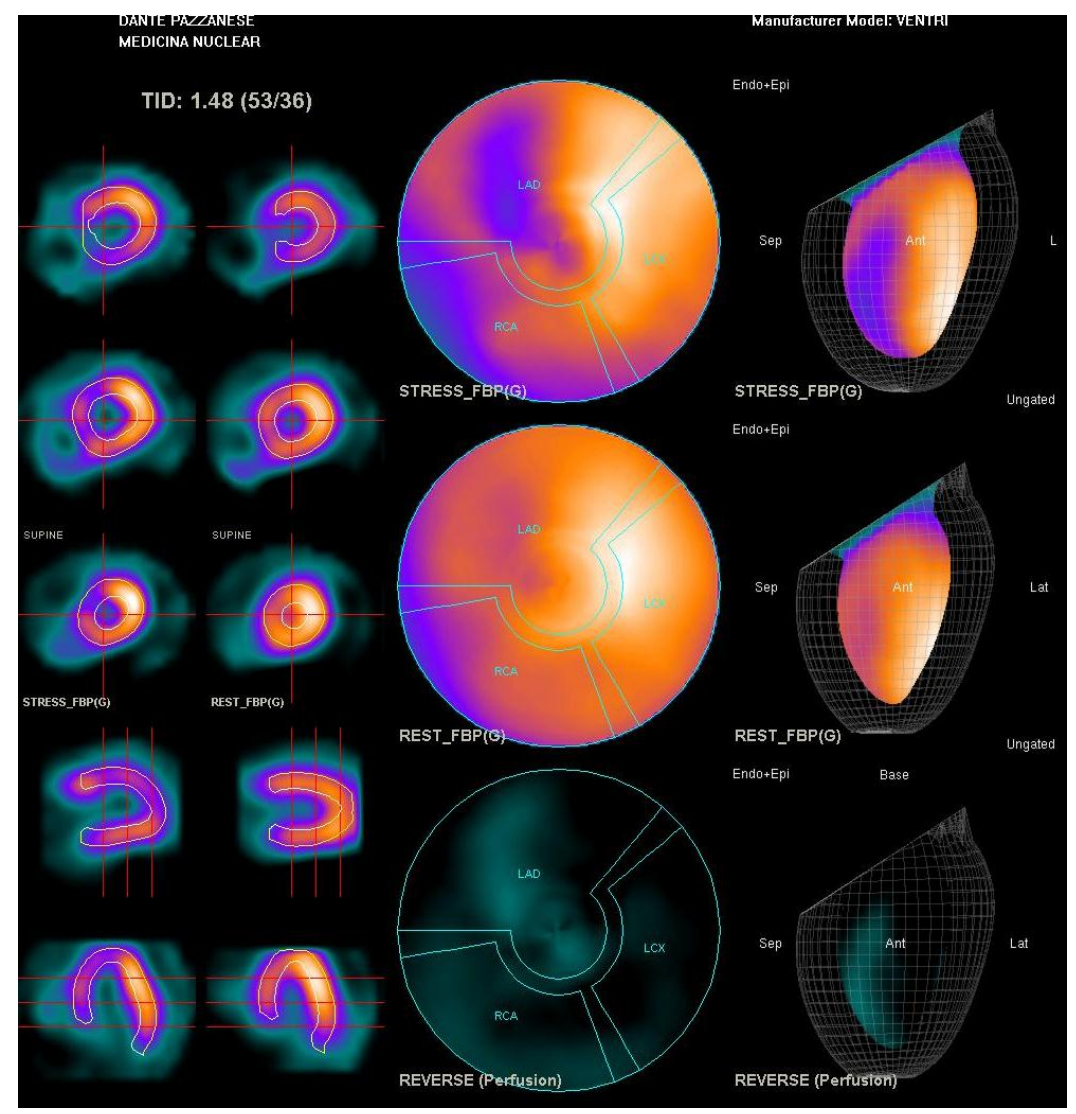

Figura 5. Gated-SPECT (Exemplo \#19).

A sincronização do estudo de perfusão miocárdica com o ECG permite a avaliação de diversas variáveis da função ventricular esquerda. 0 gated-SPECT fornece imagens tomográficas dinâmicas da perfusão miocárdica em todo o ciclo cardíaco e possibilita a avaliação da função ventricular esquerda, incluindo a análise da motilidade e do espessamento sistólico. O VE é segmentado em cada uma das oito partes do intervalo RR e, automaticamente, são localizadas as superfícies epicárdica, endocárdica e plano valvar de forma tridimensional. Desse modo são calculados os volumes diastólico e sistólico finais, e a fração de ejeção do ventrículo esquerdo (FEVE) (Germano et al.,1995). Após a identificação adequada das superfícies epicárdica e endocárdica, o espessamento e a motilidade 
miocárdica são também avaliados (figura 6). O cálculo da FEVE deriva-se da fórmula:

$$
\mathrm{FEVE}=[(\mathrm{VDF}-\mathrm{VSF}) / \mathrm{VDF}] \times 100
$$

onde: $F E V E$ = fração de ejeção do ventrículo esquerdo; $V D F=$ volume diastólico final; VSF=volume sistólico final.

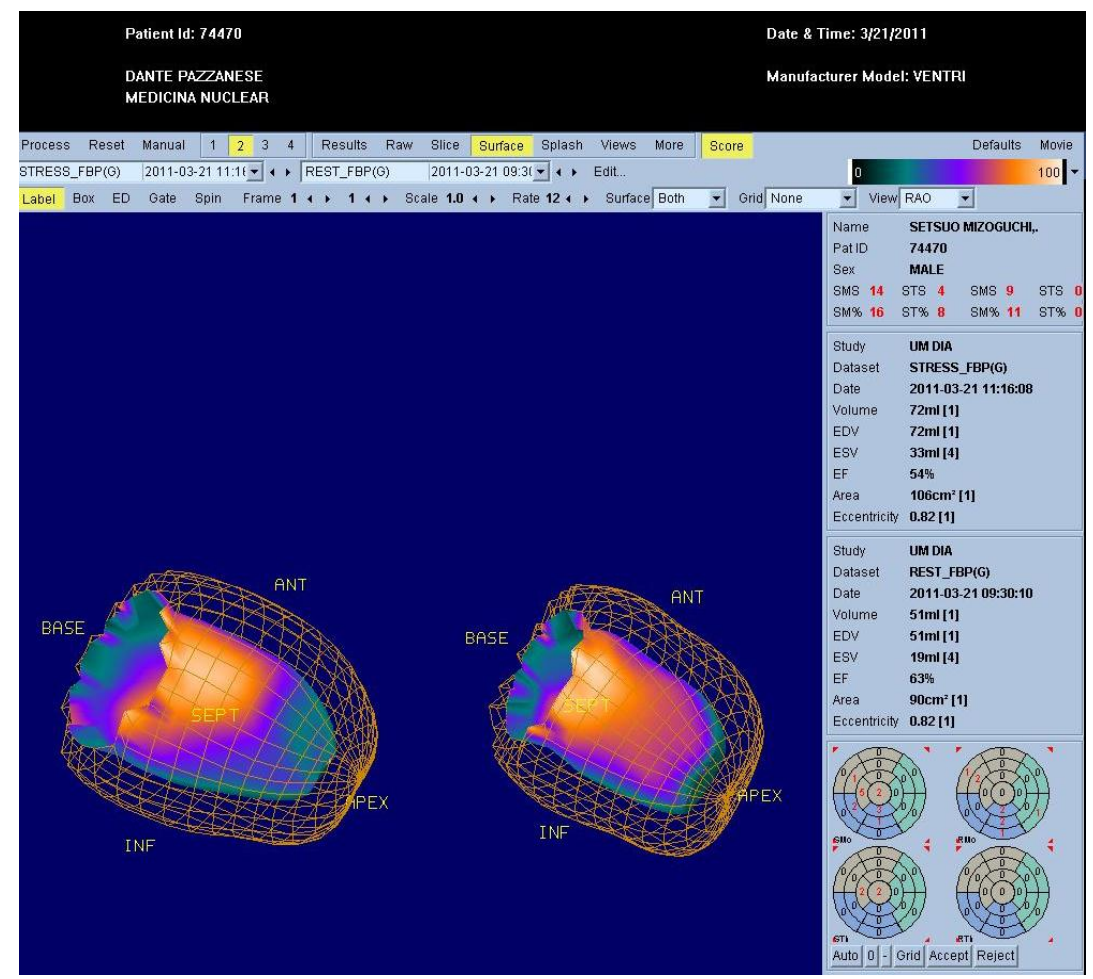

Figura 6. Fração de Ejeção - (Exemplo \#19)

As imagens digitais foram obtidas em uma matriz $64 \times 64$ e todas as informações armazenadas em disco óptico para processamento imediato e posterior gravação em CD.

O rádiofármaco empregado foi o 2-metoxi-isobutil-isonitrila (MIBI), marcado com Tecnécio-99 metaestável (sestamibi-Tc-99m) na dose de $22 \pm$ $2 \mathrm{mCi} /$ paciente/etapa. Para pacientes com peso corpóreo superior a $90 \mathrm{Kg}$, a 
dose empregada foi $0,31 \mathrm{mCi} / \mathrm{Kg}$ de peso. $\mathrm{Na}$ etapa de repouso utilizou-se dose semelhante de rádiofármaco empregada na fase de esforço, no protocolo de dois dias; no protocolo de um dia, a dose injetada na fase de repouso correspondeu a um terço da dose de esforço (de 8-12 mCi, e 24-36 $\mathrm{mCi}$, respectivamente).

\subsubsection{Interpretação das imagens}

\subsubsection{Análise de perfusão}

As imagens de estresse e repouso foram comparadas por análise visual e técnicas habitualmente empregadas na atualidade (Chalela et al.. 2002, 2005; Udelson et al., 2005). Para a avaliação da extensão e magnitude das alterações de perfusão foram empregadas as análises qualitativa, semi-quantitativa e quantitativa.

\subsubsection{Analise qualitativa}

A análise visual das imagens adquiridas permitiu avaliar a presença e a localização de isquemia miocárdica induzida pelo exercício.

Os diferentes padrões de captação e retenção do radiofármaco que caracterizam as imagens cintilográficas permitiram a diferenciação de 
tecidos normais, isquêmicos ou fibróticos pela comparação entre as condições de repouso e esforço. Desta forma, as imagens foram classificadas como:

- Perfusão normal: captação semelhante nas fases de estresse e repouso;

- Isquemia ou hipocaptação transitória: hipocaptação nas imagens de estresse e normocaptação na fase de repouso;

- Fibrose ou hipocaptação fixa: hipocaptação em ambas as fases;

- Hipocaptação fixa e transitória: traduz a coexistência de tecido isquêmico e fibrótico, ou isquemia periinfarto; há hipocaptação durante a fase de estresse que persiste durante a fase de repouso, mas de menor magnitude.

\subsubsection{Análise semi-quantitativa}

Os defeitos de perfusão foram então analisados com a utilização do sistema de escores. (Berman et al., 2004). Cada segmento foi categorizado de zero a quatro; zero representa a ausência de alteração e quatro a ausência de captação do radiofármaco no segmento em questão (Tabela 3). 
Tabela 3. Escore de perfusão à cintilografia de perfusão miocárdica (Berman et al., 2004)

\begin{tabular}{ll}
\hline Escore & Interpretação \\
\hline 0 & Perfusão normal \\
1 & Perfusão discretamente diminuída no segmento analisado \\
2 & Diminuição moderada da perfusão no segmento analisado \\
3 & Diminuição acentuada da perfusão no segmento analisado \\
4 & Ausência de perfusão no segmento analisado. \\
\hline
\end{tabular}

A extensão do território miocárdico acometido foi avaliada pela análise dos cortes tomográficos do ventrículo esquerdo, dividindo-o em 17 segmentos (Figura 7) e comparados entre as diferentes etapas do estudo; classificou-se a extensão do miocárdio acometido em pequena, moderada ou extensa, de acordo com o número de segmentos envolvidos (Tabela 4).

Tabela 4. Analise semiquantitativa (Hendel et al., 2009)

\begin{tabular}{lcc}
\hline & $\%$ VE & $\mathbf{N}^{\circ}$ de segmentos \\
\hline Pequeno & $5-10$ & $1-2$ \\
Moderado & $10-20$ & $3-4$ \\
Extenso & $>20$ & $\geq 5$ \\
\hline Onde:\%VE - porcentual de isquemia do ventrículo esquerdo; №. número
\end{tabular}

Onde: \%VE - porcentual de isquemia do ventrículo esquerdo; №: número 


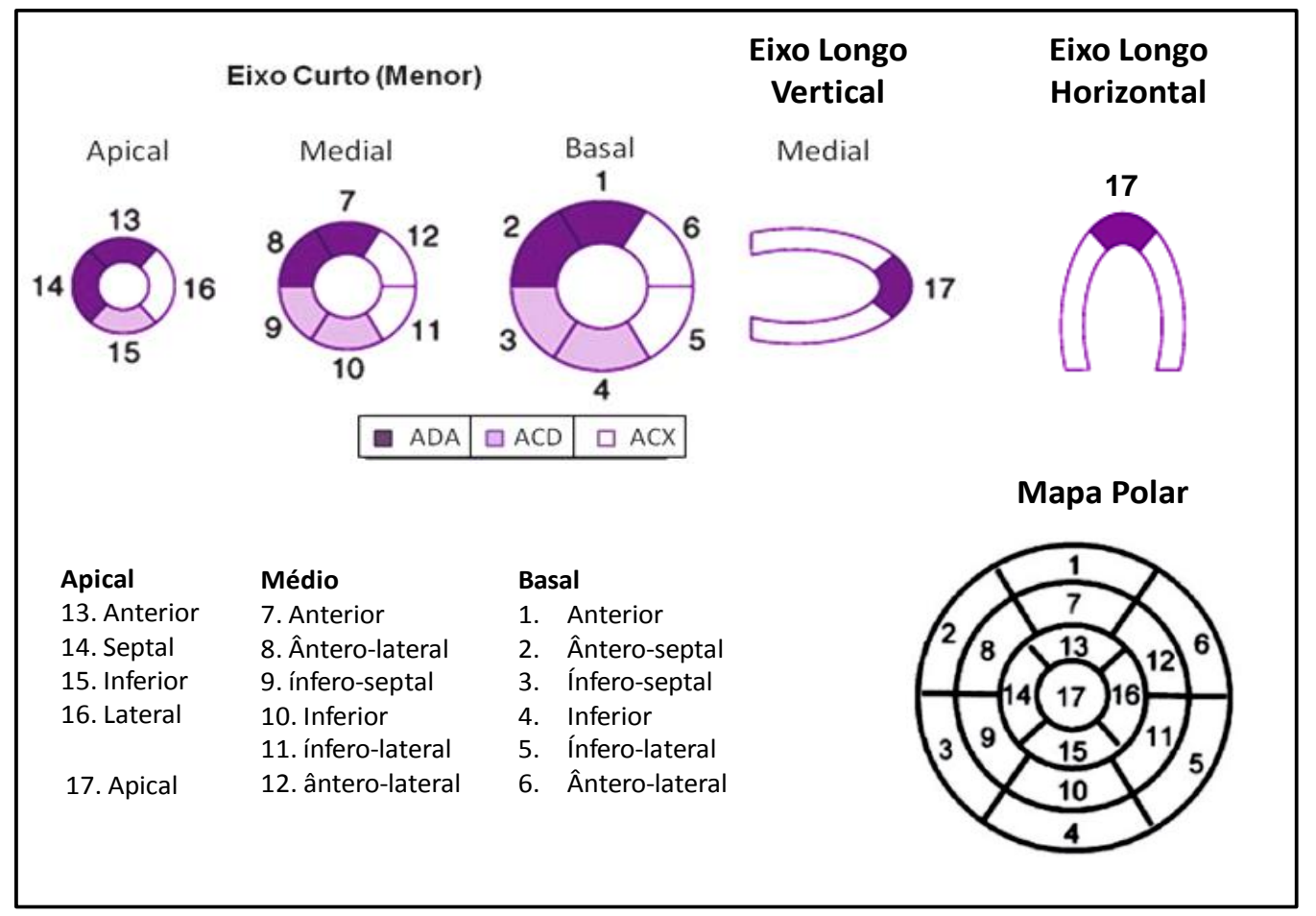

Figura 7. Representação dos 17 segmentos do VE. Esquematização para análise comparativa entre as fases de estresse e repouso

O somatório das notas atribuídas a cada um dos 17 segmentos do ventrículo esquerdo na análise qualitativa (Tabela 3) para o estresse e repouso, e a diferença entre eles formam escores que refletem áreas de isquemia (Figura 8). Assim, foram analisadas as imagens de acordo com o somatório de escores abaixo:

SSS - Somatório do Escore de Estresse (Summed Stress Score): somatório dos escores atribuídos a cada segmento, derivados das imagens obtidas ao esforço (estresse físico). Pode ser considerado dentro dos limites da normalidade entre zero e quatro; discretamente anormal entre quatro e 
oito; moderadamente anormal entre nove e 13 e, acima de 13, francamente anormal (Hachamovitch et al., 1998). Para análise dos casos deste estudo o SSS foi classificado em menor que quatro, entre quatro e oito e acima de oito (discretamente, moderadamente e francamente anormais, respectivamente).

SRS - Somatório de Escore de Repouso (Summed Rest Score): somatória dos escores atribuídos, a cada segmento, derivados das imagens obtidas em repouso.

\section{SDS - Somatório da Diferença dos Escores (Summed Difference} Score): é a diferença obtida pela fórmula: SSS - SDS. Quando $=0$ não sugere isquemia miocárdica transitória. Considerou-se para esse estudo isquemia transitória a diferença de escore $>2$ (Berman et al., 1998).

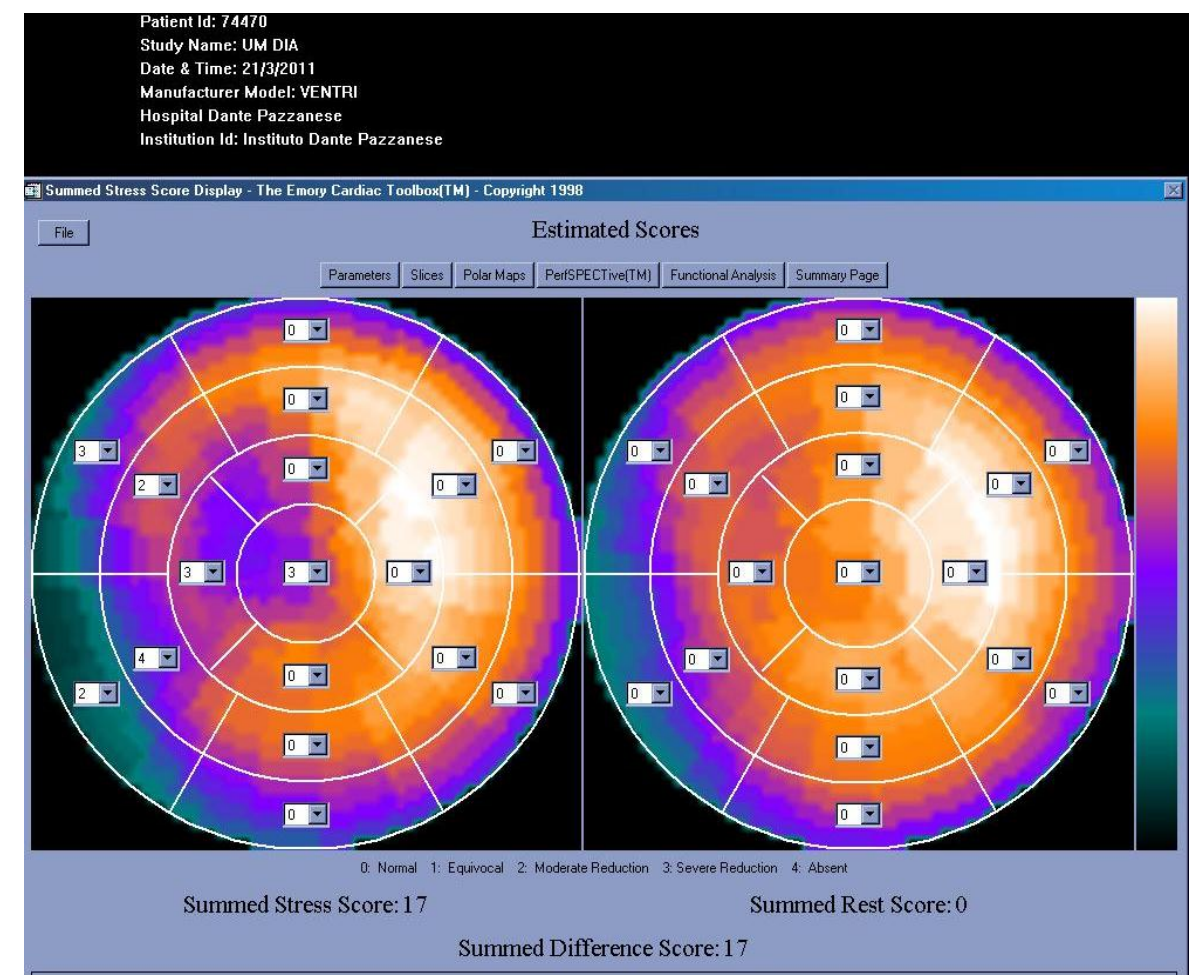

Figura 8. Escore de perfusão entre estresse e repouso, pelo mapa polar (Bull's eye) Exemplo \#19 


\subsubsection{Análise quantitativa}

Para a quantificação da extensão do território acometido pela isquemia foi utilizada a técnica de mapa polar (Bull's eye). Esta técnica consiste na reconstrução bidimensional de imagens tomográficas do ventrículo esquerdo com o objetivo de observar a distribuição relativa do radiofármaco por todo o coração. É apresentado em forma circular, assemelhando-se a um alvo. A captação do radiofármaco, representativa da perfusão, é demonstrada por uma escala de cores, sendo que o ápice do ventrículo esquerdo ocupa o centro do "alvo" e a periferia do círculo a base do coração (Figura 7).

A compreensão da imagem se torna clara quando visualizamos o ápice do coração comprimido em direção à base, tornando um órgão tridimensional em uma Figura de duas dimensões, representada nos eixos $\mathrm{x}$ e y. Os programas que permitem reconstruir tais imagens possibilitam a quantificação percentual da área hipocaptante, quando são comparadas imagens de um banco de dados de indivíduos normais do mesmo sexo e idade. Esse método de análise quantitativa serve como complementação para auxílio na análise visual qualitativa ou semiquantitativa (Figura 5).

Neste estudo contemplou-se a análise da FEVE em repouso e após o esforço. Foi considerada normal a FEVE obtida por gated-SPECT maior que $50 \%$. 
No início desta pesquisa, por razões logísticas da Seção Médica de Medicina Nuclear, foi adotado o protocolo de dois dias com intervalo de um a cinco dias entre a fase de esforço e repouso. Desta forma, a fase de esforço precedeu à fase de repouso nos primeiros 10 exames. Posteriormente, por mudanças estruturais da Instituição, o protocolo passou a ser de um dia, com a fase de esforço sendo posterior à de repouso. Segundo diretrizes brasileiras e americanas de cardiologia nuclear, seguindo-se os critérios de ajustes preconizados para cada tipo de protocolo (um ou dois dias) não existe diferença para a interpretação das imagens adquiridas. (Chalela et al., 2002; Nichols et al., 2006)

Cada paciente foi submetido a três cintilografias de perfusão miocárdica. A primeira, solicitada pelo médico assistente, foi chamada de "cintilografia de seleção" (CPM0). As duas subseqüentes foram adquiridas após a inclusão no programa, sendo a segunda para documentar e avaliar o aparecimento do precondicionamento isquêmico (CPM1), e a terceira realizada sem o acionamento do mecanismo de precondicionamento, a qual foi chamada de "cintilografia de contraprova" para efeito de comparação (CPM2). A imagem de repouso obtida na cintilografia de seleção foi utilizada para comparação com as demais imagens de esforço, de modo que, nas fases de precondicionamento e contraprova, houve a injeção apenas da dose do esforço. Isto teve por objetivo minimizar a exposição radiológica.

Todos os exames foram avaliados por dois observadores especialistas em medicina nuclear, de forma consensual. Nos casos discordantes, um terceiro especialista foi consultado. 


\subsection{Ecocardiograma}

Todos os exames foram realizados na Seção de Ecocardiografia do Instituto Dante Pazzanese, com o equipamento Vivid7® (Marca GE-General Eletrics-Vingmed, System VII, Horton, Norway), com transdutor de multifrequência. Os exames foram realizados com monitoração eletrocardiográfica simultânea, e as imagens foram adquiridas na forma de clipes digitais, com gravação e arquivamento digital das imagens, em sistema $C D$, para análise posterior, realizada por dois profissionais experientes. A execução e análise dos exames seguiram as normas descritas nas diretrizes brasileiras e americanas de ecocardiografia. (Campos $\mathrm{F}^{\circ}$ et al., 2004; Lang et al., 2005).

Os exames foram realizados com o paciente em posição supina, em decúbito dorsal e lateral esquerdo. Adquiriram-se imagens ecocardiográficas por via transtorácica em Modo-M, bidimensional, Doppler espectral (pulsado e continuado) e mapeamento com fluxo a cores.

Foram analisadas as seguintes variáveis:

1. Análise bidimensional com medidas do diâmetro do átrio esquerdo, ventrículo esquerdo em sístole e diástole, medidas das espessuras do septo e da parede posterior;

2. Fração de ejeção (pelo método de Simpson);

3. Dinâmica valvar através da avaliação do fluxo transvalvar mitral (pelo Doppler pulsátil) para avaliação da função diastólica, com análise do 
pico da onda $E$ (tempo de enchimento rápido) e onda $A$ (contração atrial) e Doppler tecidual.

4. Avaliação da contratilidade segmentar do ventrículo esquerdo

a. Descritiva: contratilidade normal, hipocinesia (leve, moderada ou acentuada), acinesia;

b. Segmentar: anterior, lateral, inferior, posterior e apical.

\subsection{Cinecoronariografia}

Todos os pacientes incluídos tinham cinecoronariografia realizada com intervalo de seis meses com pelo menos um vaso coronário principal apresentando lesão obstrutiva superior a $60 \%$.

\subsection{Métodos Estatísticos}

\subsubsection{Estimativa do tamanho da amostra}

O cálculo para o número mínimo de participantes neste estudo baseou-se no estudo de Edwards et al. (2005) que incluíram 13 pacientes e obtiveram diferença significativa do infradesnivelamento do segmento ST entre testes seqüenciais, em pacientes portadores de doença arterial coronária e ausência de medicamentos. O valor diminuiu em média de 0,23 
$m V(d p=0,03)$ para $0,17 \mathrm{mV}(\mathrm{dp}=0,02)$ (diferença de 0,06). Para uma estatística de teste t-pareado, considerando a diferença de 0,06 e, com uma variação (desvio padrão) entre os dois tempos de 0,03 , para um nível de significância do teste de 5\% e poder de teste de 95\%, o tamanho mínimo estimado da amostra para este estudo foi de 15 indivíduos.

\subsubsection{Análise dos dados}

As características e resultados dos testes da amostra de 23 pacientes estudada, foram descritos por estatísticas de frequencias, absoluta (n) e relativa (\%), quando medida qualitativa, e por estatísticas sumárias de média, desvio padrão (DP) e mediana, quando medida quantitativa.

A avaliação entre as três etapas dos testes foi feita por análise de variância (ANOVA) para medidas repetidas (Neter, 1996) quando a medida quantitativa não rejeitou a distribuição normal ou ANOVA não paramétrica para dados ordinais quando a medida quantitativa rejeitou distribuição normal ou quando qualitativa ordinal (Brunner e Langer, 2000). Nestes casos, a correção de Bonferroni (Siegel, 1988) foi aplicada no nível descritivo do teste (valor de p) para as comparações entre pares de etapas. Quando as categorias da medida qualitativa não tinham relação de ordem foi aplicado o método Kappa (Fleiss, 1981) para avaliação da concordância entre as respostas. A medida Kappa é baseada no número de respostas concordantes, a tabela abaixo apresenta possível interpretação da medida. 
Tabela 5. Medida de concordância (Landis; Koch 1977)

\begin{tabular}{ll}
\hline Valor de Kappa & Interpretação \\
\hline$<0,00$ & Nenhuma concordância \\
$0-0,19$ & Concordância fraca \\
$0,20-0,39$ & Concordância suave \\
$0,40-0,59$ & Concordância moderada \\
$0,60-0,79$ & Concordância substancial \\
$0,80-1,00$ & Concordância quase perfeita \\
\hline
\end{tabular}

Fonte: Landis JR, Koch GG. The measurement of observer agreement for categorical data. Biometrics 1977; 33: 159-174

Para avaliar da associação entre medidas do teste ergométrico e medidas da cintilografia, as diferenças relativas (\%) entre as etapas 0 e 1 ( $\Delta 01)$ e entre 1 e $2(\Delta 12)$ foram medidas nos dois casos e a correlação entre elas avaliadas por método de Pearson (Pereira, 2010). Quando correlações significativas foram encontradas o coeficiente de correlação $r$ foi avaliado. Valores absolutos de $r(|r|)$ sugerem correlação fraca quando $|r|<0,3$ correlação moderada quando $0,3 \leq|r|<0,7$ e alta correlação quando $|r| \geq$ 0,7 .

O nível de significância dos testes foi arbitrado em $5 \%$, ou seja, diferenças foram consideradas significativas quando o nível descritivo do teste (valor de p) foi menor que $5 \%$. Os casos em que $5 \% \leq$ valor de $p<$ $10 \%$ sugeriram fracas evidências de diferenças significativas.

A execução dos cálculos estatísticos e a elaboração das tabelas foram realizadas com o auxílio dos softwares: SPSS for Windows versão 19.0 e MS Office Excel. 
4 Resultados 


\subsection{Resultados clínicos}

\subsubsection{Características da população estudada}

Dos 23 pacientes que preencheram os critérios de elegibilidade para este estudo, 19 eram do sexo masculino e quatro do sexo feminino, com idade compreendida entre 48 e 75 anos, com média de 62,04 ( $\mathrm{dp}=6,84)$.

As características clínicas e distribuição dos fatores de risco encontram-se expostos na tabela 6. 
Tabela 6. Características demográficas e clínicas

\begin{tabular}{|c|c|c|c|}
\hline & $n=23(\%)$ & Média $\pm \mathrm{dp}$ & Mediana \\
\hline IDADE & & $62,04 \pm 6,84$ & 63,0 \\
\hline PESO (kg) & & $78,13 \pm 11,07$ & 80,0 \\
\hline $\operatorname{ALTURA}(\mathrm{m})$ & & $1,66 \pm 0,08$ & 1,65 \\
\hline IMC & & $28,3 \pm 3,5$ & 28,9 \\
\hline \multicolumn{4}{|l|}{ GÊNERO } \\
\hline Masculino & $19(82,6)$ & & \\
\hline Feminino & $4(17,4)$ & & \\
\hline \multicolumn{4}{|l|}{ ANTECEDENTES } \\
\hline Hipertensão & $22(95,7)$ & & \\
\hline Diabetes Mellitus & $14(60,9)$ & & \\
\hline Tabagismo & $6(26,1)$ & & \\
\hline Dislipidemia & $20(87,0)$ & & \\
\hline Acidente vascular cerebral & $1(4,3)$ & & \\
\hline Infarto prévio & $8(34,8)$ & & \\
\hline Cirurgia revascularização & $7(30,4)$ & & \\
\hline Angioplastia & $7(30,4)$ & & \\
\hline Antecedentes familiares de ICo & $6(26,1)$ & & \\
\hline \multicolumn{4}{|l|}{ MEDICAMENTOS } \\
\hline Beta-Bloqueador & $17(73,9)$ & & \\
\hline Bloqueador de Cálcio & $3(13,0)$ & & \\
\hline Diurético & $7(30,4)$ & & \\
\hline Nitrato & $7(30,4)$ & & \\
\hline Inibidores da ECA & $18(78,3)$ & & \\
\hline Ácido acetilsalicílico & $21(91,3)$ & & \\
\hline Estatina & $19(82,6)$ & & \\
\hline Metformina & $14(60,9)$ & & \\
\hline Glibenclamida & $2(8,7)$ & & \\
\hline Bloqueadores RA & $3(13,0)$ & & \\
\hline Insulina & $3(13,0)$ & & \\
\hline \multicolumn{4}{|l|}{ SINTOMAS } \\
\hline Assintomáticos & $8(34,8)$ & & \\
\hline Angina típica & $14(60,9)$ & & \\
\hline Angina atípica & $1(4,3)$ & & \\
\hline
\end{tabular}




\subsubsection{Métodos de avaliação anatômica}

\subsubsection{Ecocardiograma e Angiografia coronária}

Os vinte e três pacientes realizaram ecocardiograma no período do estudo. A cinecoronarianografia foi realizada após o protocolo somente naqueles pacientes que tinham indicação, de acordo com avaliação clínica; entretanto todos os pacientes apresentavam documentação angiográfica prévia de doença coronariana obstrutiva, condição de inclusão.

Os dados das avaliações ecocardiográficas e angiográficas das cinecoronariografias realizadas com intervalo inferior a seis meses estão expostos na tabela 7 . 
Tabela 7. Avaliação anatômica

\begin{tabular}{|c|c|c|c|c|}
\hline & $\mathrm{n}=23$ & $\%$ & Média $\pm d p$ & Mediana \\
\hline \multicolumn{5}{|l|}{ ECOCARDIOGRAMA } \\
\hline Fração de Ejeção(\%) & & & $60,57 \pm 7,05$ & 60,0 \\
\hline \multicolumn{5}{|l|}{ Motilidade } \\
\hline Normal & 12 & 52,2 & & \\
\hline Hipocinesia & 6 & 26,1 & & \\
\hline Acinesia & 5 & 21,7 & & \\
\hline \multicolumn{5}{|l|}{ Alteração segmentar } \\
\hline Inferior & 9 & 39,1 & & \\
\hline Septal & 1 & 4,3 & & \\
\hline Difusa & 1 & 4,3 & & \\
\hline \multicolumn{5}{|l|}{ Disfuncão diastólica } \\
\hline Ausente & 5 & 21,7 & & \\
\hline Leve & 15 & 65,2 & & \\
\hline Moderada & 3 & 13,0 & & \\
\hline \multicolumn{5}{|l|}{ ANGIOGRAFIA } \\
\hline Uniarterial & 7 & 30,4 & & \\
\hline Biarterial & 10 & 43,5 & & \\
\hline Triarterial & 6 & 26,1 & & \\
\hline \multicolumn{5}{|l|}{ Lesão Principal } \\
\hline $\mathrm{DA}$ & 6 & 26,1 & & \\
\hline$C D$ & 6 & 26,1 & & \\
\hline$C X$ & 9 & 39,1 & & \\
\hline$C D+C X$ & 1 & 4,3 & & \\
\hline $\mathrm{DA}+\mathrm{CD}$ & 1 & 4,3 & & \\
\hline
\end{tabular}

Onde: $\mathrm{DA}=$ artéria descendente anterior; $\mathrm{CD}=$ artéria coronária direita; $\mathrm{CX}=$ artéria circunflexa. 


\subsubsection{Métodos de avaliação funcional}

\subsubsection{Teste Ergométrico}

Para a comparação dos resultados dos testes ergométricos utilizamos os valores do teste de seleção (S), do segundo teste da primeira etapa (teste do precondicionamento isquêmico precoce - E1) e o teste da segunda etapa (teste de contraprova - E2).

O protocolo de Bruce modificado foi aplicado em 15 pacientes $(65,2 \%)$ e o protocolo original em oito pacientes $(34,8 \%)$.

O tempo total de exercício em segundos foi menor nos testes das etapas 1 e $2(486 \pm 115 ; 470 \pm 289 ; p=0,518$ e $p=0,015)$ em comparação com o teste de seleção $(516 \pm 84)$, sem diferença entre as etapas $(p=0,95)$. Para o aparecimento de infradesnivelamento de $-1,0$ e $-2,0 \mathrm{~mm}$, houve aumento do tempo na etapa 1 - precondicionamento - $(339 \pm 130 ; 431 \pm 126)$ em comparação ao teste de seleção $(245 \pm 96 ; 367 \pm 104)$, e redução na etapa 2 $(289 \pm 125 ; 374 \pm 109)$ em comparação à etapa $1, p<0,001$. Também houve redução no tempo de normalização do segmento ST após o exercício na etapa 1 (569 $\pm 191 ; 353 \pm 194 ; 507 \pm 140), \quad p<0,001$. A administração do radiofármaco foi realizada em tempo menor quando comparado com o exame inicial, porém não houve diferença significativa entre as etapas (Tabela 8).

A redução da magnitude do infradesnivelamento do segmento ST pico foi estatisticamente significativa entre as três etapas $(3,67 \pm 0,79 ; 2,33 \pm$ 
$0,58 ; 3,14 \pm 1,05) p<0,05$; bem como no momento de injeção do sestamibiTc-99m, e no sexto minuto da fase de recuperação.

Os valores do produto da frequência cardíaca pela pressão arterial (DP) entre o teste de seleção e o precondicionamento foram semelhantes no momento correspondente aos infradesnivelamento de $-1,0$ e $-2,0 \mathrm{~mm}$; mas diferiram nos momentos de injeção do sestamibi-Tc-99m e pico de esforço $(p=0,016 ; p=0,011)($ Tabela 10).

A frequência cardíaca pico não diferiu em média entre o exame de seleção $(145 \pm 12)$ e o teste de precondicionamento (142 \pm 13$)$, sendo menor no teste de contraprova (135 \pm 11$)$. A frequência cárdica média para a injeção do radiofármaco foi $140 \pm 12$ no teste de seleção, $134 \pm 13$ na primeira etapa e $128 \pm 10$ na segunda etapa. Houve diferença significativa entre as etapas e entre o teste de seleção e de contraprova; contudo esta diferença foi inerente à metodologia empregada. (Tabela 10)

A dor precordial durante o teste de seleção esteve presente em 11 pacientes $(47,8 \%$ do total). Durante o segundo teste apenas cinco pacientes mantiveram angina ao esforço, ou seja, redução de $54 \%$ em relação ao primeiro. No terceiro teste, um paciente não reproduziu o sintoma inicial. Contudo, entre os que apresentaram o sintoma nas três fases, não houve diferença significante entre os tempos de aparecimento e desaparecimento da dor precordial.

O mesmo comportamento pode ser observado quanto à presença de arritmias ventriculares. Em 12 pacientes houve o aparecimento de arritmias durante o esforço, e em seis deles reproduziram a arritmia na segunda 
etapa. Desta forma, houve redução de $50 \%$ na ocorrência de arritmias durante o teste de precondicionamento. 


\begin{tabular}{|c|c|c|c|c|c|c|c|c|c|}
\hline \multirow[t]{2}{*}{ Variáveis } & \multicolumn{2}{|l|}{ SELEÇÃO } & \multicolumn{2}{|l|}{ ETAPA 1} & \multicolumn{2}{|l|}{ ETAPA 2} & \multirow{2}{*}{$\begin{array}{l}\text { Valor de } p \\
\text { (S x E1) }\end{array}$} & \multirow{2}{*}{$\begin{array}{l}\text { Valor de } p \\
\text { (S x E2) }\end{array}$} & \multirow{2}{*}{$\begin{array}{l}\text { Valor de } p \\
\text { (E1xE2) }\end{array}$} \\
\hline & Média $\pm d p$ & Med. & Média $\pm d p$ & Med. & Média $\pm d p$ & Med. & & & \\
\hline Tempo total ex. (segundos) & $516 \pm 83$ & 480 & $486 \pm 115$ & 462 & $470 \pm 289$ & 480 & 0,518 & 0,015 & 0,95 \\
\hline $\mathrm{T}-1,0 \mathrm{~mm}$ (segundos) & $245 \pm 96$ & 230 & $339 \pm 130$ & 360 & $289 \pm 125$ & 300 & 0,000 & 0,071 & 0,036 \\
\hline $\mathrm{T}-2,0 \mathrm{~mm}$ (segundos) & $367 \pm 104$ & 360 & $431 \pm 126$ & 420 & $374 \pm 109$ & 360 & 0,001 & 1,000 & 0,010 \\
\hline Tempo MIBI (segundos) & $450 \pm 87$ & 420 & $408 \pm 102$ & 390 & $412 \pm 97$ & 420 & 0,020 & 0,024 & 1,000 \\
\hline TN (seg) & $569 \pm 191$ & 600 & $353 \pm 194$ & 360 & $507 \pm 140$ & 480 & 0,000 & 0,431 & 0,001 \\
\hline DP $-1,0$ & $21.018 \pm 4408$ & 20.800 & $22.143 \pm 5116$ & 22.400 & $19.544 \pm 3257$ & 19720 & 0,701 & 0,115 & 0,005 \\
\hline DP $-2,0$ & $24.248 \pm 4654$ & 22.800 & $25.015 \pm 4862$ & 24.160 & $22.337 \pm 3775$ & 22610 & 1,000 & 0,250 & 0,002 \\
\hline DP MIBI & $27.270 \pm 5097$ & 27.900 & $24.423 \pm 5557$ & 23.120 & $23.245 \pm 4198$ & 22780 & 0,016 & 0,000 & 0,192 \\
\hline DP Pico & $28.596 \pm 5008$ & 29.000 & $25.795 \pm 5852$ & 24.600 & $24.477 \pm 4814$ & 24300 & 0,011 & 0,000 & 0,112 \\
\hline DP DOR & $21.476 \pm 4458$ & 20.850 & $20.868 \pm 2602$ & 21.300 & $20.865 \pm 3614$ & 20655 & 0,296 & 0,647 & 0,062 \\
\hline ST pico & $3,67 \pm 0,79$ & $-3,50$ & $2,33 \pm 0,58$ & $-2,00$ & $3,14 \pm 1,05$ & $-3,00$ & 0,000 & 0,034 & 0,010 \\
\hline ST MIBI-Tc & $2,96 \pm 0,72$ & $-3,00$ & $1,5 \pm 0,40$ & $-1,50$ & $2,34 \pm 0,80$ & $-2,50$ & 0,000 & 0,016 & 0,000 \\
\hline ST Recuperação 6 minuto & $1,07 \pm 0,40$ & $-1,00$ & $0,6 \pm 0,40$ & $-0,50$ & $0,9 \pm 0,50$ & $-1,00$ & 0,000 & 0,566 & 0,003 \\
\hline Tempo angina & $379 \pm 133$ & 360 & $336 \pm 98$ & 300 & $389 \pm 119$ & 412,5 & 0,624 & 1,000 & 0,978 \\
\hline Tempo desaparecimento & $155 \pm 85$ & 120 & $120 \pm 103$ & 60 & $159 \pm 124$ & 120 & 0,160 & 1,000 & 0,422 \\
\hline Carga em MET & $7,78 \pm 1,46$ & 7,96 & $7,39 \pm 1,44$ & 7,53 & $7,15 \pm 1,49$ & 7,35 & 0,484 & 0,015 & 0,946 \\
\hline \multirow[t]{2}{*}{$\mathrm{VO}_{2}$ estimado } & $27,27 \pm 5,12$ & 27,85 & $25,88 \pm 5,04$ & 25,73 & $25,11 \pm 5,20$ & 5,20 & 0,484 & 0,015 & 0,946 \\
\hline & $\mathbf{N}$ & $\%$ & $\mathbf{N}$ & $\%$ & $\mathbf{N}$ & $\%$ & & & \\
\hline Arritmia & 12 & 52,2 & 6 & 26,1 & 12 & 52,2 & 0,005 & 1,000 & 0,043 \\
\hline Sintoma & 11 & 47,8 & 5 & 21,7 & 10 & 43,5 & 0,005 & 0,569 & 0,013 \\
\hline
\end{tabular}

Onde: $\mathrm{dp}=$ desvio padrão; T=tempo; ex=exercício; $\mathrm{TN}=$ tempo de normalização do infradesnivelamento de ST; $\mathrm{DP}=$ Produto da frequência cardíaca pela pressão arterial; $\mathrm{ST}=$ infradesnivelamento do segmento $\mathrm{ST} ; \mathrm{MIBI}=$ monoisobutil-isonitrila; $\mathrm{R} 6=$ recuperação de seis minutos; $\mathrm{MET}=$ equivalente metabólico; $\mathrm{VO}_{2}=$ consumo de oxigênio 
Tabela 9. Variáveis do Teste Ergométrico - II

\begin{tabular}{|c|c|c|c|c|c|c|c|c|c|c|}
\hline & \multicolumn{2}{|c|}{ SELEÇÃO } & \multicolumn{2}{|c|}{ ETAPA 1} & \multicolumn{2}{|c|}{ ETAPA 2} & \multicolumn{4}{|c|}{ Valor de $p$} \\
\hline Varíavel & Média $\pm \mathrm{dp}$ & Med. & Média \pm dp & Med. & Média \pm dp & Med. & p & $p$ (SxE1) & $p$ (SxE2) & $p$ (E1xE2) \\
\hline FC rep & $76,17 \pm 9,06$ & 74,00 & $80,57 \pm 9,53$ & 80,00 & $72,04 \pm 9,55$ & 69,00 & 0,01 & 0,105 & 0,345 & 0,013 \\
\hline FC pico & $145,74 \pm 12,11$ & 146,00 & $142,57 \pm 13,48$ & 146,00 & $135,65 \pm 11,36$ & 137,00 & 0,00 & 0,440 & 0,000 & 0,008 \\
\hline FC $-1,0$ & $116,13 \pm 12,02$ & 120,00 & $126,87 \pm 14,50$ & 128,00 & $114,70 \pm 10,27$ & 113,00 & 0,00 & 0,001 & 1,000 & 0,001 \\
\hline FC $-2,0$ & $128,22 \pm 12,02$ & 132,00 & $138,75 \pm 13,89$ & 141,00 & $125,05 \pm 12,00$ & 126,00 & 0,00 & 0,004 & 0,179 & 0,000 \\
\hline FC MIBI & $140,04 \pm 12,72$ & 142,00 & $134,87 \pm 13,85$ & 137,00 & $128,65 \pm 10,42$ & 130,00 & 0,00 & 0,118 & 0,000 & 0,010 \\
\hline$\%$ FCMX & $92,45 \pm 9,05$ & 95,51 & $90,51 \pm 10,40$ & 93,57 & $86,12 \pm 9,23$ & 85,80 & 0,00 & 0,476 & 0,000 & 0,007 \\
\hline IC & $0,86 \pm 0,16$ & 0,88 & $0,82 \pm 0,19$ & 0,85 & $0,74 \pm 0,17$ & 0,75 & 0,02 & 0,280 & 0,000 & 0,018 \\
\hline DC (\%) & $8,0 \pm 0,9$ & 5,00 & $9,0 \pm 1,0$ & 6,00 & $14,0 \pm 9,0$ & 14,00 & 0,01 & 0,476 & 0,000 & 0,007 \\
\hline PAS rep & $151,13 \pm 25,22$ & 150,00 & $140,30 \pm 18,22$ & 140,00 & $141,35 \pm 17,86$ & 140,00 & 0,00 & 0,110 & 0,234 & 1,000 \\
\hline PAS pico & $195,87 \pm 28,63$ & 200,00 & $179,57 \pm 29,96$ & 180,00 & $179,61 \pm 27,99$ & 176,00 & 0,01 & 0,013 & 0,008 & 1,000 \\
\hline PAS - 1,0 & $180,22 \pm 29,10$ & 180,00 & $172,83 \pm 25,53$ & 170,00 & $170,22 \pm 22,99$ & 170,00 & 0,18 & 0,522 & 0,193 & 1,000 \\
\hline PAS -2,0 & $188,70 \pm 30,23$ & 190,00 & $179,25 \pm 22,02$ & 180,00 & $178,18 \pm 21,47$ & 175,00 & 0,07 & 0,145 & 0,060 & 1,000 \\
\hline PAS MIBI & $193,48 \pm 28,54$ & 200,00 & $180,00 \pm 28,08$ & 180,00 & $180,00 \pm 25,00$ & 180,00 & 0,03 & 0,038 & 0,025 & 1,000 \\
\hline
\end{tabular}

Med.:mediana; FC: frequência cardíaca; PAS: pressão arterial sistólica; DP: produto da frequência cardíaca pela pressão arterial; IC: Índice cronotrópico; DC: déficit cronotrópico. 


\subsubsection{Cintilografia de Perfusão Miocárdica}

$\mathrm{Na}$ análise das variáveis qualitativas, observamos que dois pacientes $(8,6 \%)$ apresentaram redução completa das alterações eletrocardiográficas e normalização das imagens cintilográficas na etapa do precondicionamento. Em contrapartida, quatro pacientes $(17,3 \%)$ não apresentaram qualquer modificação, ou seja, melhora eletrocardiográfica ou cintilográfica no teste de precondicionamento. A fração de ejeção em repouso esteve normal $(>50 \%)$ em 21 pacientes no teste de seleção e precondicionamento, e em 18 no teste de contraprova $(p=0,761)$; após o esforço, a FEVE esteve normal em 20 pacientes nas duas primeiras etapas e 17 na terceira etapa $(p=0,308)$. Três pacientes (13\%) apresentaram queda maior que 5\% na FEVE no teste de seleção, e quatro nas outras duas etapas $(\mathrm{p}=0,823)$ (Tabela 10).

As análises das variáveis quantitativas das imagens de cintilografia de perfusão não foram observadas alterações significativas quanto ao porcentual de área isquêmica, função ventricular de repouso e após esforço, valor de TID. A redução da área de isquemia entre 0 teste de seleção e 0 precondicionamento foi discreta $(13,8 \pm 10,7 ; 11,4 \pm 7,7$ e $p=0,69)$ (Tabela 11).

A diminuição do somatório de escore de estresse (SSS) foi observada entre a etapa de seleção e precondicionamento $(9,35 \pm 6,27 ; 7,00 \pm 6,23$ e $\mathrm{p}=0,04)$, e entre o teste precondicionamento e contraprova $(8,13 \pm 6,45$ e $p=$ 0,05). O mesmo foi observado para o escore da diferença (SDS) entre as três etapas $(7,43 \pm 5,40 ; 4,91 \pm 3,99 ; 6,22 \pm 4,11$ e $p=0,03 ; p=0,04)$ ( Tabela 11). 
Tabela 10. Variáveis Cintilográficas Qualitativas

\begin{tabular}{lcccccccc}
\hline VARIÁVEL & \multicolumn{2}{c}{ SELEÇÃO } & \multicolumn{2}{c}{ ETAPA 1 } & \multicolumn{2}{c}{ ETAPA 2 } & Valor de p \\
\hline & N & $\%$ & $\mathbf{N}$ & $\%$ & $\mathbf{N}$ & $\%$ & \\
Perfusão alterada & 23 & 100 & 21 & 91,3 & 23 & 100 & - \\
Fibrose & 8 & 34,7 & 8 & 34,7 & 8 & 34,7 & $0,2470^{\digamma}$ \\
Função ventricular & & & & & & & &
\end{tabular}

\begin{tabular}{lccccccc} 
- repouso (>50\%) & 21 & 91,2 & 21 & 91,3 & 18 & 78,3 & $0,7612^{\mathrm{A}}$ \\
\hline - pós-esforço (> 50\%) & 20 & 86,9 & 20 & 86,9 & 17 & 73,9 & $0,3080^{\mathrm{A}}$ \\
\hline Queda FE > 5\% & 3 & 13,0 & 4 & 17,4 & 4 & 17,4 & $0,8231^{\mathrm{A}-\mathrm{NP}}$ \\
\hline TID normal $(<\mathbf{1 , 2})$ & 19 & 82,6 & 20 & 87,0 & 21 & 91,3 & $0,192^{\mathrm{A}-\mathrm{NP}}$
\end{tabular}

A: Anova pra medidas repetidas; A-NP: Anova não paramétrica para medidas repetidas; F: teste de Friedman; TID: transient ischemic dilation 
Tabela 11. Variáveis Cintilográficas Quantitativas

\begin{tabular}{|c|c|c|c|c|c|c|c|c|c|c|}
\hline \multirow[t]{2}{*}{ VARIÁVEL } & \multicolumn{2}{|c|}{ SELEÇÃO } & \multicolumn{2}{|c|}{ ETAPA 1} & \multicolumn{2}{|c|}{ ETAPA 2} & \multirow{2}{*}{$\begin{array}{l}\text { Valor p } \\
\text { (geral) }\end{array}$} & \multirow{2}{*}{$\begin{array}{l}\text { Valor p } \\
\text { (SxE1) }\end{array}$} & \multirow{2}{*}{$\begin{array}{l}\text { Valor p } \\
\text { (SxE2) }\end{array}$} & \multirow{2}{*}{$\begin{array}{l}\text { Valor p } \\
\text { (E1xE2) }\end{array}$} \\
\hline & Média (dp) & Mediana & Média (dp) & Mediana & Média (dp) & Mediana & & & & \\
\hline$\%$ isquemia $^{A}$ & $13,8 \pm 10,7$ & 10,0 & $11,4 \pm 7,7$ & 10,0 & $12,5 \pm 7,7$ & 15,0 & $0,6910^{A}$ & NS & NS & NS \\
\hline FE basal ${ }^{A}$ & $58,3 \pm 10,0$ & 57,0 & $58,5 \pm 9,6$ & 58,0 & $58,1 \pm 10,1$ & 58,0 & $0,7612^{A}$ & NS & NS & NS \\
\hline $\begin{array}{l}\text { FE pós- } \\
\text { esforço }^{A}\end{array}$ & $58,4 \pm 8,8$ & 58,0 & $59,0 \pm 10,8$ & 56,0 & $57,3 \pm 8,6$ & 56,0 & $0,3080^{A}$ & NS & NS & NS \\
\hline Valor TID ${ }^{A}$ & $1,03 \pm 0,21$ & 0,98 & $1,01 \pm 0,19$ & 0,98 & $1,06 \pm 0,19$ & 1,02 & $0,2231^{A}$ & NS & NS & NS \\
\hline SSS & $9,35 \pm 6,27$ & 8,0 & $7,00 \pm 6,23$ & 6,0 & $8,13 \pm 6,45$ & 6,0 & $0,0675^{A}$ & $0,045^{t}$ & $0,262^{t}$ & $0,056^{t}$ \\
\hline SDS & $7,43 \pm 5,40$ & 6,0 & $4,91 \pm 3,99$ & 5,0 & $6,22 \pm 4,11$ & 6,0 & $0,0406^{A}$ & $0,030^{t}$ & $0,262^{t}$ & $0,039^{t}$ \\
\hline
\end{tabular}

Onde: $\mathrm{dp}=$ desvio-padrão; $\mathrm{A}=\mathrm{ANOVA}$; $\mathrm{t}$ = teste t student; $\mathrm{FE}=$ fração de ejeção; $\mathrm{NS}=$ não significativo $(\mathrm{p}>0,05)$; SSS= Summed stress score (somatório do escore de estresse); SDS= summed diference score (somatório da diferença do escore de repouso e estresse); TID: transiente ischemic dilation (dilatação isquêmica transitório 
Entre as alterações eletrocardiográficas e as modificações cintilográficas, 18 (78,3\%) dos 23 pacientes apresentaram redução igual ou superior a 1,0 $\mathrm{mm}$ no teste de precondicionamento, porém apenas sete $(38,9 \%)$ tiveram melhora concomitante na imagem da perfusão, representada por redução do escore de estresse (SSS) e do escore da diferença (SDS), ou seja, 11 pacientes tiveram atenuação do infradesnivelamento do segmento ST, sem melhora correspondente nas imagens de perfusão e nos valores dos escores. Assim, cinco pacientes $(21,7 \%$ do total de pacientes) não apresentaram modificação eletrocardiográfica, sendo que três também não apresentaram melhora perfusional (tabela 12).

A correlação entre as variáveis: redução do infradesnível de ST igual ou maior que $1,0 \mathrm{~mm}$, redução do escore de estresse e redução do escore da diferença maior que dois, foi muito fraca, com coeficiente de correlação $r=0,15(p=0,492)$ para o infradesnível no momento de injeção do radiofármaco, e $r=0,10(p=0,629)$ para o infradenível de ST do pico do esforço (Tabela 13). 
Tabela 12. Associação das medidas categorizadas entre o infradesnível do segmento ST e o escore SSS

\begin{tabular}{|c|c|c|c|c|}
\hline ENTRE SELEÇÃO E ETAPA 1 & & & & \\
\hline \multirow{2}{*}{ Redução infradesnivel ST >1,0mm - MIBI } & & \multicolumn{2}{|c|}{ Redução Escore_SSS } & Total \\
\hline & & NÃO & SIM & \\
\hline \multirow[t]{2}{*}{ NÃO } & $\mathrm{n}$ & 3 & 2 & 5 \\
\hline & $\%$ & $60,0 \%$ & $40,0 \%$ & $21,7 \%$ \\
\hline \multirow[t]{2}{*}{ SIM } & $\mathrm{n}$ & 11 & 7 & 18 \\
\hline & $\%$ & $61,1 \%$ & $38,9 \%$ & $78,3 \%$ \\
\hline \multirow[t]{2}{*}{ Total } & $\mathrm{n}$ & 14 & 9 & 23 \\
\hline & $\%$ & $60,9 \%$ & $39,1 \%$ & $100,0 \%$ \\
\hline \multicolumn{5}{|l|}{$p=1,000 F$} \\
\hline \multirow[t]{2}{*}{ Redução infradesnivel ST >1,0mm - PICO } & & \multicolumn{2}{|c|}{ Redução Escore_SSS } & Total \\
\hline & & NÃO & SIM & \\
\hline \multirow[t]{2}{*}{ NÃO } & $\mathrm{n}$ & 4 & 2 & 6 \\
\hline & $\%$ & $66,7 \%$ & $33,3 \%$ & $26,1 \%$ \\
\hline \multirow[t]{2}{*}{ SIM } & $\mathrm{n}$ & 10 & 7 & 17 \\
\hline & $\%$ & $58,8 \%$ & $41,2 \%$ & $73,9 \%$ \\
\hline \multirow[t]{2}{*}{ Total } & $\mathrm{n}$ & 14 & 9 & 23 \\
\hline & $\%$ & $60,9 \%$ & $39,1 \%$ & $100,0 \%$ \\
\hline$p=1,000 \mathrm{~F}$ & & & & \\
\hline
\end{tabular}

\begin{tabular}{|c|c|c|c|c|}
\hline ENTRE ETAPA 1 e 2 & & & & \multirow{3}{*}{ Total } \\
\hline \multirow{2}{*}{ Aumento infradesnível ST >1,0mm - MIBI } & & \multicolumn{2}{|c|}{ Aumento do Escore SSS } & \\
\hline & & NÃO & SIM & \\
\hline \multirow[t]{2}{*}{ NÃO } & $\mathrm{n}$ & 6 & 4 & 10 \\
\hline & $\%$ & $60,0 \%$ & $40,0 \%$ & $43,5 \%$ \\
\hline \multirow[t]{2}{*}{ SIM } & $\mathrm{n}$ & 6 & 7 & 13 \\
\hline & $\%$ & $46,2 \%$ & $53,8 \%$ & $56,5 \%$ \\
\hline \multirow[t]{2}{*}{ Total } & $\mathrm{n}$ & 12 & 11 & 23 \\
\hline & $\%$ & $52,2 \%$ & $47,8 \%$ & $100,0 \%$ \\
\hline$p=0,510 P$ & & & & \\
\hline
\end{tabular}

\begin{tabular}{|c|c|c|c|c|}
\hline \multirow[t]{2}{*}{ Aumento infradesnível ST >1,0mm - PICO } & & \multicolumn{2}{|c|}{ Aumento do Escore SSS } & \multirow[t]{2}{*}{ Total } \\
\hline & & NÃO & SIM & \\
\hline \multirow[t]{2}{*}{ NÃO } & $\mathrm{n}$ & 9 & 4 & 13 \\
\hline & $\%$ & $69,2 \%$ & $30,8 \%$ & $56,5 \%$ \\
\hline \multirow[t]{2}{*}{ SIM } & $\mathrm{n}$ & 3 & 7 & 10 \\
\hline & $\%$ & $30,0 \%$ & $70,0 \%$ & $43,5 \%$ \\
\hline \multirow[t]{2}{*}{ Total } & $\mathrm{n}$ & 12 & 11 & 23 \\
\hline & $\%$ & $52,2 \%$ & $47,8 \%$ & $100,0 \%$ \\
\hline
\end{tabular}

$p=0,062 \mathrm{P}($ Kappa $=0,388)$
Onde: $\mathrm{ST}=$ segmento ST; MIBI: momento de injeção do radiofármaco sestamibi-Tc-99m; SSS=Somatório do escore de estresse; $F=$ teste de Friedmann; $p=$ valor de $p ; P=$ correlação de Pearson 
Tabela 13. Correlação entre infradesnível de ST e as diferenças do escore de perfusão

\begin{tabular}{lccccc}
\hline Correção de Pearson & & & & & \\
\hline \multicolumn{1}{c}{ Seleção x Etapa1 } & & ST MIBI & ST PICO & DP MIBI & DP PICO \\
\hline diferença SSS >2 & $\mathrm{r}$ & 0,130 & 0,071 & $-0,204$ & $-0,169$ \\
& $\mathrm{p}$ & 0,555 & 0,746 & 0,351 & 0,441 \\
& & & & & \\
SDS & $\mathrm{r}$ & 0,151 & 0,106 & $-0,161$ & $-0,146$ \\
& $\mathrm{p}$ & 0,492 & 0,629 & 0,462 & 0,506
\end{tabular}

\begin{tabular}{llllll}
\hline \multicolumn{1}{c}{ Entre etapas 1 e 2 } & & & & & \\
\hline diferença SSS >2 & $\mathrm{r}$ & $-0,224$ & $-0,366$ & $-0,148$ & $-0,321$ \\
& $\mathrm{p}$ & 0,303 & $\mathbf{0 , 0 8 6}$ & 0,500 & 0,135 \\
& & & & & \\
SDS & $\mathrm{r}$ & $-0,194$ & $-0,360$ & $-0,142$ & $-0,329$ \\
& $\mathrm{p}$ & 0,376 & $\mathbf{0 , 0 9 2}$ & 0,520 & 0,125
\end{tabular}

\begin{tabular}{llllll}
\hline \multicolumn{1}{c}{ Seleção x Etapa 2 } & & & & & \\
\hline diferença SSS >2 & $\mathrm{r}$ & $-0,028$ & 0,222 & $-0,177$ & $-0,171$ \\
& $\mathrm{p}$ & 0,899 & 0,309 & 0,419 & 0,435 \\
& & & & & \\
SDS & $\mathrm{r}$ & $-0,045$ & 0,231 & $-0,183$ & $-0,191$ \\
& $\mathrm{p}$ & 0,839 & 0,289 & 0,404 & 0,383 \\
\hline
\end{tabular}

SSS= somatório do escore de estresse; SDS= somatório da diferenças dos escores repouso e esforço; $r=$ coeficiente de correlação; $p=$ valor de $p$

A comparação entre a etapa do precondicionamento e o teste de contraprova (etapas 1 e 2) mostrou que houve associação entre o aumento do infradesnivelamento de ST e o aumento do escore de estresse (SSS) com $p=0,062$, porém com concordância fraca (Kappa $=0,388$ ) e coeficiente de correlação= $-0,366$ (Figura 9). 
(A)

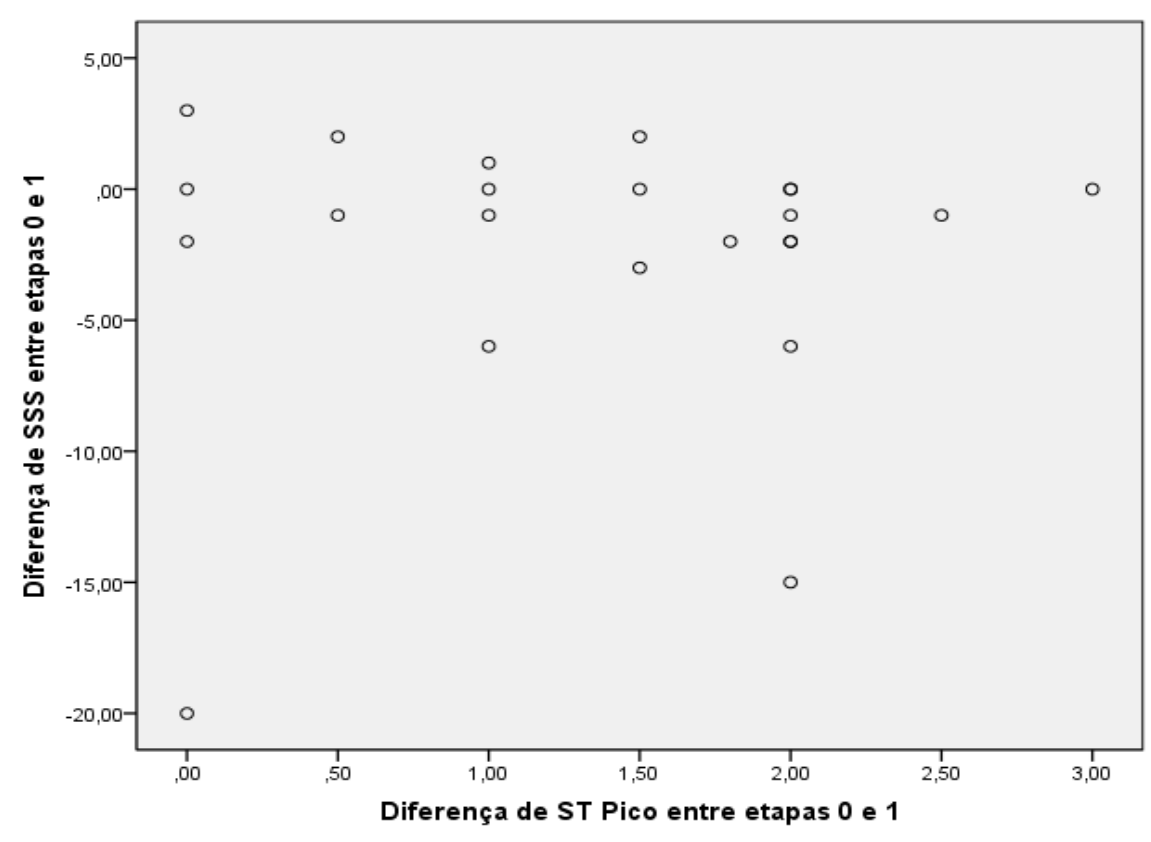

(B)

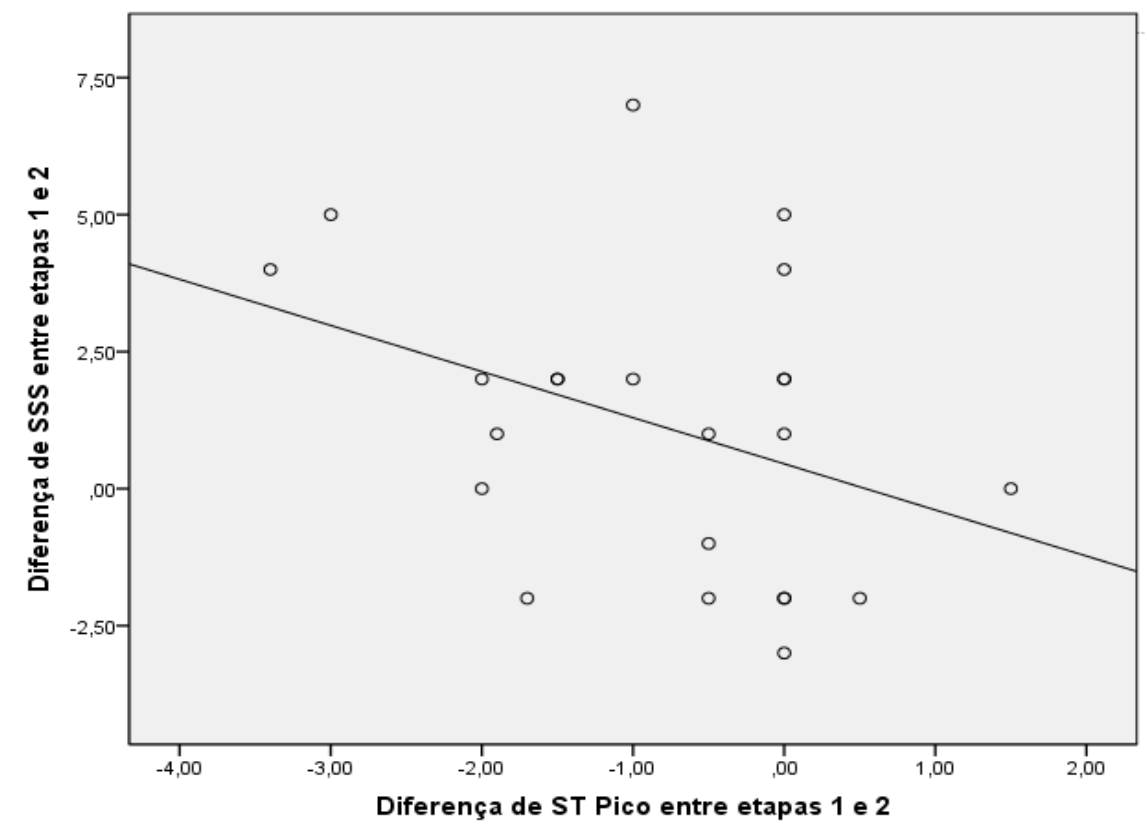

Figura 9. Correlação de Pearson para a diferença do SSS e a diferença do desnível de ST no pico do exercício: (A) entre as etapas 0 e 1; (B) entre as etapas 1 e 2 
4 Discussão 
O precondicionamento isquêmico foi reconhecido há cerca de 25 anos. Embora descrito inicialmente no músculo cardíaco em experimentos animais (Murry et al., 1986), este fenômeno manifesta-se em outros órgãos como cérebro, fígado, rins (Yellon; Downey, 2003) e musculatura esquelética (Cappecchi et al., 1997). O precondicionamento é conceituado como o aumento da tolerância celular à isquemia e lesão de isquemia/reperfusão induzido por curtos episódios de redução do fluxo sanguíneo prévios à ocorrência de isquemia prolongada.

A angina do aquecimento e a angina pré-infarto são duas situações clínicas que induzem a ativação do precondicionamento isquêmico em indivíduos com doença arterial coronária crônica. Em procedimentos de intervenção coronária percutânea, a sucessão de curtos períodos de insuflação do balão em artérias coronárias associou-se à progressiva redução da magnitude do supradesnivelamento do segmento ST e dos níveis de marcadores de lesão celular (Deutsch, 1990). Isto denota que existe um mecanismo de proteção tecidual que é acionado a partir do episódio inicial de isquemia, e que impede ou retarda a lesão de reperfusão, apoptose e morte celular.

Duas fases de proteção são reconhecidas: fase inicial, designada precondicionamento clássico ou precoce, e fase tardia, o precondicionamento tardio. O mecanismo pelo qual ocorre este fenômeno protetor é complexo e convencionalmente dividido em fatores deflagradores, mediadores e efetores que culminam em aumento da reserva de energia (ATP). O precondicionamento tardio é consequente à sequência de eventos 
deflagrados pela fase precoce, e é decorrente essencialmente de síntese protéica que influencia a regulação da concentração de cálcio dentro da célula.

A atenuação eletrocardiográfica observada nas salas de cateterismo após momentos de isquemia resultantes da insuflação do balão foi também documentada durante episódios isquêmicos diários provocados por exercício físico (Tvizoni; Maybaum et al., 1997) e em testes ergométricos sequenciais (Maybaum et al., 1996; Tomai et al., 1999; Kay et al., 2000; Lambiase et al., 2003; Paraskevaidis et al., 2005). Dois estudos foram publicados com o objetivo de evidenciar o precondicionamento isquêmico precoce em imagens de cintilografia de perfusão miocárdica, porém apresentaram resultados divergentes (Bogaty et al., 2001; Koutelou et al.,2010).

\subsection{Casuística}

A população deste estudo constituiu-se predominantemente de homens (82,6\%), com média de idade $64 \pm 7$ anos, hipertensos $(95,7 \%)$, diabéticos $(60,9 \%)$. Oito pacientes $(34,7 \%)$ apresentavam história de infarto do miocárdio prévio, sem alterações eletrocardiográficas correspondentes, porém com área de fibrose detectada pela cintilografia.

Dados da literatura não indicam que 0 precondicionamento isquêmico se manifeste de forma diferente em ambos os sexos, embora o número de mulheres incluídas nos estudos seja pequeno, e algumas 
pesquisas tenham sido realizadas exclusivamente em homens (Bogaty et al., 2001; Koutelou at al, 2010). A inclusão de quatro mulheres neste estudo foi pequena, com resultados divergentes entre si. Desta forma, não consideramos que o fator sexo teria influenciado os resultados.

O precondicionamento pode estar inibido em diabéticos (Ferdinandy et al., 2007) e em idosos (Abete et al., 1996; Abete et al., 1997). É também descrito que área de hipocaptação fixa nas imagens de perfusão podem interferir na avaliação da isquemia em território adjacente (Hendel et al., 2009). Estas condições podem ter influenciado a baixa correlação encontrada neste estudo entre as alterações eletrocardiográficas e cintilográficas.

\subsection{Testes ergométricos}

Algumas diferenças observadas nos resultados deste estudo ocorreram de forma concordante com o esperado. O teste de seleção foi limitado por sinal e/ou sintoma, e os testes das etapas 1 e 2 foram vinculados ao tempo de aparecimento do infradesnível do segmento ST de 2,0 mm. Desta forma, o tempo total de exercício, a frequência cardíaca atingida e os valores de pressão arterial foram influenciados pelo protocolo estabelecido.

A limitação da carga de esforço pelo nível de infradesnivelamento do segmento ST de 2,0 $\mathrm{mm}$ pode ter interferido no consumo máximo de 
oxigênio e, consequentemente, nas imagens de perfusão. Alguns autores (Kay et al., 2000; Bogaty et al., 2003) sugeriram que seria necessário limiar mínimo de isquemia para acionar o fenômeno do precondicionamento, proporcionado pela carga de trabalho e pelo tempo de exposição de pelo menos cinco minutos. Em nossa pesquisa, o tempo médio de exercício situou-se entre sete e oito minutos, sendo que 15 pacientes $(65,2 \%)$ realizaram o protocolo de Bruce modificado, com consumo de oxigênio médio estimado em cerca de sete MET. Comparando com o estudo de Koutelou et al., que utilizaram o protocolo de Bruce original, os pacientes deste estudo realizaram carga de trabalho inferior $(7,4 \pm 1,4$ versus $8,9 \pm$ 13). Estes dados poderiam justificar as diferenças entre a redução nos valores dos escores de perfusão e da extensão da área de isquemia verificados entre os dois trabalhos, e sugerir menor efeito do precondicionamento isquêmico precoce nesta pesquisa. Contudo, os valores da frequência cardíaca atingida na etapa do precondicionamento foram em média superiores a $85 \%$ da máxima preconizada (90 $\pm 10 \%$, mediana=93\%).

O duplo produto, variável que reflete o consumo miocárdico de oxigênio, foi menor na etapa de precondicionamento do que no teste de seleção no momento da injeção do radiofármaco e no pico do esforço, embora tenha sido semelhante nos momentos de depressão de ST de 1,0 $\mathrm{mm}$ e 2,0 mm. Além disso, os valores do duplo produto no pico do esforço foram similares ( $25.795 \pm 5852$ versus $24.900 \pm 5500)$ nos dois estudos.

Consideramos que alguns fatores possam ter influenciado valores menores de duplo produto no teste de contra-prova, como a maior 
familiaridade com o ergômetro, confiança e maior observância nas recomendações dietéticas. O efeito agudo do exercício provocado pelo teste precedente pode ter contribuído para os menores valores do duplo produto no teste de precondicionamento.

O retardo no tempo para o aparecimento do infradesnivelamento de ST e a menor magnitude das alterações eletrocardiográficas na maioria dos pacientes foi evidente na etapa do precondicionamento. Em síntese, 78,2\% dos pacientes apresentaram atenuação da depressão do segmento ST, com redução de $34 \%$ na magnitude do infradesnivelamento do segmento ST no pico do exercício do teste de precondicionamento, aumento de $45 \%$ no tempo para aparecimento do infradesnível de $1,0 \mathrm{~mm}$, normalização mais rápida na fase de recuperação, com redução de $36 \%$. Comparados os testes de precondicionamento e de contraprova, houve diminuição de 13\% tanto no tempo de aparecimento da depressão do segmento ST para 1,0 mm como para 2,0 $\mathrm{mm}$, porém com valores menores do produto da frequência cardíaca pela pressão arterial; ainda assim, houve diferença significativa no aumento do escore de perfusão.

A ocorrência de angina e de arritmias também apresentou redução relevante, $45,4 \%$ e $50 \%$, respectivamente. Estes dados são congruentes com outras pesquisas (Maybaum et al., 1996; Anzai et al., 1995; Tzivoni et al., 1997; Lambiase et al., 2003), e sugerem que os mecanismos envolvidos no precondicionamento interferam no padrão elétrico celular, tornando o miocárdio menos vulnerável à ação deletéria da isquemia. 


\subsection{Cintilografia miocárdica}

Nesta pesquisa, dois pacientes apresentaram reversão completa do defeito de perfusão na fase de precondicionamento; em sete houve diminuição parcial da isquemia, ou seja, $39,1 \%$ dos pacientes evidenciaram melhora cintilográfica pelo precondicionamento isquêmico, dos quais, dois não apresentaram melhora eletrocardiográfica correspondente.

A redução significativa dos escores de perfusão de estresse (SSS) e da diferença (SDS), embora em valores menores, foi concordante com os dados de Koutelou et al. (2010), porém discordante quanto à redução da extensão da área de isquemia induzida pelo precondicionamento precoce. Nesse aspecto, os dados desta pesquisa assemelharam-se aos de Bogaty et al.(2001), tanto em relação à extensão da área isquêmica como ao percentual de redução da magnitude da depressão do segmento ST.

Essas diferenças podem estar relacionadas aos isótopos e protocolos de aplicação utilizados nas três pesquisas. Bogaty et al. (2001), aplicaram testes ergométricos sequenciais em duas condições distintas e com três semanas de intervalo. Foi utilizado o mesmo valor do duplo produto do primeiro teste, como ponto de referência para a administração do radiofármaco (Tálio-201) no segundo teste, no qual haveria o efeito do precondicionamento. Ocorreu evidente atenuação eletrocardiográfica da isquemia, contudo sem modificações significativas nas imagens de perfusão e extensão da isquemia. Atualmente, o Tálio-201 é menos utilizado para a avaliação de isquemia miocárdica, pelo maior custo e exposição à 
radioatividade. Em 2008, outro estudo sobre avaliação cintilográfica neste campo de investigação foi realizado por lliodromitis et al., porém restringiuse à avaliação do precondicionamento tardio.

Na pesquisa mencionada de Koutelou et al. (2010) a documentação do precondicionamento precoce realizou-se por meio de testes ergométricos sequenciais, com técnica cintilográfica de duplo isótopo. Para o primeiro teste foram injetados $3 \mathrm{mCi}$ de Tálio-201 no pico do esforço; após cinco minutos foi realizada a aquisição das imagens. Outro teste foi realizado ao término da captação cintilográfica, com a administração de $8 \mathrm{mCi}$ de tetrosfosmin-Tc-99m no mesmo tempo de exercício do primeiro teste em que foi aplicado o Tálio-201; nova aquisição de imagens foi realizada após 30-45 minutos. A imagem de repouso foi adquirida após a realização dos dois testes de esforço, com a utilização de $16 \mathrm{mCi}$ tetrofosmin-Tc-99m. Observou-se significante melhora da perfusão no segundo teste, acompanhada de retardo no tempo de aparecimento do infradesnivelamento do segmento ST. Nesse trabalho, houve inversão do protocolo convencional de aplicação da técnica de duplo isótopo, utilizando o Tálio-201 no primeiro teste e tetrofosmin-Tc-99m no segundo. Além disso, a fase de repouso foi realizada após as duas fases de esforço, com isótopo tetrofosmim-Tc-99m. Essa inversão, a rigor, não está validada como protocolo preconizado para cintilografia com duplo isótopo. É compreensível a mudança na sequência de aplicação dos isótopos nesse estudo, para completar-se o protocolo em um dia, porém, isso pode ter influenciado o resultado final, com comprometimento da interpretação das imagens. Adicionalmente, as doses 
de radiofármaco empregadas estavam abaixo da proporção da dose preconizada em diretrizes internacionais (Henzlova et al., 2009).

Este estudo apresentou resultados divergentes dos encontrados por Bogaty et al., provavelmente pelo emprego de métodos de avaliação distintos, tanto na sequência de aplicação do exercício, como no radiofármaco utilizado.

O protocolo de duplo isótopo foi validado por Berman et al. (1993) e tem algumas peculiaridades. O Tálio-201 apresenta maior radioatividade e maior extração pelo miocárdio, com fotopico menor $(70-80 \mathrm{KeV})$ do que o do sestamibi-Tc-99m (140 KeV). Convencionalmente, a técnica de duplo isótopo envolve a fase de repouso com Tálio-201, seguida pela fase de esforço com Tecnécio-99m. As características físicas dos dois radionuclídeos são distintas, resultando em diferença na densidade da contagem da emissão de fótons de energia. Isto pode afetar a avaliação do grau de reversibilidade das imagens. Adicionalmente, a qualidade de imagem de repouso do Tálio-201 pode, algumas vezes, não ser ideal para da avaliação da hipoperfusão em repouso (Henzlova; Duvall, 2011). A limitação mais significativa no protocolo de estudo cintilográfico com Tálio201 é a maior proporção de resultados falso-positivos, em consequência de atenuações artefatuais, particularmente em indivíduos obesos e mulheres (Chalela et al., 2001). Desta forma, a sobreposição de diferentes intensidades de radioatividade, apesar da calibração diferenciada, pode ter afetado a real diferença de captação por diferentes fotopicos dos isótopos. 
Além disso, o protocolo de duplo isótopo não foi incorporado à rotina na maioria dos serviços de medicina nuclear, estando atualmente em desuso.

No presente estudo, o precondicionamento isquêmico foi avaliado em pacientes que apresentavam testes ergométricos com alterações eletrocardiográficas e cintilográficas de perfusão miocárdica compatíveis com isquemia. Foram realizados dois testes sequenciais e, sete dias após, o teste de contraprova. Utilizamos a técnica de único isótopo com sestamibiTc-99m em protocolos de um e dois dias, para o teste de seleção. A dose do rádiofármaco utilizada para a fase de esforço correspondeu a três vezes a dose utilizada para a fase de repouso no protocolo de um dia, procedimento este comumente empregado nos serviços brasileiros de medicina nuclear (Chalela et al., 2002), e de acordo com a metodologia já descrita.

Estas diferenças metodológicas podem ter influenciado a comparabilidade dos resultados pelo protocolo de isótopo utilizado. Nesta pesquisa, seguimos a sequência de execução dos testes ergométricos de maneira similar aos trabalhos anteriormente publicados e que denotaram as atenuações eletrocardiográficas significativas decorrentes do efeito de precondicionamento isquêmico. Koutelou et al. realizaram o primeiro teste ergométrico com critérios clássicos de interrupção, e o segundo foi interrompido com base no tempo do primeiro. Nosso protocolo incluiu o limite do tempo de aparecimento do infradesnível de 2,0 $\mathrm{mm}$ para o segundo e terceiro testes. Contudo, o consumo de oxigênio miocárdico, avaliado pelo produto da frequência cardíaca e pressão arterial, e o nível de esforço realizado, acima de $85 \%$ da frequência cardíaca máxima preconizada, 
mostram que a carga de trabalho realizada foi suficiente para a detecção adequada da perfusão miocárdica. Cabe lembrar que a sensibilidade das imagens de perfusão pode ser afetada pelo baixo nível de frequência cardíaca atingida e baixa carga realizada, o que não ocorreu nesta pesquisa.

\subsection{Correlação entre teste ergométrico e cintilografia miocárdica}

A redução do infradesnivelamento do segmento ST no teste de precondicionamento, em comparação aos testes de seleção, ocorreu em 18 pacientes $(78,2 \%)$, sete dos quais $(38,4 \%)$ também apresentaram redução do escore de perfusão, como exposto na tabela 12. De outra parte, dois pacientes apresentaram redução do escore de perfusão sem modificações eletrocardiográficas.

A análise do somatório do escore de estresse e do escore da diferença mostrou redução significativa na etapa de precondicionamento em comparação ao teste de seleção $(p=0,04$ e $p=0,03$, respectivamente). No entanto, não foi observada correlação entre a magnitude do infradesnivelamento de ST no momento da injeção do radiofármaco e a redução do escore de estresse $(r=0,13$ e $p=0,55)$. Tampouco houve correlação com o valor da depressão de ST no pico do exercício $(r=0,07$ e $p=0,74)$.

A comparação entre as etapas de precondicionamento e de contraprova mostrou que houve redução nos valores do somatório dos escores de estresse e da diferença $(p=0,056$ e $p=0,039)$. Houve também 
associação e concordância "suave" $(p=0,062 ; \mathrm{Kappa}=0,39)$ entre o aumento do escore de perfusão e o aumento do infradesnivelamento no pico do exercício $(r=0,36$ e $p=0,08)$, porém sem associação com o aumento do infradesnível do ST no momento da injeção do radiofármaco $(r=0,22$ e $\mathrm{p}=0,30$ ). $\mathrm{O}$ pequeno número de pacientes e a menor carga de trabalho realizada no teste de contraprova em relação ao teste de seleção podem ter sido responsáveis por esta fraca correlação.

Nossa pesquisa mostrou que as modificações eletrocardiográficas no teste ergométrico induzidas pelo precondicionamento isquêmico foram identificadas com maior frequência do que as alterações das imagens perfusionais. Também observamos que a resposta clínica foi relevante, com redução em torno de $50 \%$ na manifestação de angina e de arritmias.

$\mathrm{Na}$ maioria dos casos, o infradesnivelamento do segmento ST durante o teste ergométrico associa-se à presença de DAC significativa. Entretanto, há condições nas quais essa alteração pode ocorrer independentemente da presença de estenoses coronarianas, tais como diminuição da reserva coronária e/ou sistema de transporte de oxigênio, distúrbios eletrolíticas, modificações na regulação do sistema autônomo (Brito, 1992).

Por outro lado, a cintilografia também apresenta limitações; a principal delas é o defeito por atenuação diafragmática decorrente de artefatos, sobretudo em mulheres e obesos, aumentando o número de falsopositivos. Esta situação tende a ser minimizada com uso do isótopo Tecnécio-99m, por apresentar emissão de fótons de maior energia do que o 
Tálio-201(Heo; Iskandrian, 1994). Condições que diminuem a sensibilidade das imagens cintilográficas obtidas com Tálio-201e, em menor proporção, com Tecnécio-99m, são lesões em artéria circunflexa, lesões distais, e estenoses subcríticas (50-70\%) (Beller; Zaret, 2000).

Os resultados discordantes entre os métodos ergométricos e cintilográficos estão relacionados à probabilidade pré-teste de DAC. Mattera et al.(1998) observaram que, em pacientes com alta probabilidade pré-teste, $15 \%$ dos que apresentavam teste de esforço normal tinham alterações de perfusão miocárdica, enquanto $41 \%$ dos pacientes com resultados ergométricos anormais não apresentavam alterações nas imagens cintilográficas.

De modo semelhante, algumas discrepâncias entre 0 teste ergométrico e a cintilografia de perfusão miocárdica manifestaram-se também na avaliação do precondicionamento isquêmico. Nesta pesquisa observamos que nem todos os indivíduos apresentam este mecanismo protetor, manifestado por alterações eletrocardiográficas ou cintilográficas.

Os resultados deste estudo indicam que o teste ergométrico seria a melhor ferramenta para detectar a presença do precondicionamento isquêmico. A cintilografia pode ser uma das formas de avaliação eficaz, porém ainda não está claro o porquê da melhora eletrocardiográfica não se traduzir em melhora da perfusão em alguns pacientes.

Estudos com maior número de pacientes poderão elucidar a real utilidade da cintilografia miocárdica na avaliação do precondicionamento isquêmico 


\subsection{Limitações do estudo}

O número pequeno de pacientes e a presença significante de diabetes pode ter influenciado nossos resultados. Igualmente, a inclusão de pacientes com infarto do miocárdio prévio, ainda que o eletrocardiograma de repouso fosse normal ou sem alterações que pudessem influenciar a análise eletrocardiográfica. Contudo, a presença de pequenas áreas de fibrose sem expressão eletrocardiográfica pode ter contribuído para diminuição da sensibilidade das imagens cintilográficas. Outra possível limitação seria a proporção de pacientes com estenose em artéria circunflexa. 
6 Conclusões 
Os resultados deste estudo permitem concluir que:

1) A demonstração do precondicionamento isquêmico precoce pelas atenuações eletrocardiográficas em testes ergométricos sequenciais ocorreu em maior proporção do que a observada nas respectivas imagens de cintilografia de perfusão miocárdica.

2) Não houve correlação entre os valores do infradesnivelamento do segmento ST com o escore de perfusão e com a extensão da área de isquemia detectada pela cintilografia. 


\section{Anexos}


ANEXO A. Exemplo selecionado (\#3) da manifestação eletrocardiográfica do precondicionamento isquêmico em testes sequenciais em paciente incluído na pesquisa

Masculino, 75 a, Hipertenso, Tabagista, Infarto prévio em 2003, Revascularização Cirúrgica em 2003. Quadro de Angina Estável.

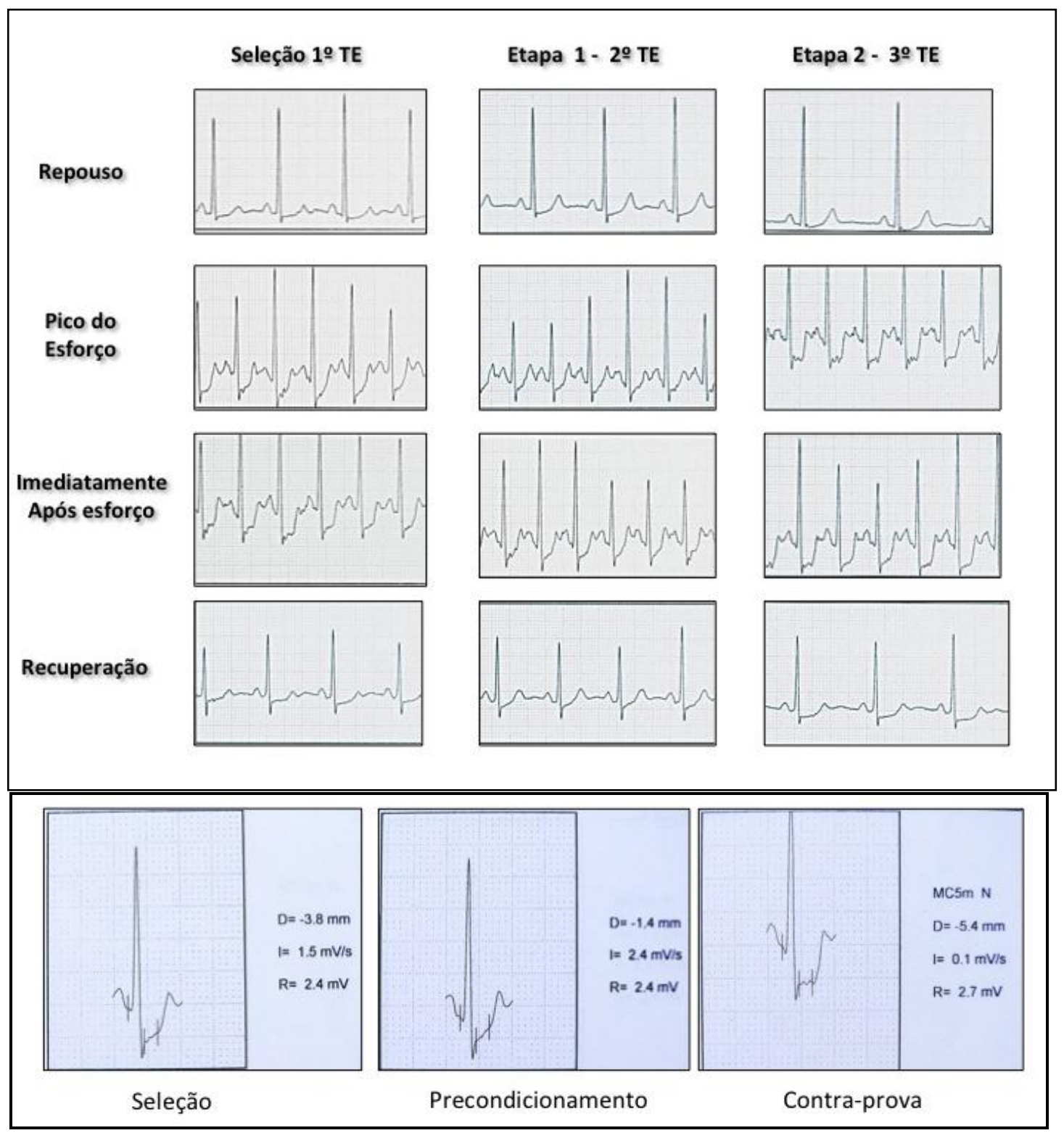

Figura 10 Anexo A. Evolução eletrocardiográfica durante as três etapas do protoloco (seleção, etapa 1, etapa 2) em momentos distintos do teste (repouso, pico do esforço, imediatamente após esforço e recuperação). Exemplo \#3 
ANEXO A. Exemplo selecionado (\#3) da manifestação cintilográfica de perfusão no precondicionamento isquêmico precoce. (Continuação).

Masculino, 75 a, Hipertenso, Tabagista, Infarto prévio em 2003, Revascularização Cirúrgica em 2003. Quadro de Angina Estável.

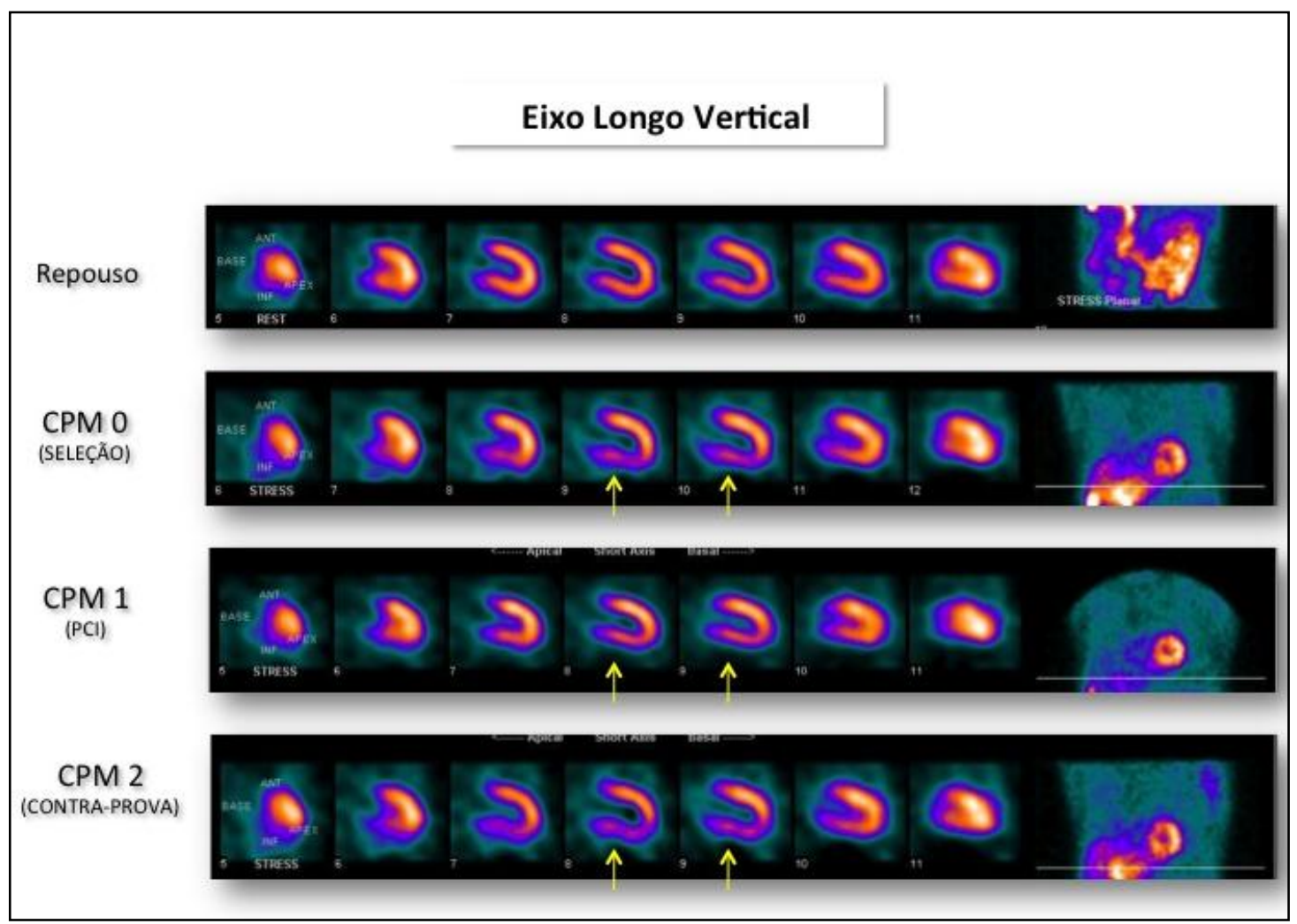

Figura 11. Cortes tomográficos em eixo longo vertical mostrando isquemia em área inferior (CPM0 e CPM2) e o efeito do precondicionamento (CPM1), em comparação com a imagem de repouso. Exemplo \# 3

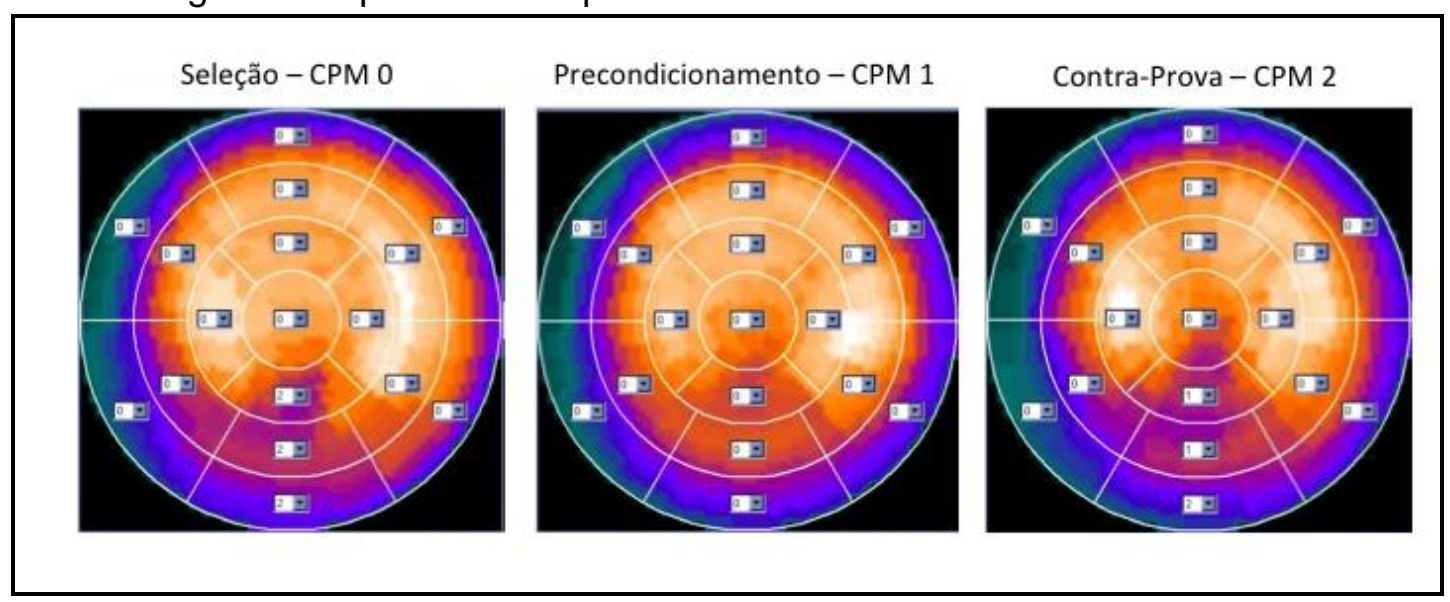

Figura 12. Mapa polar com análise por segmentos nos momentos de CPMO, CPM1 e COM2. Exemplo \#3 
ANEXO B. Termo de Consentimento Livre e Esclarecido para a pesquisa "Será o precondicionamento isquêmico apenas precondicionamento elétrico".

\section{SECRETARIA DE ESTADO DA SAÚDE \\ Coordenadoria de Serviços de Saúde INSTITUTO DANTE PAZZANESE DE CARDIOLOGIA}

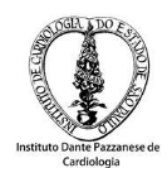

TERMO DE CONSENTIMENTO LIVRE E ESCLARECIDO

\section{TÍTULO DE ESTUDO}

"Será o pré-condicionamento isquêmico apenas pré-condicionamento elétrico?"

CENTRO: INSTITUTO DANTE PAZZANESE DE CARDIOLOGIA - SEÇÃO DE REABILITAÇÃO

INVESTIGADOR: Dra. Susimeire Buglia

NÚMERO DO PACIENTE:

INICIAIS DO PACIENTE:

\section{INTRODUÇÃO}

Você está sendo convidado a participar de uma pesquisa clínica que visa avaliar o benefício do exercício físico na proteção de doença do coração através da realização de testes ergométricos consecutivos associados à cintilografia (mapeamento), que ajuda a verificar a circulação do sangue nas artérias do coração e que você provavelmente já conhece. Os testes ergométricos serão realizados em dois dias diferentes. No primeiro dia você irá realizar dois testes e no segundo dia, um teste.

\section{OBJETIVO DO ESTUDO}

Este estudo tem como objetivo avaliar qual é o real benefício do exercício para a circulação das artérias do coração que estão quase entupidas.

\section{DESCRIÇÃO DO ESTUDO}

Este estudo será realizado em pacientes com teste ergométrico positivo, cintilografia alterada e com o diagnóstico de obstrução ou entupimento das artérias do coração já mostrado pelo cateterismo. Eles serão selecionados a partir dos ambulatórios de coronariopatias e angioplastia, bem como do setor de ergometria e de medicina nuclear.

\section{PROCEDIMENTO DO ESTUDO}

Eu, Susimeire Buglia, médica da Seção de Reabilitação, irei explicar para você o objetivo deste estudo e perguntar se está interessado em participar. Se desejar participar, você será submetido a 3 (três) testes ergométricos divididos em dois dias diferentes, em datas combinadas de comum acordo, com intervalo de cinco a dez dias entre eles. $O$ teste ergométrico será realizado em esteira rolante, com velocidade confortável para você e de acordo com a sua capacidade. Após 
ANEXO B. Continuação

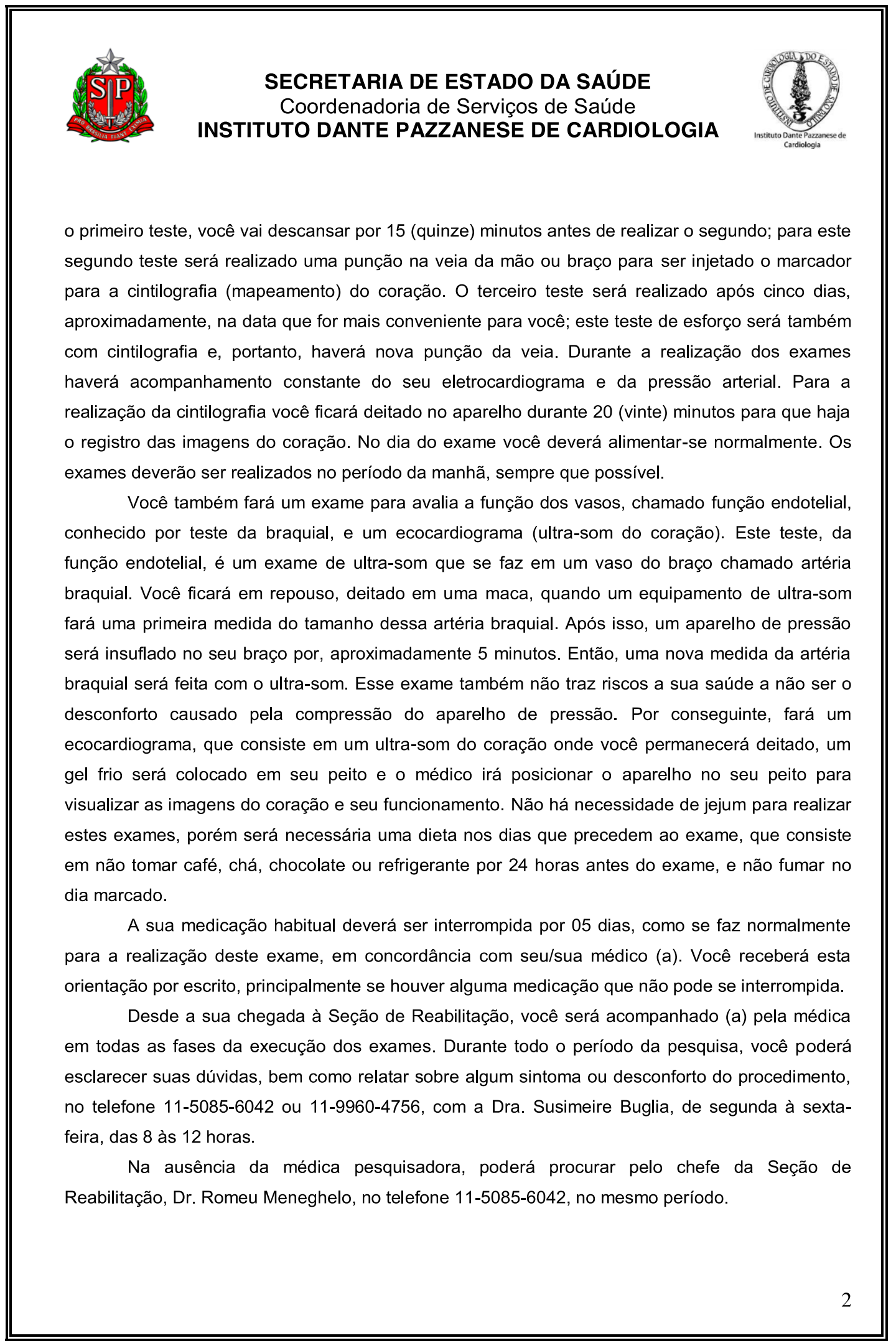


ANEXO B. Continuação

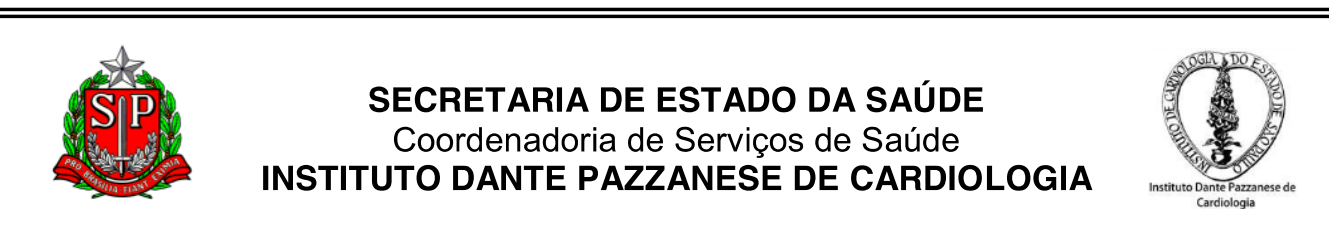

\section{RISCOS E DESCONFORTOS}

O teste ergométrico é um exame seguro, e com baixo risco complicação grave. Existe a possibilidade de ocorrer irritação da pele, por reação à limpeza necessária para a instalação dos eletrodos de monitorização ou devido à alergia por algum dos componentes dos mesmos. Durante a execução do teste poderá ocorrer alteração do ritmo do coração, cansaço, tontura, falta de ar e dor no peito. O seu exame será realizado por um médico (a) cardiologista que tem o conhecimento necessário para perceber rapidamente qualquer problema e fazer o tratamento que for necessário nesta situação.

A cintilografia também não oferece problemas, contudo poderá haver inflamação ou hematoma na veia que foi puncionada. O marcador não provoca qualquer sintoma, contudo, apesar de ser extremamente raro é possível apresentar alergia e, caso isso ocorra você será excluído do término do estudo.

A prova de função endotelial poderá provocar desconforto devido ao aperto do aparelho de pressão no braço, e pode eventualmente sentir uma dor leve. O ecocardiograma poderá provocar desconforto no momento de colocação do gel devido à sensação rápida de frio ou gelado.

Se, em qualquer momento na realização dos exames, for observado algum problema que possa implicar em risco para você, o teste será imediatamente interrompido e a sua participação será reavaliada.

\section{POTENCIAIS BENEFÍCIOS}

Participando deste estudo, você irá ajudar a obter informações importantes que servirão de base para seu próprio tratamento e para outros pacientes com quadros semelhantes ao seu.

\section{PARTICIPAÇÃO DO ESTUDO}

Sua participação neste estudo é inteiramente voluntária. Você não será penalizado de nenhuma forma caso escolha não participar ou quiser desistir durante o andamento da pesquisa. Se houver alguma nova informação que possa afetar sua decisão de participar neste estudo, você será avisado. Sua participação é estritamente confidencial e não afetará qualquer seguro médico ao qual você tenha direito.

\section{RETIRADA DO CONSETIMENTO}

Você poderá desistir de participar a qualquer momento durante o andamento do estudo. Seu/sua médico (a) pode solicitar que você realize exames adicionais se ele/ela considerar que os exames necessários. 
ANEXO B. Continuação

\section{SECRETARIA DE ESTADO DA SAÚDE \\ Coordenadoria de Serviços de Saúde INSTITUTO DANTE PAZZANESE DE CARDIOLOGIA}

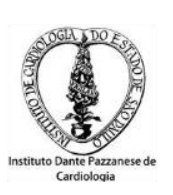

Se seu/sua médico (a) decidir que è em seu próprio benefício ou se você não seguir as instruçōes em relação aos exames, você será retirado do estudo, com ou sem a sua concordância. Além disto, o pesquisador poderá terminar o estudo a qualquer momento.

A sua saida deste estudo, por qualquer razão, não irá afetar em nenhuma forma a qualidade do tratamento de saúde que você recebe nesta instituição.

\section{CUIDADOS MÉDICOSICOMPENSAÇĀO}

No caso de lesão causada pelo fato de participar deste estudo, o tratamento médico apropriado será fomecido pelo Instituto Dante Pazzanese de Cardiologia, desde que:

- Fique determinado que o dano causado esteja relacionado com os procedimentos deste estudo;

- Todas as pessoas e instituiçōes envolvidas tenham seguido as exigências do estudo;

- A equipe médica tenha agido de acordo com a prática científica e técnicas e conhecimentos atualmente aceitos.

Você nada pagará nem receberá qualquer quantia monetária para participar desta pesquisa.

O medicamento do estudo e os exames específicos deste estudo serão fornecidos a você de graça.

Caso você apresente uma reação adversa (efeito colateral) durante o estudo, você deve entrar em contato imediatamente com a Dra. Susimeire Buglia no telefone (11) 5085-6042 ou (11) 9960-4756.

\section{CONFIDENCIALIDADE}

Se você aceitar participar deste estudo, todos os seus registros médicos serão verificados pela equipe de pesquisa em busca de dados para o estudo.

Assinando o Termo de Consentimento Livre e Esclarecido você está dando permissão para que isso seja feito. Sua identidade será mantida em segredo quando os resultados do estudo forem publicados, pois, você está autorizando que os seus dados sejam publicados em revistas e artigos e que sejam temas de debates e aulas. As informaçōes coletadas durante o estudo serão armazenadas em um computador, mas seu nome não. Seu médico será informado de sua participação neste estudo.

Toda informação obtida durante este estudo, incluindo os registros médicos, dados pessoais e da pesquisa são confidenciais. Ao assinar o Termo de Consentimento Livre e Esclarecido, você concorda com estas possiveis situaçōes.

Esta pesquisa foi aprovada pelo Comitê de Ética e Pesquisa do Instituto "Dante Pazzanese" de C rdiologia. 
ANEXO B. Continuação

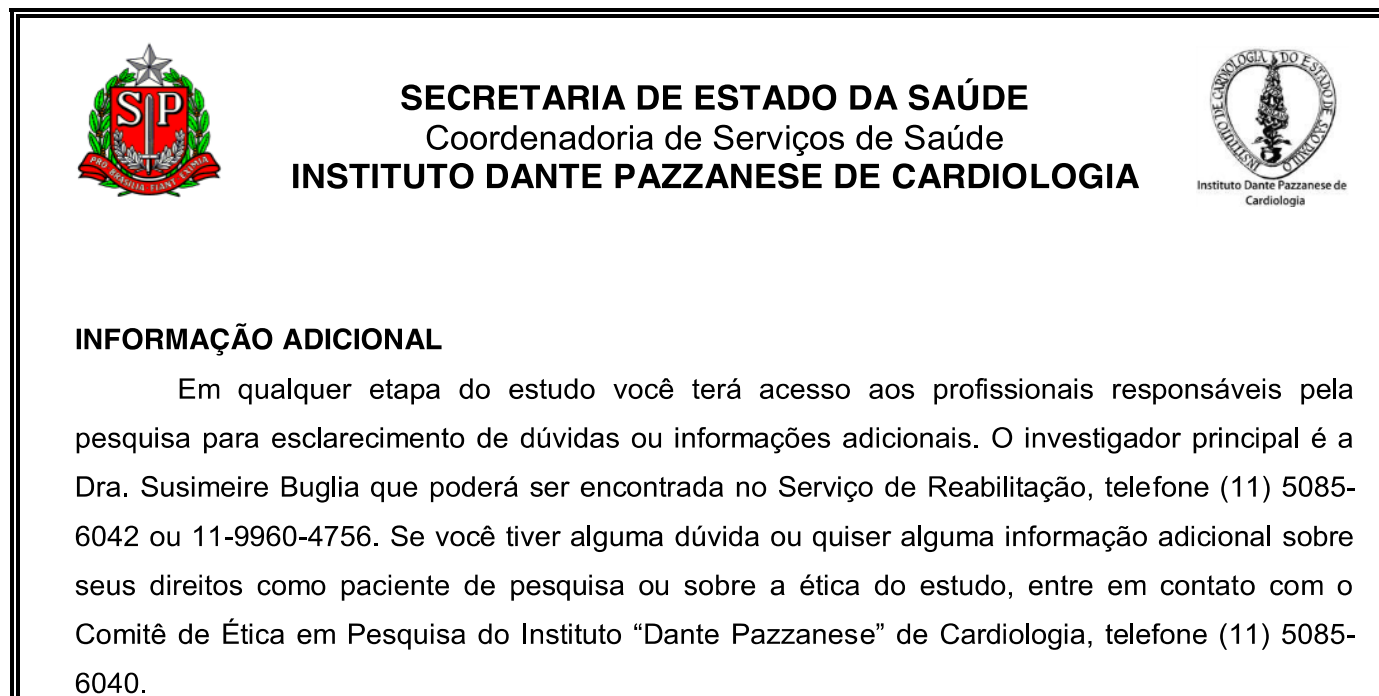


ANEXO B. Continuação
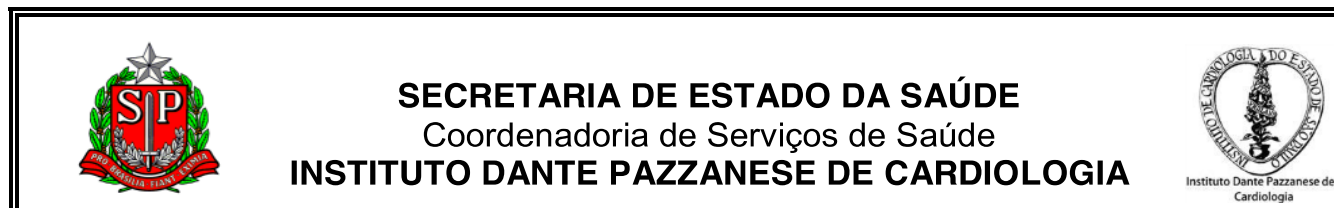

CONSENTIMENTO LIVRE E ESCLARECIDO

Declaro que li e entendi as informações ao paciente do estudo "Será o précondicionamento isquêmico apenas pré-condicionamento elétrico?"

1. Fui adequadamente informado dos objetivos, procedimentos, andamento e riscos do estudo. A qualquer momento, durante e após minha participação no estudo, estou ciente de que o investigador é responsável por me fornecer qualquer informação adicional sobre a pesquisa bem como no caso de danos relacionados.

2. Eu voluntariamente concordo em participar do estudo.

3. Eu aceito que as informações obtidas através desta pesquisa clínica serão mantidas sob sigilo (em segredo) pelo investigador.

4. Eu fui adequadamente informado que posso retirar meu consentimento ou desistir em participar do estudo a qualquer momento no decorrer do mesmo sem nenhuma conseqüência negativa para o meu tratamento.

5. Meu nome e qualquer informação que me identifique como participante do estudo não será divulgado sem a minha permissão por escrito.

Após assinar este documento, eu receberei uma cópia deste Termo de Consentimento Livre e Esclarecido.

Nome do Paciente

Assinatura do Paciente

Assinatura do representante legal, quando aplicável

Assinatura da pessoa que obteve o consentimento

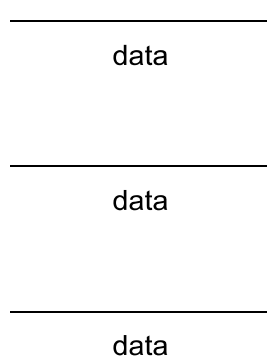

data

Assinatura do investigador 
Abete P, Ferrara N, Cioppa A, Ferrara P, Bianco S, Calabrese C, Cacciatore F, Longobardi G, Rengo F. Preconditioning does not prevent postischemic dysfunction in aging heart. J Am Coll Cardiol. 1996; 27(7): 1777-86

Abete P, Ferrara N, Cacciatore F, Madrid A, Bianco S, Calabrese C, Napoli C, Scognamiglio P, Bollella O, Cioppa A, Longobardi G, Rengo F. Anginainduced protection against myocardial infarction in adult and elderly patients: a loss of preconditioning mechanism in the aging heart? $J A m$ Coll Cardiol.1997; 30:947-54.

ACSM. Diretrizes do ACSM para teste de esforço e sua prescrição. American College of Sports Medicine, 7a. Ed. Traduzido por Giuseppe Taranto - Rio de Janeiro. Editora Guanabara Koogan, 2007; p:107.

Andrade J (editor). II Diretrizes da Sociedade Brasileira de Cardiologia Sobre Teste Ergométrico. Arq Bras Cardiol. 2002; 78:supl. II

Anzai T, Yoshikawa T, Asakura Y, Abe S, Akaishi M, Mitamura H, Handa S, Ogawa S. Preinfarction angina as a major predictor of left ventricular function and long-term prognosis after a first $Q$ wave myocardial infarction. J Am Coll Cardiol. 1995; 26:319. 
Beller AG, Zaret LB. Contributions of nuclear cardiology to diagnosis and prognosis of patients with coronary artery disease. Circulation. 2000;101:1465-78.

Berman DS, Kiat H, Friedman JD, Wang FP, Van Train K, Matzer L, Maddahi J, Germano G. Separate acquisition rest thallium-201/stress technetium-99m sestamibi dual-isotope myocardial perfusion single-photon emission omputed tomography: a clinical validation study. J Am Coll Cardiol.1993;22:1455-64.

Berman DS, Kang X, Van Train KF, Lewin HC, Cohen I, Areeda J, Friedman JD, Germano G, Shaw LJ, Hachamovitch R. Comparative prognostic value of automatic quantitative analysis versus semiquantitative visual analysis of exercise myocardial perfusion single-photon emission computed tomography. J Am Coll Cardiol. 1998;32:1987-95

Berman DS, Abidov A, Kang X, Hayes SW, Friedman JD, Sciammarella MG, Cohen I, Gerlach J, Waechter PB, Germano G, Hachamovitch R. Prognostic validation of a 17-segment score derived from a 20 -segment score for myocardial perfusion SPECT interpretation. J Nucl Cardiol. 2004;11:414-23.

Bogaty P, Kingma JG, Guimond J, Poirier P, Boyer L, Charbonneau L, Dagenais GR. Myocardial perfusion imaging finding and the role adenosine in the warm-up angina phenomenon. J Am Coll Cardiol. $2001 ; 37: 463-9$. 
Bogaty P, Poirier P, Boyer RN, Jobin J, Dagenais R. What induces the warmup ischemia/angina phenomenon: exercise or myocardial ischemia? Circulation 2003; 107:1858-1863.

Bolli R. The late phase of preconditioning. Circ Res. 2000;87(11):972-83.

Brito AHX. O teste ergométrico na cardiopatia isquêmica à luz do conceito de reserva coronária. Arq Bras Cardiol. 1992;59:409-22.

Bruce RA, Blackmon JR, Jones JW, Strait G. Exercising testing in adult normal subjects and cardiac patients. Pediatrics. 1963;32(SUPPL):742-56. No abstract are available.

Bruce RA, Blackmon JR, Jones JW, Strait G. Exercising testing in adult normal subjects and cardiac patients (1963). Ann Noninvasive Electrocardiol. 2004; 9:291-303.

Bruce RA, Kusumi F, Hosmer D. Maximal oxygen intake and nomographic assessment of functional aerobic impairment in cardiovascular disease. Am Heart J. 1973; 85:546-562.

Bruce RA. Exercise testing of patients with coronary heart disease. Principles and normal standards for evaluation. Ann Clin Res. 1971;3(6):323-32. 
Brunner E, Langer F. Nonparametric analysis of ordered categorical data in designs with longitudinal observations and small sample sizes. Biometrical Journal. 2000;42:663-675.

Campos $\mathrm{F}^{\circ} \mathrm{O}$ (editor). Diretrizes para indicação e utilização da ecocardiografia na prática clínica. Arq Bras Cardiol. 2004;82:11-34(suppl II)

Capecchi PL, Pasini FL, Cati G, Colafati M, Acciavatti A, Ceccatelli L, Petri S, de Lalla A, Di Perri T. Experimental model of short-time exerciseinduced preconditioning in POAD patients. Angiology. 1997;48:469-80

Chalela WA, Oliveira CG, Falcão AM, Meneghetti JC. Discordância entre resultados do teste de esforço e da cintilografia de perfusão miocárdica. Rev. Soc. Cardiol Estado de São Paulo. 2001;11:673-681.

Chalela WA (editor). I Diretriz sobre Cardiologia Nuclear - Arq Bras Cardiol. [on line] 2002; 78 (Suppl 3):1-42.

Chalela WA, Meneghetti JC (editores). Atualização da Diretriz da Sociedade Brasileira de Cardiologia Sobre Cardiologia Nuclear 2005 - [Citado em 20 de dezembro de 2011] Disponível em: http://publicacoes.cardiol.br/consenso/2005/cardiologianuclear.asp 
Cohen MV, Liu GS, Downey JM. Preconditioning causes improved wall motion as well as smaller infarcts after transient coronary occlusion in rabbits. Circulation. $1991 \mathrm{Jul} ; 84(1): 341-9$.

Deutsch E, Berger M, Kussmaul WG, Hirshfeld JW Jr, Herrman HC, Laskey WK. Adaptation to ischemia during percutaneous transluminal coronary angioplasty: clinical, hemodynamic and metabolic features. Circulation. 1990; 82:2044-51.

Edwards RJ, Redwood SR, Lambiase PD, Marber MS. The effects of an angiotensin-converting enzyme inhibitor and a $\mathrm{K}^{+}$ATP channel opener on warm up angina. Eur Heart J. 2005;26:598-606.

Ferdinandy P, Schulz R, Baxter G. Interaction of cardiovascular risk factors with myocardial ischemia/reperfusion injury, preconditioning and postconditioning. Pharmacol Rev. 2007;59:418-458.

Ferreira BM, Moffa PJ, Falcão A, Uchida A, Camargo P, PereyraP, Soares PR, Hueb W, Ramires JA. The effects of glibenclamide, a K(ATP) channel blocker, on the warm-up phenomenon. Ann Noninvasive Electrocardiol. $2005 ; 10: 356-62$.

Fleiss, JL. Statistical Methods for rates and proportions. New York: John Wiley, 1981. 
Germano G, Kiat H, Kavanagh PB, Moriel M, Mazzanti M, Su HT, Van Train $\mathrm{KF}$, Berman DS. Automatic quantification of ejection fraction from gated myocardial perfusion SPECT. J Nucl Med. 1995;36:2138-47.

Gheeraert PJ, Henriques JP, De Buyzere ML, De Pauw M, Taeymans Y, Zijlstra F. Preinfarction angina protects against out-of-hospital ventricular fibrillation in patients with acute occlusion of the left coronary artery. $J A m$ Coll Cardiol 2001; 38:1369-74.

Gibbons RJ, Balady GJ, Bricker JT, Chaitman BR, Fletcher GF, Froelicher VF, Mark DB, McCallister BD, Mooss AN, O'Reilly MG, Winters WL Jr, Gibbons RJ, Antman EM, Alpert JS, Faxon PFP, Fuster V, Gregoratos G, Hiratzka LF, Jacobs AK, Russell RO, Smith SC Jr; American College of Cardiology/American Heart Association Task Force on Practice Guidelines (Committee to Update the 1997 Exercise Testing Guidelines). ACC/AHA 2002 guideline update for exercise testing: summary article: a report of the American College of Cardiology/American Heart Association Task Force on Practice Guidelines (Committee to Update the 1997 Exercise Testing Guidelines). Circulation. 2002;106:1883-92. Erratum in: J Am Coll Cardiol. 2006 Oct 17;48(8):1731.

Hachamovitch R, Berman DS, Shaw LJ, Kiat H, Cohen I, Cabico JA, Friedman J, Diamond GA. Incremental prognostic value of myocardial 
perfusion single photon emission computed tomography for the prediction of cardiac death: differential stratification for risk of cardiac death and myocardial infarction. Circulation. 1998;97:535-43.

Hendel RC, Budoff MJ, Cardella JF, Chambers CE, Dent JM, Fitzgerald DM, Hodgson JM, Klodas E, Kramer CM, Stillman AE, Tilkemeier PL, Ward RP, Weigold WG, White RD, Woodard PK; American College of Cardiology (ACC);ACC/AHA/ACR/ASE/ASNC/HRS/NASCI/RSNA/SAIP/SCAI/SCCT/SC MR/SIR. 2008 Key Data Elements and Definitions for Cardiac Imaging A Report of the American College of Cardiology/American Heart Association Task Force on Clinical Data Standards (Writing Committee to Develop Clinical Data Standards for Cardiac Imaging). J Am Coll Cardiol. 2009 Jan 6;53(1):91-124. Erratum in: J Am Coll Cardiol. 2009 Jun 9;53(23):2230.

Henzlova MJ, Cerqueira MD, Mahmarian JJ, Yao SS. Stress protocols and tracers. Quality Assurance Committee of the American Society of Nuclear Cardiology. Imaging Guidelines For Nuclear Cardiology Procedures. J NuCl Cardiol. 2006;13:e80-90.

Henzlova JM, Duvall L. SPECT radionuclide myocardial perfusion imaging protocols. In: Heller GV, Hendel RC (eds). Nuclear Cardiology: Pratical Applications. Printed in China, McGraw Hill Companies, Inc.- 2nd ed. 2011, pp 71-79. 
Heo J, Iskandrian AS. Technetium-labeled myocardial perfusion agents. Cardiol Clin. 1994;12:187-98.

Holmuhamedov EL, Jovanović S, Dzeja PP, Jovanović A, Terzic A. Mitochondrial ATP-sensitive $\mathrm{K}+$ channels modulate cardiac mitochondrial function. Am J Physiol. 1998;275:H1567-76.

Holmuhamedov EL, Wang L, Terzic A. ATP-sensitive K+ channel openers prevent Ca2+ overload in rat cardiac mitochondria. J Physiol. 1999;519:34760.

Hueb W, Uchida AH, Gersh BJ, Betti RT, Lopes N, Moffa PJ, Ferreira BM, Ramires JA, Wajchenberg BL. Effect of a hypoglycemic agent on ischemic preconditioning in patients with type 2 diabetes and stable angina pectoris. Coron Artery Dis. 2007 Feb;18:55-9.

Iliodromitis EK, Koutelou M, Paraskevaidis IA, Theodorakos A, Farmakis D, Tsoutsanis J, Kremastinos DT. Treadmill exercise test with dual isotope scintigraphy documents the secondwindow of preconditioning in humans. Atherosclerosis. 2008 May;198(1):122-8. Epub 2007 Dec 21.

Inoue T, Fujito T, Hoshi K, Sakay Y, Yamaguchi H, Takayanagi K, Morooka S, Takebatake Y. A mechanism of ischemia preconditioning during percutaneous transluminal coronary angioplasty. Cardiology 1996;87:216-23. 
Ishihara M, Inoue I, Kawagoe T, Shimatani Y, Kurisu S, Nishioka K, Kouno Y, Umemura T, Nakamura S, Sato H. Diabetes mellitus prevents ischemic preconditioning in patients with a first acute anterior wall myocardial infarction. J Am Coll Cardiol 2001;38:1007.

Iwasaka T, Nakamura S, Karakawa M, Sugiura T, Inada M. Cardioprotective effect of unstable angina prior to acute anterior myocardial infarction. Chest 1994;105:57.

Kay P, Kittelson J, Stewart RA. Relation between duration and intensity of first exercise and "warm up" in ischemic heart disease. Heart. 2000;83:1721.

Kern MJ. Fluxo sanguíneo coronariano e isquemia miocárdica. In: Braunwald, Tratado de doenças cardiovascularess. Tradução da 7a. ed. Rio de Janeiro: Editora Elsevier Ltda. 2005; cap. 44, p: 1122.

Klepzig H, Kober G, Matter C, Luus H, Schneider H, Boedeker KH, Kiowski W, Amann FW, Gruber D, Harris S, Burger W. Sulfanylureas and ischemic preconditioning: a double-blind, placebo-controlled evaluation of glimepiride and glibenclamide. Eur Heart J. 1999; 20:439-446. 
Kloner RA, Shoot T, Przyklenk K, Davis VS, Junio L Matthews RV, Burstien S, Gibson CM, Poole WK, Cannon CP, McCabe CH, Braunwald E. Previous angina alters in-hospital outcome in TIMI4: a clinical correlate to preconditioning? Circulation. 1995;91:37-45.

Kloner RA., Bolli,R., Marban E, Reinlib L., Braunwald E. Medical and cellular implications of stunning, hibernation, and preconditioning: an NHLBI Workshop. Circulation. 1998; 97:1848-67

Kobayashi Y, Miyazaki S, Itoh A, Daikoku S, Morii I, Matsumoto T, Goto Y, Nonogi H.et al. Previous angina reduces in-hospital death in patients with acute myocardial infarction. Am J Cardiol. 1998; 81:117-22.

Koutelou M, Katsikis A, Theodorakos A, Tsapaki V, Kouzoumi A, Dritsas A, Cokkinos D. Stress test with dual isotope studies for the documentation of classical ischemic preconditioning. Atherosclerosis. 2010 Jun;210:445-51.

Landis JR, Koch GG. The measurement of observer agreement for categorical data. Biometrics. 1977;33:159-74.

Lambiase PD, Edwards RJ, Cusack MR, Bucknall CA, Redwood SR, Marber MS. Exercise-induced ischemia initiates the second window of protection in humans independent of collateral recruitment. $J A m$ Coll Cardiol 2003;41:1174-82. 
Lang RM, Bierig M, Devereux RB, Flachskampf FA, Foster E, Pellikka PA et al.. Recommendations for chamber quantification: a report from the American Society of Echocardiography's Guidelines and Standards Committee and the Chamber Quantification Writing Group, developed in conjunction with the European Association of Echocardiography, a branch of the European Society of Cardiology. Chamber Quantification Writing Group; American Society of Echocardiography's Guidelines and Standards Committee; European Association of Echocardiography. $J A m$ Soc Echocardiogr. 2005;18:1440-63.

Marber MS, Latchman DS, Walker JM, Yellon DM. Cardiac stress protein elevation 24 hours after brief ischemia or heat stress is associated with resistance to myocardial infarction. Circulation 1993;88:1264-72.

Mason RE, Likar I. A new system of multiple-lead exercise electrocardiography. Am Heart J. 1966;71:196-205.

Mattera JA, Arain AS, Sinusas AJ, Finta L,Wackers FJ. Exercise testing with myocardial perfusion imaging in patients with normal baseline electrocardiograms: cost savings with a stepwise diagnostic strategy. J Nucl Cardiol 1998;5:498-506. 
Maybaum S, Ilan M, Mogilevsky, Tzivoni D. Improvement in ischemic parameters during repeated exercise testing: a possible model for myocardial preconditioning. Am J Cardiol.1996;78(10):1087-91.

Minners J, Lacerda L, McCarthy J, Meiring JJ, Yellon DM, Sack MN. Ischemic and pharmacological preconditioning in Girardi cells and $\mathrm{C} 2 \mathrm{C} 12$ myotubes induce mitochondrial uncoupling. Circ Res. 2001 Oct 26;89(9):787-92.

Murry CE, Jennings RB, Reimer KA. Preconditioning with ischemia: a delay or lethal cell injury in ischemic myocardium. Circulation. 1986;74:1124-36.

Neter J, Kutner MH, Nachtsheim CJ, Wasserman W. Applied Linear Statistical Models. Times Mirror Higher Education Group. USA: McGraw Hill Companies, Inc. $4^{\text {th }}$ ed. 1996, pp 1408.

Nichols KJ, Bacharach SL, Bergmann SR, Cullom SJ, Ficaro EP, Galt JR, Heller GV, Links J, Machac J. Instrumentation quality assurance and performance. Quality Assurance Committee of the American Society of Nuclear Cardiology. J Nucl Cardiol. 2006;13:e25-41.

Okubo S, Xi L, Bernardo NL, Yoshida K, Kukreja RC. Myocardial preconditioning: basic concepts and potential mechanisms. Mol Cell 
Biochem, 1999;196:3-12.

Osler W. Lecture on angina pectoris an allied state: New York: D Aplleton, 1897:52.

Ottani F, Galvani M, Ferrini D, Sorbello F, Limonetti P, Pantoli D, Rusticali F. Prodromal angina limits infarct size. A role for ischemic preconditioning. Circulation 1995; 91:291-7.

Paraskevaidis IA, Iliodromitis EK, Mavrogeni S, Karavolias GK, Theodorakis GN, Georgiadis M, Kremastinos DT. Repeated exercise testing identifies early and late preconditioning. Int. J Cardiol 2005; 89:221-6.

Pasqualin RC, Auler Jr. JOC. Proteção miocárdica pelo pré- e póscondicionamento anestésico. Rev. Bras Anestesiol. 2008; 58: 506-19.

Pereira, J.C.R. Bioestatística em Outras Palavras. EDUSP, São Paulo, Brasil, 2010.

Perry RA, Seth A, Hunt A, Smith SC, Westwood E, Woolgar N, Shiu MF. Balloon occlusion during coronary angioplasty as a model of myocardial ischaemia: reproducibility of sequential inflations. Eur Heart J. 1989 Sep;10(9):791-800. 
Rajesh KG, Sasaguri S, Zhitian Z, Suzuki R, Asakai R, Maeda H. Second window of ischemic precondicioning regulates mitochondrial permeability transition pore by enhancing Bcl-2 expression. Cardiovasc Res 2003; 59:297-307.

Rubino A, Yellon DM - Ischemic preconditioning of vasculature: an overlooked phenomenon for protecting the heart? Trends Pharmacol Sci, $2000 ; 21: 225-30$.

Siegel S, Castellan N.J. Nonparametric statistics. New York: McGraw-Hill. 2nd ed.; 1988.

Tamura K, Tsuji H, Nishiue T, Tokunaga S, Iwasaka T. Association of preceding angina with in hospital life threatening ventricular tachyarrhythmias and late potencials in patients with a first acute myocardial infarction. Am Heart J 1997;133:297-301.

Tomai F, Crea F, Gaspardone A, Versaci F, De Paulis R, Penta de Peppo A, Chiariello L, Gioffrè PA. Ischemic preconditioning during coronary angioplasty is prevent by glibenclamide, a selective ATP-sensitive $\mathrm{K}^{+}$channel blocker. Circulation 1994; 90:700-5. 
Tomai F, Perino M, Ghini AS, Crea F, Gaspardone A, Versaci F, Chiariello L, Gioffre PA. Exercise-induced myocardial ischemia triggers the early phase of preconditioning but not late phase. Am J Cardiol. 1999;83:586-8, A7-8.

Tzivoni D, Maybaum S. Attenuation of severity of myocardial ischemia during repeated daily isquemic episodes. J Am Coll Cardiol. 1997;30:119-24

Uchida A, Moffa P, Hueb W, Cesar LA, Ferreira BM, Ramires JA. Electrocardiographic score: application in exercise test for the assessment of ischemic preconditioning. Arq Bras Cardiol. 2010;95(4):486-92.

Udelson JE, Dilsizian V, Bonow RO.Cardiologia Nuclear. In: Braunwald, Tratado de doenças cardiovasculares (2006). Tradução de Braunwald's Heart Disease: A Textbook of Cardiovascular Medicine. Rio de Janeiro, Brasil, 7a ed. - Editora Elsevier, 2005; p: 289.

Walker DM, Yellon DM. Ischaemic preconditioning: from mechanisms to exploitation. Cardiovasc Res. 1992 Aug;26(8):734-9.

Yellon DM, Alkhulaifi AM, Pugsley WB. Preconditioning the human myocardium. Lancet. 1993;342:276-7.

Yellon DM, Downey JM. Preconditioning the myocardium: from cellular physiology to clinical cardiology. Physiol Rev 2003;83:1113-51. 
Ylitalo K, Peuhkurinen K. Clinical relevance of ischemic preconditioning. Scand Cardiovasc J. 2001;35:359-65.

Zaugg M, Schaub MC. Signaling and cellular mechanisms in cardiac protection by ischemic and pharmacological precondi- tioning. J Mus Res Cell Mot, 2003;24:219-49. 